\title{
Proton pump inhibitors in childhood cystic fibrosis
}

Citation for published version (APA):

Hendriks, J. J. E. (2002). Proton pump inhibitors in childhood cystic fibrosis. [Doctoral Thesis, Maastricht University]. Datawyse / Universitaire Pers Maastricht. https://doi.org/10.26481/dis.20020328jh

Document status and date:

Published: 01/01/2002

DOI:

10.26481/dis.20020328jh

Document Version:

Publisher's PDF, also known as Version of record

\section{Please check the document version of this publication:}

- A submitted manuscript is the version of the article upon submission and before peer-review. There can be important differences between the submitted version and the official published version of record.

People interested in the research are advised to contact the author for the final version of the publication, or visit the DOI to the publisher's website.

- The final author version and the galley proof are versions of the publication after peer review.

- The final published version features the final layout of the paper including the volume, issue and page numbers.

Link to publication

\footnotetext{
General rights rights.

- You may freely distribute the URL identifying the publication in the public portal. please follow below link for the End User Agreement:

www.umlib.nl/taverne-license

Take down policy

If you believe that this document breaches copyright please contact us at:

repository@maastrichtuniversity.nl

providing details and we will investigate your claim.
}

Copyright and moral rights for the publications made accessible in the public portal are retained by the authors and/or other copyright owners and it is a condition of accessing publications that users recognise and abide by the legal requirements associated with these

- Users may download and print one copy of any publication from the public portal for the purpose of private study or research.

- You may not further distribute the material or use it for any profit-making activity or commercial gain

If the publication is distributed under the terms of Article $25 \mathrm{fa}$ of the Dutch Copyright Act, indicated by the "Taverne" license above, 


\section{PROTON PUMP INHIBITORS IN}

CHILDHOOD CYSTIC FIBROSIS 
(อ) Han Hendriks, Maastricht 2002

ISBN 9052783411

Vormgeving en druk

Datawyse | Universitaire Pers Maastricht 


\section{PROTON PUMP INHIBITORS IN CHILDHOOD CYSTIC FIBROSIS}

\section{PROEFSCHRIFT}

ter verkrijging van de graad van doctor aan de Universiteit Maastricht, op gezag van de Rector Magnificus, Prof.dr. A.C. Nieuwenhuijzen Kruseman, volgens het besluit van het College van Decanen, in het openbaar te verdedigen op donderdag 28 maart 2002 om 12.00 uur door

Johannes Jozef Edmond Hendriks

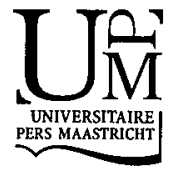


Promotor:

Prof.dr. R.A.M.G. Donckerwolcke

Prof.dr. E.F.M. Wouters

Co-promotor:

Dr. P.Ph. Forget

Beoordelingscommissie:

Prof.dr. R.W. Stockbrügger (voorzitter)

Prof.dr. J.C. de Jongste (Sophia Kinderziekenhuis, Rotterdam)

Prof.dr.ir. C.P. van Schayck

Dr.ir. A.M.W.J. Schols

Prof.dr. D.J. Shale (University of Wales, South Glamorgan, United Kingdom)

Publication of this thesis was kindly supported by Alk-abelló BV, AstraZeneca BV, Aventis Pharma BV, Boehringer Ingelheim BV, Chiron BV, GlaxoWellcome BV, Merck Sharp \& Dohme BV, 3M-Pharma Nederland BV, Pfizer Pharmaceuticals Group, Roche Nederland BV and Solvay Pharma.

The paper used for this thesis, was kindly donated by Meerssen \& Palm, Papier BV. 


\section{CONTENTS}

1. Rationale for the use of Proton Pump Inhibitors in CF patients

J. Hendriks and Ph. Forget

2. An observational study to assess the effects of a pharmacologic modulation of gastric acid secretion on biologic variables in children with Cystic Fibrosis

J. Hendriks

3. Longitudinal growth of children with Cystic Fibrosis: a retrospective study 41 J. Hendriks, F. Schuurmans, W.J. Gerver and Ph. Forget

4. Potential short and long-term effects of lansoprazole on body composition in children with Cystic Fibrosis

J. Hendriks, E. Rekkers, I. van der Sluis, G. Heidendal, A. Kester, and

Ph. Forget

5. Changes in pulmonary hyperinflation and bronchial hyperresponsiveness following treatment with lansoprazole in children with Cystic Fibrosis J. Hendriks, A. Kester, R. Donckerwolcke, Ph. Forget and E. Wouters

6. Effects of therapy with lansoprazole on intestinal permeability and inflammation in young Cystic Fibrosis patients J. Hendriks, B. v. Kreel and Ph. Forget

7. Fatty acid status of plasma and red blood cells phospholipids in Cystic Fibrosis patients treated with and without lansoprazole

J. Hendriks, A. Brouwers, R. v. Houwelingen, H. Heijmans,

A. v.d. Neucker, A. Kester, G. Hornstra and Ph. Forget

8. Are children with Cystic Fibrosis treated with a proton pump inhibitor at risk for vitamin $\mathrm{B} 12$ deficiency?

H. ter Heide, J. Hendriks, H. Heijmans, P. Menheere, L. Spaapen,

J. Bakker, Ph. Forget

9. General conclusions

J. Hendriks

10. Summary in English and Dutch

11. Dankwoord en Curriculum Vitae 


\section{LIST OF ABBREVIATIONS}

$\begin{array}{ll}\text { BHR } & \text { bronchial hyper responsiveness } \\ \text { BL } & \text { bronchial lability } \\ \text { BMC } & \text { bone mineral content } \\ \text { BMD } & \text { bone mineral density } \\ \text { BMI } & \text { body mass index }\end{array}$

CF cystic fibrosis

CFTR CF transmembrane regulator (protein)

COPD chronic obstructive pulmonary disease

DEXA dual energy x-ray absorptio metry

ERV expiratory reserve volume

ECFS European CF Society

ENT ear - nose - throat

ESCF epidemiologic study of CF

(E)FA (essential) fatty acid

FFM fat free mass

FM fat mass

$\mathrm{FEV}_{1} \quad$ forced expiratory volume in one second

FVC forced vital capacity

(s)GAW (specific) airway conductance

GER(D) gastro esophageal reflux disease

GI gastro intestinal

(t)Hcy (total) homocysteine

ITGV intra thoracic gas volume

IP intestinal permeability

II intestinal inflammation

Lcp tong chain poly unsaturated FA

L/M/Rh lactulose - mannitol - L-rhamnose

$\mathrm{NO}(\mathrm{x}) \quad$ nitric oxide (oxidation products)

NS not significant

$\mathrm{MIF}_{50 \% \text { VCin }}$ maximal inspiratory flow halfway VCin

MUFA mono unsaturated fatty acid

PEF peak expiratory flow

PImax maximal inspiratory mouth pressure

PEmax maximal expiratory mouth pressure

PERT pancreatic enzyme replacement therapy
PL phospholipids

PUFA poly unsaturated fatty acid

PPI proton pump inhibitor

(s)RAW (specific) airway resistance

RBC red blood cell

RDA recommended daily allowance

REE resting energy expenditure

RV residual volume

SDS standard deviation score

SFA saturated fatty acid

TBF total body fat

TLC total lung capacity 
CHAPTER ONE

Rationale for the use of Proton Pump Inhibitors in CF patients

Han Hendriks and Philippe Forget

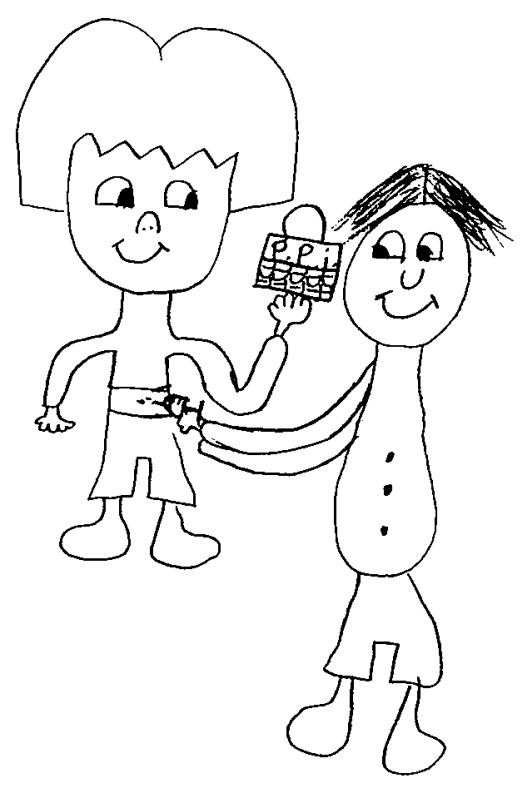




\subsection{GENERAL INTRODUCTION}

Cystic Fibrosis (CF) is one of the most common lethal genetic diseases in Caucasians, affecting approximately 1 in 3,400 live births $[1,2]$. A similar incidence has been reported in the Netherlands [3]. Although this autosomal recessive inherited disorder affects only one gene, a heterogenous phenotypic presentation of CF is seen. This can be explained by the many different mutations of this single gene, and by the presence of the so-called modifier genes interacting with the affected gene. The genetic defect causing the primary disease affects the cystic fibrosis transmembrane conductance regulator protein (CFTR), leading to a defect in the chloride and bicarbonate transport regulating channel at the luminal side of exocrine cells [4].

Since the first description of CF as a separate disease entity by Fanconi in 1936 and Anderson in 1938, many other researchers have contributed to the present knowledge of the pathophysiology of this disease. Besides the name Cystic Fibrosis, the term Mucoviscoidosis is also commonly used. This term refers to one of the most striking abnormalities present in CF patients, namely the insufficient clearance of increased amounts of viscous mucus from the lungs. The designation "Mucoviscoidosis" has been translated in many languages, for example in Dutch "taai-slijm-ziekte", but many other terms are being used worldwide.

It was not until 1989 that the gene, which encodes for the CAMP dependent chloride channel, the CFTR, was first identified [5-8]. This discovery led to a new direction, and an explosive growth, in CF research improving our knowledge of the basal pathophysiology. In this review we will try to describe in detail some new insights in the pathophysiology of CF as well as the rationale behind the use of proton pump inhibitors (PPI) in CF patients.

\subsection{PATHOPHYSIOLOGY OF CYSTIC FIBROSIS}

Most patients with CF are born with $(>65 \%)$ or acquire $(>90 \%)$ insufficiency of exocrine pancreatic function soon after birth. Nearly all have at that time a sweat chloride concentration of more than $60 \mathrm{mMol} / \mathrm{L}$ and only 1 out of thousand typical CF patients will have a lower value. At presentation lung involvement is reported to be less than $40 \%$. However, pulmonary problems causes most of the morbidity and nearly all mortality in CF patients. An abnormal sweat test together with pulmonary and pancreatic disease forms the classical triad of findings confirming the clinical diagnosis of CF [9]. All these patients have mutations in both copies of the CFTR gene on the long arm of chromosome 7, but not everyone with two mutant alleles will manifest the full CF syndrome. Meanwhile over 1000 different mutations have been identified, of which $\triangle F 508$ is the most common (more than $70 \%$ of the mutations in Caucasians from Northern and Western European origin). These different mutations, coding for the same single protein of about $250 \mathrm{~kb}$ of genomic DNA, containing 27 exons, are classified in 5 different classes. While for pancreatic insufficiency there is a fairly good correlation between phenotype and genotype, this is not the case for the pul- 
monary involvement. [10] This has led to the concept of so-called modifier genes present on other locations and in other chromosomes. This may result in totally different phenotypes of CF, within the same genotype of one family. This is perhaps the most important reason why a given set of CF mutations cannot reliably predict the prognosis. This makes it difficult not only to describe one common pathophysiologic process in all CF patients, but also to compare CF patients with each other.

At least two basic functional abnormalities are attributable to a dysfunctional CFTR. Not only does this involve a defective, energy-dependent, anion channel in apical epithelial membranes, but it also affects other membrane proteins, regulating other ion channels allowing ions to flow either in or out of cells. Therefore CFTR is crucial in both absorption and secretion of ions, especially in wet epithelia [4]. As a result of this basic mechanism two different, not necessarily conflicting, pathophysiologic hypotheses have been developed. First, the so-called low volume hypothesis suggests that the decreased water content of the secretions provides a sticky, viscous product, easily blocking the excretory ducts. This results in an impaired ciliary functioning, with decreased or absent mucociliar clearance, allowing a state of permanent bacterial colonisation and infection of the airways, inducing inflammation [11]. Second, the high salt hypothesis describes the condition where high concentrations of chloride and sodium, as seen in CF, impair normal functioning of small peptides floating in the epithelial lining fluid. Some of these peptides play an important role in host defence against bacteria and, if defective, will give rise to the growth of bacteria, in particular Pseudomonas Aeruginosa and Burkholderia Cepacia, bacteria which are commonly cultured in sputum of CF patients [12].

As mucosal exocrine glands from various organs are differently affected, this can explain why loss of CFTR function will have differing consequences depending upon the cell type involved. Furthermore, findings, for instance in the vas deferens in man and mice, show that in different species the same gland with the same defective CFTR may be affected differently $[13,14]$.

\subsection{THE LINK BETWEEN NUTRITIONAL CONDITION AND PROGNOSIS IN CF}

In chronic obstructive pulmonary disease (COPD) a deterioration of the nutritional condition, as measured by decreased body mass index (BMI)[15], fat free mass (FFM) is correlated with a poor prognosis, independently of airflow obstruction and clinical symptoms [16-20]. Because of this relationship it may be that the decrease in body composition precedes the decline of lung function [21]. Despite the clinical similarity between COPD and CF, regarding pulmonary involvement and its relation with body composition, there are remarkable differences between those diseases. It has been shown in COPD that an abnormal protein metabolism, as reflected by lower plasma branched-chain amino acid concentrations and different muscle amino acid patterns, is responsible for the decreased FFM $[16,22,23]$. As mentioned in the previous section, in CF there seems to be a depletion in fat mass (FM) rather than an abnormal 
FFM as found in COPD. In both disorders, however, FFM is decreased, resulting in problems of endurance of skeletal muscles and in particular of respiratory muscles, where inspiratory muscles are more affected than expiratory muscles $[24,25]$. Besides a direct impairment of the respiratory muscles, an increase of inflammatory markers has been found to be associated with decreasing FFM in COPD [26]. Serum levels of leptin, an important regulating peptide for energy homeostasis which increases body weight, has been shown to correlate with FFM in COPD [27]. Whether or not such a relationship also exists in $C F$ is unknown. Several researchers have studied the relationship between nutritional condition, lung function and survival in CF patients [28, 29]. In some CF subgroups, such as pre-lung-transplant patients and pregnant patients, this relationship has been established [30-32]. Although strongly suspected, a direct relation between nutritional condition, lung function and survival in the whole CF population has, until now, not been unequivocally proven. Even the large epidemiologic study of CF (ESCF) $[33,34]$ was unable to demonstrate a significant correlation between lung disease and nutritional status. Only in adolescent and young adult females, due to a survivor effect, could some relationship be shown. The cross-sectional design of the ESCF was held responsible for the lack of correlation between nutritional status and lung disease. Studies supporting a direct relation between lung function and nutritional status in CF are sparse $[35,36]$. There is a strong need for a large longitudinal, long-term, placebo-controlled study to evaluate the effect of therapies improving nutritional status on lung function and survival. Such a study, however, is difficult to perform; it should be multicentric, and consequently would be very expensive.

\subsection{FACTORS AFFECTING NUTRITIONAL CONDITION OF CF PATIENTS}

Low energy intake, high fecal losses and increased energy expenditure can all contribute to a poor nutritional condition in CF.

\section{INTAKE}

Studies conducted in the 1980s have shown that energy and fat enriched diets are mandatory to improve survival in CF patients [37-39]. In CF infants with pancreatic insufficiency, there is no need for (semi-) elemental predigested formula feeding, because absorption of these is not better than that of ordinary formulas, administered with enzyme replacement [40]. Because of ongoing stool losses, it is recommended to provide a high fat diet ( $35-40 \%$ total energy), which, in most patients, results in normal growth for height and weight until their lung disease deteriorates significantly. Patients who develop a negative energy balance seldom if ever respond to such a dietary therapy and will need supplemental, nocturnal, gastrostomy feeds, to improve nutritional status [41]. One should be aware that CF children often cannot consume the required intake of $120 \%$ of recommended dietary allowances (RDA) for both energy and fat. Energy intakes are often insufficient to meet requirements for normal growth [42]. The Cochrane library has collected evidence of the benefit of oral 
protein and calorie supplements to improve the nutritional status of children with chronic diseases. Only three trials assessed the effects of such food supplements in children with CF and apparently it was not possible to draw any firm conclusions concerning the benefit of these therapies $[43,44]$. We therefore suggest that the improvement in the nutritional status reported in the 1980s was mainly due to improvement of malabsorption by introducing (enteric-coated) pancreatic enzymes and not so much the result of increased dietary fat intake.

\section{MALABSORPTION}

While the main cause of malabsorption in CF is a deficiency of pancreatic enzymes, bicarbonate deficiency, abnormalities of bile salts, impaired mucosal transport and motility, as well as anatomical structural changes are contributory factors too. Appropriate pancreatic enzyme replacement therapy will achieve satisfactory absorption in many patients. Therefore it is important to identify both malabsorption and evidence of pancreatic insufficiency in all CF patients. All those who have evidence of fat malabsorption are considered pancreatic insufficient and require enzyme replacement therapy. [45]. As long ago as the early 1960 s exogenous pancreatic enzymes were used in an attempt to decrease steatorrhea. Relatively crude extracts of porcine pancreas with low enzyme potency were used initially [46]. Later several different enteric-coated enzymes were introduced [47]. Pancreatic enzyme replacement therapy (PERT) is a major factor for achieving normal growth and nutritional status in CF patients with pancreatic insufficiency. Combining PERT with supplemental energy intake further improves the nutritional condition. This approach should also include patient education to improve compliance with treatment. Patients and their families will have a better understanding of the relationship between PERT and nutritional status if appropriate guidelines are given and correctly applied [48].

\section{ENERGY EXPENDITURE (EE)}

CFTR mRNA is expressed in the human anterior hypothalamus, an area involved in regulation of appetite, resting energy expenditure (REE) and sexual differentiation [49]. It has been suggested that in CF there is an energy-wasting lesion that will increase total EE (TEE) and hence energy requirement. Recent data, with the double labelled water technique, collected from babies with CF strongly suggest that this is not the case. It is probable that previous data were confounded by heterogeneity of disease status [50]. In CF children with mild to moderate lung disease, an acute pulmonary exacerbation has not been found to be associated with an increase of REE $[51,52]$. Therefore it has been concluded that no direct relationship between the increase of basic metabolic rate, as assessed by REE in CF, and nutritional status or pulmonary disease can be demonstrated [53]. 


\subsection{PANCREATIC INSUFFICIENCY AND ENZYME SUPPLETION IN CF}

As already mentioned, one of the most serious consequences of an impaired CFTR function is pancreatic insufficiency, causing maldigestion and in particular fat malabsorption. This pancreatic insufficiency is only partially corrected by exogenous pancreatic enzymes [54]. Increasing the dose of these enzymes might result in serious complications like fibrosing colonopathy, where pancreatic enzymes if still active in the colon are held responsible for scarring of the colon tissue [55].

In most patients with CF the pancreas is gradually destroyed and replaced by fibrous cysts. This process already starts in fetal life [56]. Normally, exocrine pancreatic gland cells secrete digestive enzymes which mix with a bicarbonate-rich fluid secreted by duct cells, flowing into the duodenum. The production of the ductal juice is probably first reduced, and not the enzyme production itself, causing the ducts to be blocked by enzyme precipitates leading to the destruction of excretory ducts $[57,58]$. The exocrine pancreas is different from other exocrine glands in that its acini entirely lack myoepithelial cells supporting the ducts. Hence they are sensitive to damage by increases in pressure that occur when the duct is blocked. Mutations that spare some CFTR function (estimated to be more than $5 \%$ of normal) leave enough secretion to maintain patency of the ductular system and thus avoid destruction of the pancreas, preventing pancreatic insufficiency. However, the vast majority of CF patients will be pancreatic insufficient, from the first year of life, resulting in a variable degree of growth failure. While the cause of malnutrition seems clear, the degree of impaired digestion and absorption of nutrients will determine the severity of it. Normally the pancreas produces several types of enzymes: lipase, necessary for the absorption of lipids, proteases, for the cleavage of proteins, and amylase, for the hydrolysis of large carbohydrate molecules. These enzymes are secreted, together with bicarbonate, into the intestine. Although secretion of all these types of enzymes by the pancreas will be equally reduced, secretion of the gastrointestinal (GI) tract will compensate for deficiencies in amylases and proteases, in contrast to lipase. Deficiency of lipase will result in decreased fat absorption and steatorrhea, resulting in failure to grow. The complete pathophysiology of fat malabsorption is much more complicated. This is apparent from the fact that the addition of exogenous pancreatic enzymes alone does improve but does not normalize malabsorption completely. Increasing the dose of enzymes does not result in an equivalent increase of nutritional absorption, and will lead to a plateau of maximal effect, most often beneath the level of normalization. Further addition of enzymes does not give any further improvement, while it can induce complications such as fibrosing colonopathy [59].

The lack of normalization of steatorrhea despite sufficient suppletion of exogenous pancreatic enzymes has been related to several factors:

1. Mixing between enzymes from capsules and food is never as optimal as in vivo.

2. The orally supplemented enzymes need to be supplied with an enteric-coating in order to resist destruction by gastric acid. If released from these capsules in an acid milieu, they will be denaturated, which makes them inactive. Lipase, for instance, is irreversibly destroyed at a pH of 4.0 or lower [60]. 
3. Although there are some small differences between preparations, the enteric-coating capsules dissolves at a pH above 5.5. [61] Normally this will take place in the proximal duodenum, where as a result of production of bicarbonate by the pancreatic ducts, gastric acid is buffered. As already mentioned, it is this lack of buffering capacity of the pancreas, which occurs in a very early phase of the disease. Consequently, the $\mathrm{pH}$ of the duodenal contents will be lower than 5.5 for a variable but longer distance in the GI tract compared to healthy persons [62]. Dissolution of the coating will therefore be delayed, while the transit of the contents continues. Therefore a valuable mucosal absorption area will be left unutilized, especially for fat absorption, as this takes place in the duodenum and proximal jejunum [63].

4. A well-known finding in CF is an important increase of intestinal permeability (IP). [64]. It might be that the acid intestinal contents affect the intestinal mucosa, increasing IP, which might provoke several undesired effects such as allergic reactions or increased intestinal inflammation, worsening malabsorption and abdominal complaints.

5. Ionised bile salts, in a sufficient concentration, are necessary to form micelles. In CF the output of bile salts is decreased because of precipitation in the bile ducts, and with the steatorrhea secreted bile salts are lost in the stools. If the concentration of these bile salts is lower than required to form micelles, the critical micelles concentration (CMC), this will lead to reduced transport of the lipolytic products to the microvilli for absorption. An increasing number of papers present evidence that supplementation of bile salts (ursodeoxycholic acid) to CF patients will not only diminish the degree of cirrhosis but will also improve fat malabsorption $[65,66]$.

Reviewing the literature (1966-1994) concerning $\mathrm{pH}$, motility/transit, and permeability of the GI tract in CF, Gregory [67] reported that most studies were performed with very small numbers of patients. But even when considered the published data together, they do not confirm some generally expressed views on these topics. The only consistent observations were:

- A high incidence of gastroesophageal reflux in CF

* Pre- and postprandial duodenal pH 1-2 units lower in CF patients compared to healthy controls

- Small intestinal paracellular permeability 4-10 times greater than normal in CF.

A decrease in duodenal $\mathrm{pH}$ in CF has been evaluated by Barraclough and Taylor [54]. By assessing gastric and proximal duodenal $\mathrm{pH}$, during 24-h ambulatory $\mathrm{pH}$ measurements, they showed that children with CF had a normal fasting gastric and duodenal $\mathrm{pH}$, while their postprandial duodenal $\mathrm{pH}$ was markedly decreased compared to that of controls. This became even more pronounced with successive meals. The total time that duodenal $\mathrm{pH}$ was $<5$ varied from $15-90 \%$ of the recordings (mean $57 \%$ ). Duodenal $\mathrm{pH}$ returned to normal levels only overnight, in the fasting state. The pancreas has an enormous reserve capacity, so significant malabsorption most often signals severe reduction of exocrine function. Complete duodenal hydrolysis of fat requires a series of complex interdependent physicochemical events involving pancreatic lipase, colipase, 
phospholipase $\mathrm{A} 2$ and bile salts in an environment where the $\mathrm{pH}$ must be close to neutrality [68]. Digestion of lipids can be described by a chain of events: emulsification, lipolysis, solubilization, uptake with re-esterification in the enterocyte, and transportation into the circulation via the lymph. Defects at any of these stages can cause steatorrhea.

The low pH may also contribute to the development of fibrosing colonopathy. High dose pancreatic enzyme preparations might fail to dissolve because of the acidity in the small intestinal lumen, leaving unutilized proteolytic enzymes enter the colon. Adherence to the colonic wall might lead to destruction, with scarring and strictures of the colonic wall.

\subsection{THERAPEUTICAL APPROACHES TO OPTIMIZE THE EFFECT OF EXOGENOUS PANCREATIC ENZYMES}

\section{ACID LIPASES}

Acid duodenal contents hamper the effectiveness of the coated pancreatic enzymes, as already mentioned. Acid lipases of non-pancreatic origin, such as gastric lipases or lipases from other species, have been shown to be present in animal models with CF and could be used therapeutically. So far no trial using acid lipases in CF patients has been published.

\section{UROGUANYLIN}

Uroguanylin is an intestinal peptide hormone that may regulate epithelial ion transport by activating a receptor, guanylyl cyclase, on the luminal surface of the intestine. In mice this drug stimulated ion transport mainly in the proximal duodenum and in the cecum and less in the jejunum, ileum, and distal colon. Acidification of the lumen of the proximal duodenum ( $\mathrm{pH}$ 5.0-5.5) enhanced the stimulatory action of uroguanylin. Experiments, using $\mathrm{pH}$-stat titration, revealed that uroguanylin stimulates serosal-to-luminal $\mathrm{HCO}_{3}{ }^{-}$secretion. In CFTR knockout mice, the duodenal response to uroguanylin was markedly reduced, but not eliminated, despite a similar density of functional receptors. It was concluded that uroguanylin is most effective in acidic regions of the small intestine, where it stimulates both $\mathrm{HCO}_{3}{ }^{-}$and $\mathrm{Cl}^{-}$secretion primarily via a CFTR-dependent mechanism. In vivo studies in mice have demonstrated that orally administered uroguanylin resists luminal proteolysis and stimulates net intestinal fluid accumulation. On the basis of its action to increase $\mathrm{HCO}_{3}{ }^{-}$ secretion, oral uroguanylin may be potentially useful as a pharmacological agent for the prevention and treatment of duodenal ulcers and probably to improve function of pancreatic enzymes in CF. [69]. However no trial with this petide hormone has. been published in CF. 


\section{ALTERNATIVE INTESTINAL BICARBONATE PRODUCTION}

It has been demonstrated that human duodenal enterocytes contain at least three acid/base transporters: a $\mathrm{Na}^{+} / \mathrm{H}^{+}$exchanger that serves to extrude acid, a $\mathrm{Na}$-bicarbonate cotransporter that functions as base loader, and a $\mathrm{Cl}^{-} / \mathrm{HCO}_{3}{ }^{-}$exchanger that operates as a base extruder [70]. These alternative pathways can be activated by carbachol and by heat-stable toxin of Escherichia coli. [71]. Until now no attempts concerning the use of such therapies in CF patients have been reported.

\section{ANTACIDS}

One of the most commonly used self-prescribed drugs are antacids, consisting of calcium carbonate and magnesium - aluminium salts in various compounds or combinations. The effect of antacids on the stomach is due to partial neutralization of gastric hydrochloric acid $(\mathrm{HCl})$ and inhibition of the proteolytic enzyme, pepsin. Antacids have been used in CF, but no beneficial effect was observed. Therefore antacids alone are insufficient in improving fat malabsorption in CF [72].

\section{$\mathrm{H}_{2}$ RECEPTOR ANTAGONISTS}

The need of antacids for intestinal ulcer related diseases was reduced after the introduction of $\mathrm{H}_{2}$ receptor antagonists. These drugs were investigated in $\mathrm{CF}$ and have shown to be only slightly effective in improving malabsorption when compared to PPI $[72,73]$. In the tables 1.1. and 1.2. we have included trials with this type of medication.

\section{PROTON PUMP INHIBITORS (PPI)}

The most effective agents for suppressing gastric acidity are PPIs, which are the treatment of choice for many acid-related GI tract conditions [74]. These drugs potently inhibit acid secretion from gastric parietal cells by irreversibly inhibiting activity of the $\mathrm{H}^{+} / \mathrm{K}^{+}$ATPase (proton pump). They are predominantly inactivated by the 2C19 isoform of the hepatic cytochrome P450 mixed function oxidase system. Some individuals present several different mutations for this system and will consequently metabolize PPIs more slowly resulting in higher drug levels. Therefore, the efficacy of acid suppression by standard doses of a PPI varies in the general population [75]. This might also explain the differences in potency between several PPIs, where lansoprasole and rabeprazole provide earlier and better symptom relief than omeprazole and pantoprazole. [76]. Rabeprazole is less dependent on 2C19 for metabolization and therefore the most potent [77]. Small molecular changes can result in important improvements as has been shown for esomeprazole [78]. PPIs do increase the $\mathrm{pH}$ of the proximal duodenum for a prolonged period, especially shortly after meals, and based on superior efficacy profiles they are the drugs of choice in patients with peptic ulcer disease, gastroesophageal reflux disease (GERD) and Zollinger-Ellison syndrome [79]. Also in CF patients they have been used with success $[93,94,98]$. 


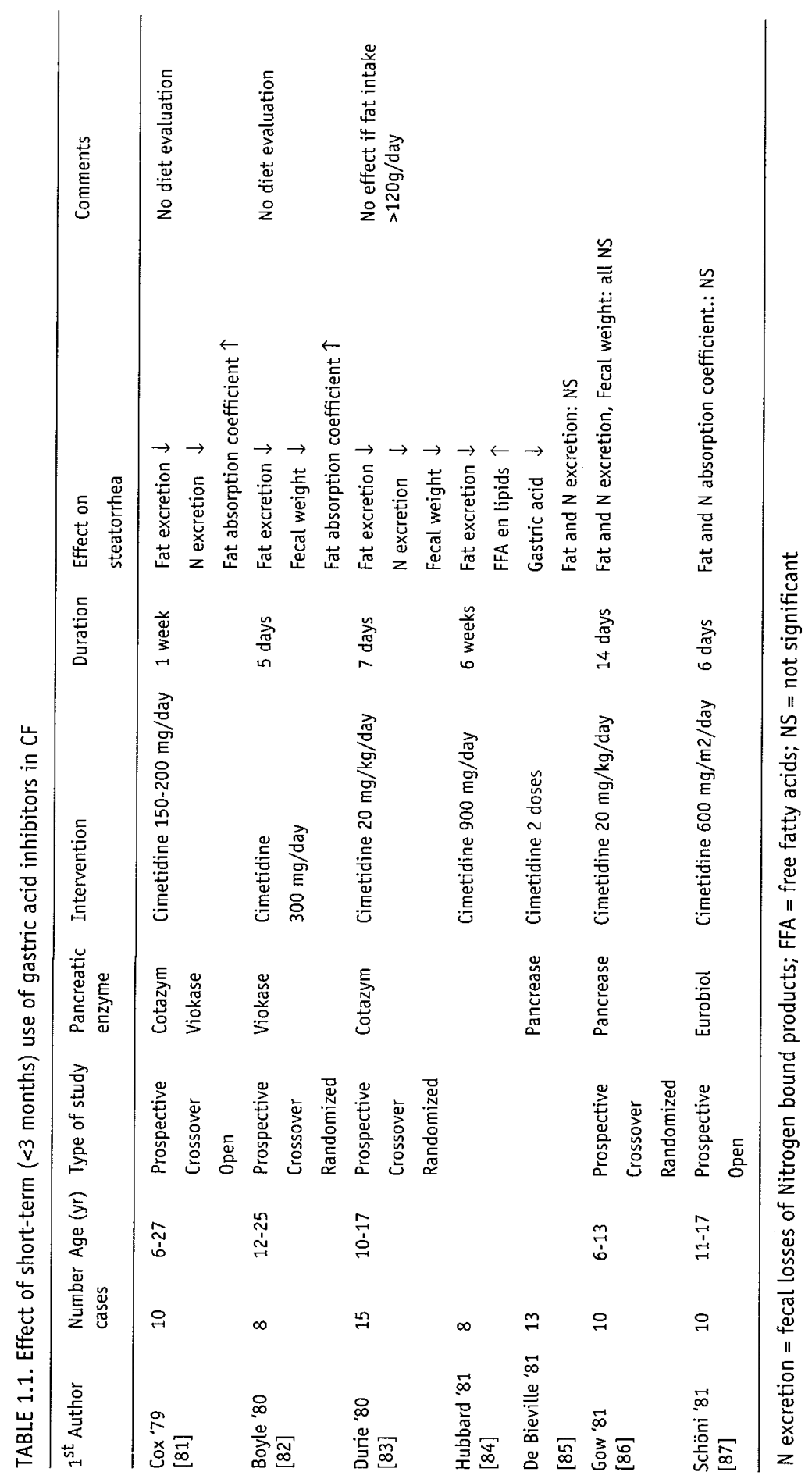




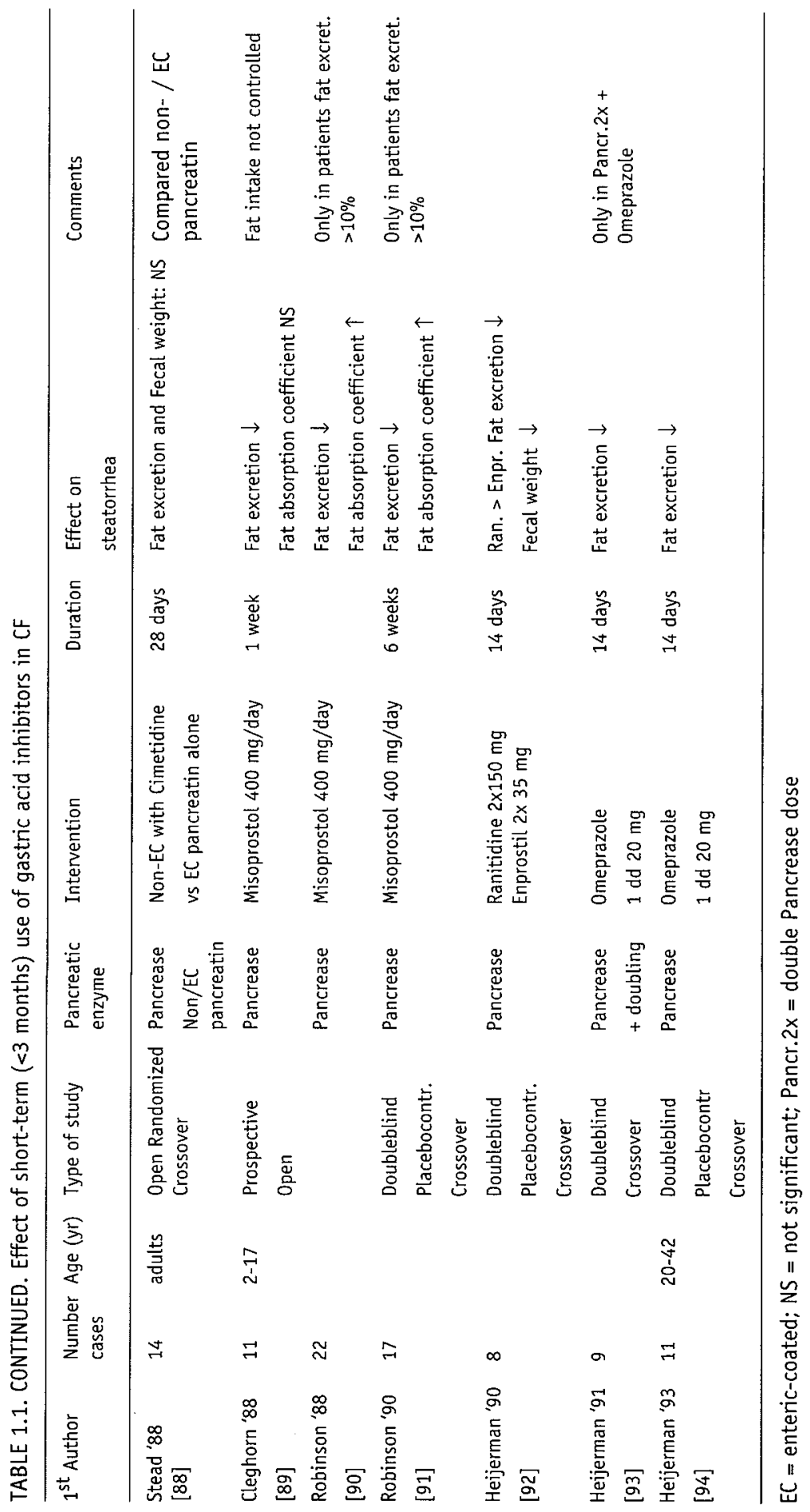




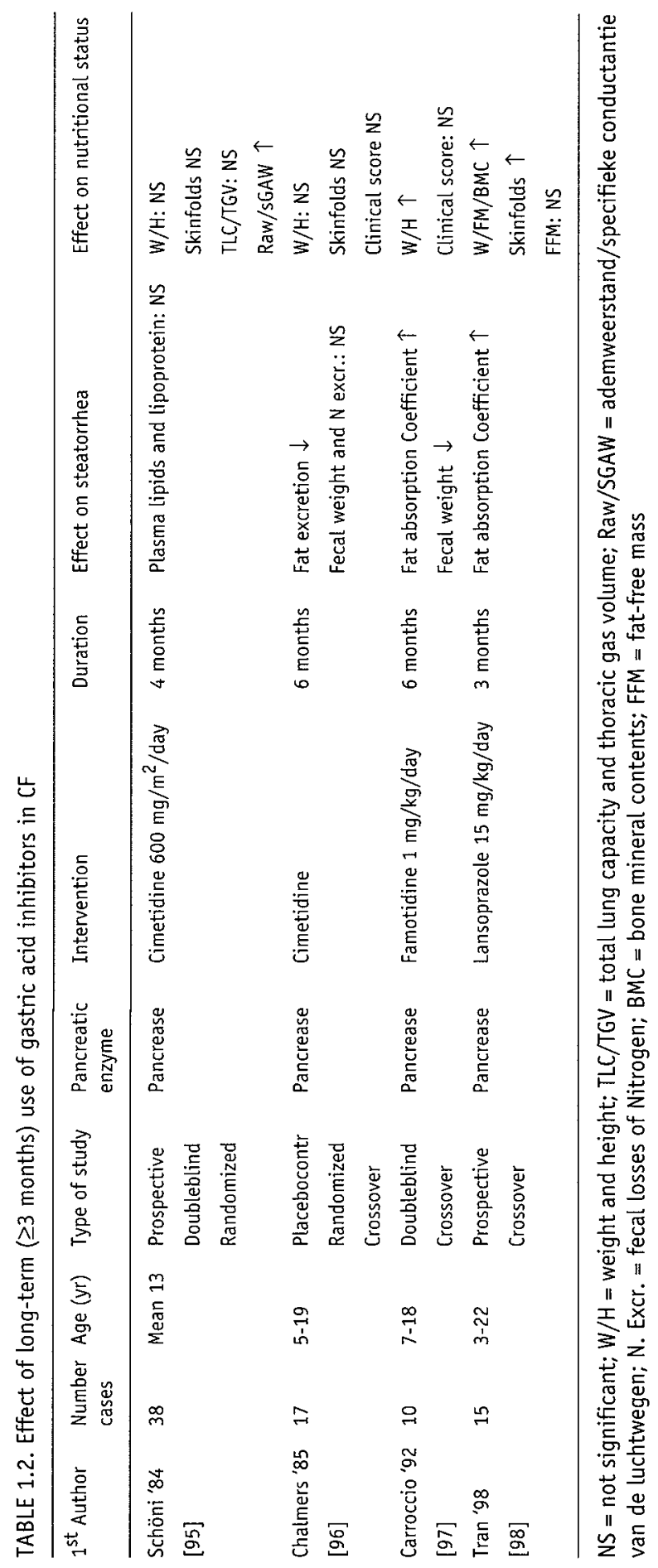




\section{VAGAL NERVE RESECTION}

Although vagal nerve resection could have a beneficial effect on luminal $\mathrm{pH}$, by decreasing gastric acid production, the vagal nerve also stimulates hepatic, pancreatic and duodenal mucosa bicarbonate production. The latter was demonstrated by electrical vagal stimulations in pigs [80]. As vagal nerve resection would decrease the necessary non-pancreatic bicarbonate secretion. Due to its invasiveness we consider this technique not as a real option in CF patients.

\section{SUMMARY}

In CF several studies concerning the use of duodenal pH increasing therapy, have been performed. Table 1.1. shows the short term studies ( $<3$ months) of gastric acid inhibitors, mainly $\mathrm{H}_{2}$ blockers, on malabsorption. These studies were too short to evaluate the effects on the nutritional status. Table 1.2. shows the few long-term studies ( $\geq 3$ months) of gastric acid inhibition, assessing nutritional status. More studies assessing nutritional interventions and/or trials with different pancreatic enzymes have been performed. The possible disadvantages of the use of PPIs, especially in children with $C F$, are discussed in the next section.

\subsection{PROS AND CONS FOR THE USE OF PPI IN CHILDREN WITH CF}

\section{POTENTIAL BENEFICIAL ROLE OF PPI IN CF}

In the following sub-sections several considerations for the use of PPI in CF are described.

Fat malabsorption: The major effect of PPIs is a decreased need of pancreatic bicarbonate for buffering gastric acid entering the duodenum. This should result in an earlier opening of the enteric-coated capsules, less denaturation of enzymes, better lipolysis, and an increase in the concentration of ionized bile salts. All these factors will improve fat absorption.

Absorption of fat soluble vitamins: Besides the fecal loss of lipids, steatorrhea will also result in increased losses of several hydrophobic vitamins. At risk for deficiencies are the fat-soluble vitamins A, D, E and K. Despite supplementation with standard multivitamins and pancreatic enzymes, the occurrence of persisting fat-soluble vitamin deficiency is relatively common in CF [99]. Vitamin K deficiency is a typical example. This vitamin is an important co-factor in the carboxylation of osteocalcin (OC), an important protein in bone formation. In CF patients a greater fraction of $O C$ seems to be under-carboxylated. Recent work has highlighted the association of reduced bone density with the prevalence of vitamin K deficiency. Deficiency of both vitamins $D$ and $\mathrm{K}$ could explain the decrease in bone density in CF patients before their puberty, reaching a lower peak bone mass as adolescent $[100,101]$. By decreasing fat excretion, the addition of a PPI might improve the vitamin status of CF patients. 
Gastroesophageal reflux disease (GERD): Another important issue is GERD, which has been shown to occur frequently in CF. In untreated infants with CF, one in five had pathological GERD and one in four had increased acid reflux time, while only 54\% showed normal oesophageal $\mathrm{pH}$ recordings. Pathologically increased reflux was found to be present before radiological lung disease was established. Apart from frequent vomiting, no useful clinical symptoms of pathological reflux were found [102]. By inhibiting gastric acid production, acid reflux will decrease. This acid reflux can induce inflammation in the ENT area [103]. It might also contribute to pulmonary inflammation and therefore almost half of the young CF patients could benefit from the use of PPIs.

Increased intestinal permeability (IP): As already mentioned IP is severely increased in $\mathrm{CF}$, and abnormalities related to the presence of pancreatic dysfunction in CFTR may contribute to this increase of IP. Especially the associated decrease in ductular bicarbonate secretion, resulting in a decreased duodenal buffering capacity and therefore in

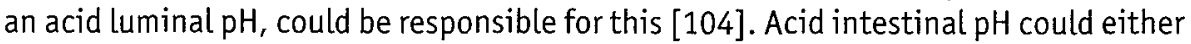
directly damage tight junctions between enterocytes or be responsible for late opening of the enzyme coating in the small bowel, resulting in elevated luminal proteolytic activity, which will also damage enterocytes and increase IP. Therefore the use of PPIs, by increasing the intestinal $\mathrm{pH}$, may have a beneficial effect on intestinal permeability.

\section{ADVERSE EVENTS BECAUSE OF THE USE OF PPIS}

Potential areas of concern regarding long-term PPI use have included:

Carcinoid formation and development of gastric adenocarcinoma: Prolonged PPI use may lead to enterochromaffin-like cell hyperplasia, but it has not been shown to increase the risk of carcinoid formation. There is no documentation of long-term PPI treatment hastening the development or the progression of atrophic gastritis to intestinal metaplasia and gastric cancer, although long-term studies are required to allow definitive conclusions. It seems that patients with Helicobacter pylori infection could be more prone to developing carcinoid formation [105].

Bacterial overgrowth and enteric infections: Gastric bacterial overgrowth is related to the degree of acid suppression, but clinically important sequelae, such as a higher rate of gastric adenocarcinoma, have not been seen. The risk of enteric infection may increase with acid suppression, although this does not seem to be a common clinical problem with prolonged PPI use [105].

Malabsorption of minerals, and vitamins: The absorption of vitamin $B_{12}$ may be decreased when gastric acid is markedly suppressed for prolonged periods (e.g. Zollinger-Ellison syndrome) due to an impaired release of vitamin $B_{12}$ from food in a non-acid environment. The malabsorption of crystalline vitamin $B_{12}$ observed in $C F$ is due to a mechanism independent of either intrinsic factor secretion or intrinsic factor biological activity. The absorption of crystalline vitamin $B_{12}$ in $C F$ is corrected in most 
patients by administration of pancreatic supplements [106]. Anyhow PPIs do not promote the development of pernicious anemia [107].

\section{THE LONG-TERM USE OF PPIS IN CHILDREN}

Knowledge about this class of drugs in pediatrics is still fragmentary, but the reported pharmacokinetic and clinical data indicate that they are suitable for use in children. While the short-term risk of complications appears to be minimal, the long-term tolerance requires careful monitoring because of the potential consequences of prolonged inhibition of acid secretion [108]. Current evidence suggests that prolonged gastric acid suppression with proton pump inhibitors rarely, if ever, produce adverse events. Nevertheless, continued follow-up of patients taking proton pump inhibitors for extended periods will provide greater experience regarding the potential gastrointestinal adverse effects of long-term acid suppression.

\section{CONCLUSION ABOUT PROS AND CONS OF PPIS IN CHILDREN}

In the present state of knowledge the potential advantages of using PPIs in pancreatic insufficient CF patients seem to outweigh the potential drawbacks. Awareness for unknown adverse effects after long-term use of these type of drugs is particularly required in children.

\subsection{AIMS OF THE STUDY}

In view of the persisting malabsorption in pancreatic insufficient CF patients despite enzyme supplementation and while awaiting the potential breakthrough of gene therapy, we aimed at improving the nutritional condition of our patients, by using PPIs in order to increase luminal $\mathrm{pH}$ and consequently decrease their persisting malabsorption. We assessed not only the effects on fat malabsorption of such a treatment but tried also to elucidate the following questions:

- Is there a relationship between body composition and lung function?

- Could PPIs modify the gut permeability?

Could PPIs modify airway hyperresponsiveness?

Could PPIs modify the essential fatty acid deficiency?

- Is vitamin $B_{12}$ deficient after prolonged use of PPIs?

The successive chapters in this thesis will give the study design, aims, results and interpretations of these questions. As the complete set of studies is of an observational design, definite conclusions can not been made. Therefore at the end of this thesis we will sum up the results, delineate a role for the use of proton pump inhibitors in young CF patients, but we can not advise the routine use of PPIs in children with CF. 


\subsection{REFERENCES}

1. Lewis, P.A., The epidemiology of CF, in Cystic Fibrosis, H.M.E.a.G. D.M., Editor. 1995, Chapman\&Hall Medical: London. 1-13.

2. Morgan, W.J.etal, Epidemiologic study of CF: Design and implementation of a prospective, multicenter, observational study of patients with CF in the US and Canada. Paediatr Pulmonol, 1999;28:231-41.

3. Ten Kate, L.P., CF in the Netherlands. Int J Epidemiol, 1977;6:23-34.

4. Wine, J.J., Cystic fibrosis lung disease. Science\&Medicine, 1999(May/June):34-43.

5. Tsui, L.C., Buchwald, M., Barker, D., et al., Cystic fibrosis locus defined by a genetically linked polymorphic DNA marker. Science, 1985;245:1059-65.

6. Rommens, J.M., Iannuzzi, M.C., Kerem, B., et al., Identification of the CF gene: chromosome walking and jumping. Science, 1989;245:1059-65.

7. Riordan, J.R., Rommens J.M., Kerem, B., et al., Identification of the CF gene: cloning and characterization of complementary DNA. Science, 1989;245:1066-73.

8. Kerem, B., Rommens, J.M., Buchanan, J.A., et al., Identification of the CF gene: genetic analysis. Science, 1989;245:1073-1080.

9. Davis, P.B., Drumm Mitchell, Konstan Michael W., State of the art: Cystic Fibrosis. Am J Respir Crit Care Med, 1996;154:1229-56.

10. Mickle, J.E. and G.R. Cutting, Genotype-phenotype relationships in cystic fibrosis. Med Clin North Am, 2000;84(3):597-607.

11. Matsui, H., B.R. Grubb, R. Tarran, S.H. Randell, J.T. Gatzy, C.W. Davis, and R.C. Boucher, Evidence for periciliary liquid layer depletion, not abnormal ion composition, in the pathogenesis of cystic fibrosis airways disease. Cell, 1998;95(7):1005-15.

12. Smith, J.J., S.M. Travis, E.P. Greenberg, and M.J. Welsh, Cystic fibrosis airway epithelia fail to kill bacteria because of abnormal airway surface fluid. Cell, 1996;85(2):229-36.

13. Verlingue, C., S. Vuillaumier, B. Mercier, M. Le Gac, J. Elion, C. Ferec, and E. Denamur, Absence of mutations in the interspecies conserved regions of the CFTR promoter region in cystic fibrosis (CF) and CF related patients. J Med Genet, 1998;35(2):137-40.

14. Reynaert, I., B. Van Der Schueren, G. Degeest, M. Manin, H. Cuppens, B. Scholte, and J.J. Cassiman, Morphological changes in the vas deferens and expression of the cystic fibrosis transmembrane conductance regulator (CFTR) in control, deltaF508 and knock-out CFTR mice during postnatal life. Mol Reprod Dev, 2000;55(2):125-35.

15. Landbo, C., E. Prescott, P. Lange, J. Vestbo, and T. Almdal, Prognostic value of nutritional status in chronic obstructive pulmonary disease. Am J Respir Crit Care Med, 1999;160:1856-61.

16. De Benedetto, F., A. Del Ponte, S. Marinari, and A. Spacone, In COPD patients, body weight excess can mask lean tissue depletion: a simple method of estimation. Monaldi Arch Chest Dis, 2000;55(4):273-8. 
17. Schols, A.M., J. Slangen, L. Volovics, and E.F. Wouters, Weight loss is a reversible factor in the prognosis of chronic obstructive pulmonary disease. Am J Respir Crit Care Med, $1998 ; 157(6$ Pt 1):1791-7.

18. Kobayashi, A., T. Yoneda, M. Yoshikawa, M. Ikuno, H. Takenaka, A. Fukuoka, N. Narita, and $K$. Nezu, The relation of fat-free mass to maximum exercise performance in patients with chronic obstructive pulmonary disease. Lung, 2000;178(2):119-27.

19. Engelen, M.P., A.M. Schols, J.D. Does, and E.F. Wouters, Skeletal muscle weakness is associated with wasting of extremity fat-free mass but not with airflow obstruction in patients with chronic obstructive pulmonary disease. Am $\mathrm{J}$ Clin Nutr, 2000;71(3):733-8.

20. Mostert, R., A. Goris, C. Weling-Scheepers, E.F. Wouters, and A.M. Schols, Tissue depletion and health related quality of life in patients with chronic obstructive pulmonary disease. Respir Med, 2000;94(9):859-67.

21. Wouters, E.F., Nutrition and metabolism in COPD. Chest, 2000;117(5 Suppl 1):274S-80S.

22. Engelen, M.P., E.F. Wouters, N.E. Deutz, P.P. Menheere, and A.M. Schols, Factors contributing to alterations in skeletal muscle and plasma amino acid profiles in patients with chronic obstructive pulmonary disease. Am J Clin Nutr, $2000 ; 72(6): 1480-7$.

23. Forli, L., J.I. Pedersen, Bjortuft, M. Vatn, J. Kofstad, and J. Boe, Serum amino acids in relation to nutritional status, lung function and energy intake in patients with advanced pulmonary disease. Respir Med, 2000;94(9):868-74.

24. Serres, I., V. Gautier, A. Varray, and C. Prefaut, Impaired skeletal muscle endurance related to physical inactivity and altered lung function in COPD patients. Chest, 1998;113(4):900-5.

25. Ionescu, A.A., K. Chatham, C.A. Davies, L.S. Nixon, S. Enright, and D.J. Shale, Inspiratory muscle function and body composition in cystic fibrosis. Am J Respir Crit Care Med, 1998;158(4):1271-6.

26. Schols, A.M., W.A. Buurman, A.J. Staal van den Brekel, M.A. Dentener, and E.F. Wouters, Evidence for a relation between metabolic derangements and increased levels of inflammatory mediators in a subgroup of patients with chronic obstructive pulmonary disease. Thorax, 1996;51(8):819-24.

27. Schols, A.M., E.C. Creutzberg, W.A. Buurman, L.A. Campfield, W.H. Saris, and E.F. Wouters, Plasma leptin is related to proinflammatory status and dietary intake in patients with chronic obstructive pulmonary disease. Am J Respir Crit Care Med, 1999;160(4):1220-6.

28. Bell, S.C., A.R. Bowerman, C.A. Davies, I.A. Campbell, D.J. Shale, and J.S. Elborn, Nutrition in adults with cystic fibrosis. Clin Nutr, 1998;17(5):211-5.

29. Schoni, M.H. and C. Casaulta-Aebischer, Nutrition and lung function in cystic fibrosis patients: review. Clin Nutr, 2000;19(2):79-85.

30. Schwebel, C., I. Pin, D. Barnoud, G. Devouassoux, P.Y. Brichon, P. Chaffanjon, 0. Chavanon, C. Sessa, D. Blin, M. Guignier, X. Leverve, and C. Pison, Prevalence and 
consequences of nutritional depletion in lung transplant candidates. Eur Respir J, 2000;16(6):1050-5.

31. Stern, M., M. Reynaud-Gaubert, A. Haloun, M. Bertocchi, and D. Grenet, [Lung transplantation in cystic fibrosis in adults. Patient selection criteria]. Rev Mal Respir, 2000;17(3 Pt 2):779-84.

32. Gilljam, M., M. Antoniou, J. Shin, A. Dupuis, M. Corey, and D.E. Tullis, Pregnancy in cystic fibrosis. Fetal and maternal outcome. Chest, 2000;118(1):85-91.

33. Konstan, M.W., et al., Patterns of medical practice in CF: Part I. Evaluation and monitoring of health status of patients. Paediatr Pulmonol, 1999;28:242-47.

34. Konstan, M.W., et al., Patterns of medical practice in CF: Part II. Use of therapies. Paediatr Pulmonol, 1999;28:248-54.

35. Zemel, B.S., D.A. Kawchak, A. Cnaan, H. Zhao, T.F. Scanlin, and V.A. Stallings, Prospective evaluation of resting energy expenditure, nutritional status, pulmonary function, and genotype in children with cystic fibrosis. Pediatr Res, 1996;40(4):578-86.

36. Pilewski, J.M. and R.A. Frizzell, Role of CFTR in airway disease. Physiol Rev, 1999;79(1 Suppl):\$215-55.

37. Pencharz, P.B., Energy intakes and low-fat diets in children with cystic fibrosis. J Pediatr Gastroenterol Nutr, 1983;2(3):400-2.

38. Dodge, J.A., The nutritional state and nutrition. Acta Paediatr Scand Suppl, 1985;317:31-7.

39. Gaskin, K.J., The impact of nutrition in cystic fibrosis: a review. J Pediatr Gastroenterol Nutr, 1988;7(Suppl 1): S12-7.

40. Erskine, J.M., C.D. Lingard, M.K. Sontag, and F.J. Accurso, Enteral nutrition for patients with cystic fibrosis: comparison of a semi-elemental and nonelemental formula. J Pediatr, 1998;132(2):265-9.

41. Pencharz, P.B. and P.R. Durie, Pathogenesis of malnutrition in cystic fibrosis, and its treatment. Clin Nutr, 2000;19(6):387-94.

42. Kawchak, D.A., H. Zhao, T.F. Scanlin, J.L. Tomezsko, A. Cnaan, and V.A. Stallings, Longitudinal, prospective analysis of dietary intake in children with cystic fibrosis. J Pediatr, 1996;129(1):119-29.

43. Poustie, V.J., R.L. Smyth, and R.M. Watling, Oral protein calorie supplementation for children with chronic disease. Cochrane Database Syst Rev, 2000;3.

44. Smyth, R. and S. Walters, Oral calorie supplements for cystic fibrosis. Cochrane Database Syst Rev, 2000;2.

45. Littlewood, J.M. and S.P. Wolfe, Control of malabsorption in cystic fibrosis. Paediatr Drugs, 2000;2(3):205-22.

46. Mullinger, M., The effect of exogenous pancreatic enzymes on fat absorption. Pediatrics, 1968;42(3):523-5.

47. Beverley, D.W., J. Kelleher, A. MacDonald, J.M. Littlewood, T. Robinson, and M.P. Walters, Comparison of four pancreatic extracts in cystic fibrosis. Arch Dis Child, $1987 ; 62(6): 564-8$. 
48. Anthony, H., C.E. Collins, G. Davidson, C. Mews, P. Robinson, R. Shepherd, and D. Stapleton, Pancreatic enzyme replacement therapy in cystic fibrosis: Australian guidelines. Pediatric Gastroenterological Society and the Dietitians Association of Australia. J Paediatr Child Health, 1999;35(2):125-9.

49. Mulberg, A.E., R.T. Weyler, S.M. Altschuler, and T.M. Hyde, Cystic fibrosis transmembrane conductance regulator expression in human hypothalamus. Neuroreport, 1998;9(1):141-4.

50. Davies, P.S., Energy requirements for growth and development in infancy. Am J Clin Nutr, 1998;68(4):939S-943S.

51. Stallings, V.A., E.B. Fung, P.M. Hofley, and T.F. Scanlin, Acute pulmonary exacerbation is not associated with increased energy expenditure in children with cystic fibrosis. J Pediatr, 1998;132(3 Pt 1):493-9.

52. Reilly, J.J., J.M. Ralston, J.Y. Paton, C.A. Edwards, L.T. Weaver, J. Wilkinson, and T.J. Evans, Energy balance during acute respiratory exacerbations in children with cystic fibrosis. Eur Respir J, 1999;13(4):804-9.

53. Shepherd, R.W., R.M. Greer, S.A. McNaughton, M. Wotton, and G.J. Cleghorn, Energy expenditure and the body cell mass in cystic fibrosis. Nutrition, 2001;17(1):22-5.

54. Barraclough, M. and C.J. Taylor, Twenty-four hour ambulatory gastric and duodenal $\mathrm{pH}$ profiles in cystic fibrosis: effect of duodenal hyperacidity on pancreatic enzyme function and fat absorption. J Pediatr Gastroenterol Nutr, 1996;23(1):45-50.

55. van Velzen, D., Colonic strictures in children with cystic fibrosis on low-strength pancreatic enzymes. Lancet, 1995;346(8973):499-500.

56. Imrie, J.R., Fagan, D.G., Sturgess, J.M., Quantative evaluation of the development of the exocrine pancreas in CF and control infants. Am J Pathol, 1979;95:697-707.

57. Borowitz, D., Evidence for the diagnosis of pancreatic insufficiency. Pediatr Pulmonol, 2000;29(3):167-8.

58. Quinton, P.M., International symposium on $\mathrm{HCO}_{3}^{-}$and $\mathrm{CF}$. Preface. J.Pancreas, 2001;2((4 suppl)):150-153.

59. Ramsden, W.H., E.F. Moya, and J.M. Littlewood, Colonic wall thickness, pancreatic enzyme dose and type of preparation in cystic fibrosis. Arch Dis Child, $1998 ; 79(4): 339-43$.

60. Youngberg, C.A., R.R. Berardi, W.F. Howatt, M.L. Hyneck, G.L. Amidon, J.H. Meyer, and J.B. Dressman, Comparison of gastrointestinal $\mathrm{pH}$ in cystic fibrosis and healthy subjects. Dig Dis Sci, 1987;32(5):472-80.

61. Walters, M.P. and J.M. Littlewood, Pancreatin preparations used in the treatment of cystic fibrosis - lipase content and in vitro release. Aliment Pharmacol Ther, $1996 ; 10(3): 433-40$.

62. Robinson, P.J., A.L. Smith, and P.D. Sly, Duodenal $\mathrm{pH}$ in cystic fibrosis and its relationship to fat malabsorption. Dig Dis Sci, 1990;35(10):1299-304.

63. Gonong, W.F., Digestion and absorption of lipids, in review of medical physiology. 1999, Appleton \& Lange: Stamford. 
64. Leclercq-Foucart, J., P.P. Forget, and J.L. Van Cutsem, Lactulose-rhamnose intestinal permeability in children with cystic fibrosis. J Pediatr Gastroenterol Nutr, 1987;6(1):66-70.

65. Henig, N.R. and M.L. Aitken, Update on clinical trials of cystic fibrosis. Curr Opin Pulm Med, 1997;3(6):404-9.

66. Nousia-Arvanitakis, S., M. Fotoulaki, H. Economou, M. Xefteri, and A. Galli-Tsinopoulou, Long-term prospective study of the effect of ursodeoxycholic acid on cystic fibrosis-related liver disease. J Clin Gastroenterol, 2001;32(4):324-8.

67. Gregory, P.C., Gastrointestinal $\mathrm{pH}$, motility/transit and permeability in cystic fibrosis. J Pediatr Gastroenterol Nutr, 1996;23(5):513-23.

68. Roy CC, W.A., Lepage G, Smith L, Levy E, Digestive and absorptive phase anomalies associated with the exocrine pancreatic insufficiency of cystic fibrosis. J Pediatr Gastroenterol Nutr, 1988;7(Suppl. 1):S1-7.

69. Joo, N.S., R.M. London, H.D. Kim, L.R. Forte, and L.L. Clarke, Regulation of intestinal $\mathrm{Cl}$ - and $\mathrm{HCO}_{3}^{-}$-secretion by uroguanylin. Am J Physiol, 1998;274(4 Pt 1):G633-44.

70. Ainsworth, M.A., Hogan, D.L., Rapier, R.C., Amelsberg, M., Dreilinger A.D., Isenberg J.I., Acid/base transporters in human duodenal enterocytes. Scand J Gastroenterol, 1998;33(10):1039-46.

71. Pratha, V.S., D.L. Hogan, B.A. Martensson, J. Bernard, R. Zhou, and J.I. Isenberg, Identification of transport abnormalities in duodenal mucosa and duodenal enterocytes from patients with cystic fibrosis. Gastroenterology, 2000;118(6):1051-60.

72. Maton, P.N., Burton, M.E., Antacids revisited: a review of their clinical pharmacology and recommended therapeutic use. Drugs, 1999;57(6):855-70.

73. Huang, J.Q., Hunt, R.H., Pharmacological and pharmacodynamic essentials of $\mathrm{H}_{2}$-receptor antagonosts and PPI for the practising physician. Baillieres Best Pract Res Clin Gastroenterol, 2001;15(3):355-70.

74. Metz, D.C., Potential uses of intravenous proton pump inhibitors to control gastric acid secretion. Digestion, 2000;62(2-3):73-81.

75. Egan, L.J., Murray, J.A., New perspectives in gastric acid suppression: genetic polymorphisms predict the efficacy of PPI. Dig Dis, 2000;18(2):58-63.

76. Stedman, C.A., Barclay, M.L., Review article: comparison of the pharmacokinetics, acid suppresion and efficacy of PPI. Aliment Pharmacol Ther, 2000;14(8):963-78.

77. Ishizaki, T., Horai, Y., Review article: Cytochrome P450 and the metabolism of PPI-emphasis on rabeprazole. Aliment Pharmacol Ther, 1999;13(suppl.3):27-36.

78. Spencer, C.M. and D. Faulds, Esomeprazole. Drugs, 2000;60(2):321-9; discussion 330-1.

79. Welage, L.S., Berardi, R.R., Evaluation of omeprazole, lansoprazole, pantoprazole, and rabeprazole in the treatment of acid-related diseases. J Am Pharm Assoc (Wash), 2000;40(1):52-62.

80. Glad, H., Svendsen, P, Olsen, 0, Schaffalitzky de Muckadell, 0.B., Importance of vagus nerves in duodenal acid neutralization in anaesthetized pigs. Am J Physiol, 1997;272(1 Pt 1):G154-60. 
81. Cox, K.L., J.N. Isenberg, A.B. Osher, and R.R. Dooley, The effect of cimetidine on maldigestion in cystic fibrosis. J Pediatr, 1979;94(3):488-92.

82. Boyle, B.J., W.B. Long, W.F. Balistreri, S.J. Widzer, and N. Huang, Effect of cimetidine and pancreatic enzymes on serum and fecal bile acids and fat absorption in cystic fibrosis. Gastroenterology, 1980;78(5 Pt 1):950-3.

83. Durie, P.R., L. Bell, W. Linton, M.L. Corey, and G.G. Forstner, Effect of cimetidine and sodium bicarbonate on pancreatic replacement therapy in cystic fibrosis. Gut, 1980;21(9):778-86.

84. Hubbard, V.S., G.D. Dunn, and L.A. Lester, Effectiveness of cimetidine as an adjunct to supplemental pancreatic enzymes in patients with cystic fibrosis. Am J Clin Nutr, 1980;33(11):2281-6.

85. de Bieville, F., H.J. Neijens, J. Fernandes, M. van Caillie, and K.F. Kerrebijn, Cimetidine as an adjunct to oral enzymes in the treatment of malabsorption due to cystic fibrosis. Acta Paediatr Scand, 1981;70(1):33-7.

86. Gow, R., R. Bradbear, P. Francis, and R. Shepherd, Comparative study of varying regimens to improve steatorrhea and creatorrhoea in cystic fibrosis: Effectiveness of an enteric-coated preparation with and without antacids and cimetidine. Lancet, 1981;2(8255):1071-4.

87. Schoni, M., R. Kraemer, and E. Rossi, Cimetidine and fat malabsorption in children with cystic fibrosis. Helv Paediatr Acta, 1981;36(4):359-69.

88. Stead, R.J., I. Skypala, and M.E. Hodson, Treatment of steatorrhea in cystic fibrosis: a comparison of enteric- coated microspheres of pancreatin versus non-enteric-coated pancreatin and adjuvant cimetidine. Aliment Pharmacol Ther, 1988;2(6):471-82.

89. Cleghorn, G.J., R.W. Shepherd, and T.L. Holt, The use of a synthetic prostaglandin E1 analogue (misoprostol) as an adjunct to pancreatic enzyme replacement in cystic fibrosis. Scand J Gastroenterol Suppl, 1988;143:142-7.

90. Robinson, P.J., P.D. Sly, and A.L. Smith, Effect of misoprostol on fat malabsorption in cystic fibrosis. Arch Dis Child, 1988;63(9):1081-2.

91. Robinson, P. and P.D. Sly, Placebo-controlled trial of misoprostol in cystic fibrosis. J Pediatr Gastroenterol Nutr, 1990;11(1):37-40.

92. Heijerman, H.G., C.B. Lamers, J.H. Dijkman, and W. Bakker, Ranitidine compared with the dimethylprostaglandin E2 analogue enprostil as adjunct to pancreatic enzyme replacement in adult cystic fibrosis. Scand J Gastroenterol Suppl, 1990;178:26-31.

93. Heijerman, H.G., C.B. Lamers, and W. Bakker, Omeprazole enhances the efficacy of pancreatin (pancrease) in cystic fibrosis. Ann Intern Med, 1991;114(3):200-1.

94. Heijerman, H.G., C.B. Lamers, W. Bakker, and J.H. Dijkman, Improvement of fecal fat excretion after addition of omeprazole to pancrease in cystic fibrosis is related to residual exocrine function of the pancreas. Dig Dis Sci, 1993;38(1):1-6.

95. Schoni, M., R. Kraemer, A. Ruedeberg, M.J. Lentze, R.C. Mordasini, W.F. Riesen, M.P. Klay, and E. Rossi, Long-term cimetidine in children with cystic fibrosis: a randomized double-blind study. Pediatr Res, 1984;18(1):66-70. 
96. Chalmers, D.M., R.C. Brown, M.G. Miller, P.C. Clarke, J. Kelleher, J.M. Littlewood, and M.S. Losowsky, The influence of long-term cimetidine as an adjuvant to pancreatic enzyme therapy in cystic fibrosis. Acta Paediatr Scand, 1985;74(1):114-7.

97. Carroccio, A., F. Pardo, G. Montalto, L. Iapichino, M. Soresi, M.R. Averna, G. Iacono, and $A$. Notarbartolo, Use of famotidine in severe exocrine pancreatic insufficiency with persistent maldigestion on enzymatic replacement therapy. A long-term study in cystic fibrosis. Dig Dis Sci, 1992;37(9):1441-6.

98. Tran, T.M., A. Van den Neucker, J.J. Hendriks, P. Forget, and P.P. Forget, Effects of a proton-pump inhibitor in cystic fibrosis. Acta Paediatr, 1998;87(5):553-8.

99. Feranchak, A.P., M.K. Sontag, J.S. Wagener, K.B. Hammond, F.J. Accurso, and R.J. Sokol, Prospective, long-term study of fat-soluble vitamin status in children with cystic fibrosis identified by newborn screen. J Pediatr, 1999;135(5):601-10.

100. Wilson, D.C. and P.B. Pencharz, Nutrition and cystic fibrosis. Nutrition, $1998 ; 14(10): 792-5$.

101. Grey, V., L. Lands, H. Pall, and D. Drury, Monitoring of 25-OH vitamin D levels in children with cystic fibrosis. J Pediatr Gastroenterol Nutr, 2000;30(3):314-9.

102. Heine, R.G., B.M. Button, A. Olinsky, P.D. Phelan, and A.G. Catto-Smith, Gastro-oesophageal reflux in infants under 6 months with cystic fibrosis. Arch Dis Child, 1998;78(1):44-8.

103. Lippincott, L.L. and K.R. Brown, Medical management of pediatric chronic sinusitis. J La State Med Soc, 2000;152(10):470-4.

104. Shumaker, H., H. Amlal, R. Frizzell, C.D. Ulrich, 2nd, and M. Soleimani, CFTR drives $\mathrm{Na}^{+}-$ $\mathrm{HCO}_{3}^{-}$cotransport in pancreatic duct cells: a basis for defective $\mathrm{HCO}_{3}^{-}$secretion in $\mathrm{CF}$. Am J Physiol, 1999;276(1 Pt 1):C16-25.

105. Laine, L., D. Ahnen, C. McClain, E. Solcia, and J.H. Walsh, Review article: potential gastrointestinal effects of long-term acid suppression with proton pump inhibitors. Aliment Pharmacol Ther, 2000;14(6):651-68.

106. Monin, B., J.L. Gueant, A. Gerard, J.C. Michalski, M. Vidailhet, G. Grignon, and J.P. Nicolas, Physicochemical characterization and biological activity of intrinsic factor in cystic fibrosis. J Pediatr Gastroenterol Nutr, 1990;10(1):87-94.

107. Howden, C.W., Vitamin B12 levels during prolonged treatment with proton pump inhibitors. J Clin Gastroenterol, 2000;30(1):29-33.

108. Faure, C., C. Pelatan, and J. Languepin, [Proton pump inhibitors in pediatrics]. Arch Pediatr, 1999;6(6):650-6. 
CHAPTER TWO

Trial Design: An open study to assess the effects of one year lansoprazole treatment on nutritional status, body composition, lung function and intestinal permeability in children with Cystic Fibrosis

Han Hendriks

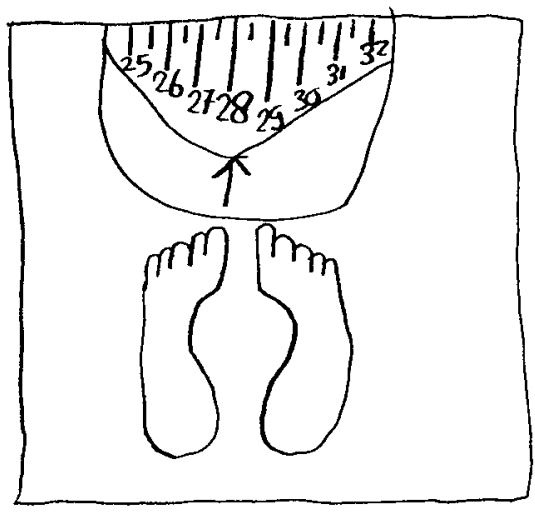




\section{AN OPEN STUDY TO ASSESS THE EFFECTS OF ONE YEAR LANSOPRAZOLE TREATMENT ON NUTRITIONAL STATUS, BODY COMPOSITION, LUNG FUNCTION AND INTESTINAL PERMEABILITY IN CHILDREN WITH CYSTIC FIBROSIS}

An observational study to assess the effects of a pharmacologic modulation of gastric acid secretion on biological variables in children with Cystic Fibrosis. This chapter describes the aims, the subjects and the methods used in our studies performed in young CF patients which are presented in the chapters 4 through 8 .

\subsection{BACKGROUND AND AIMS OF THE COMBINED STUDY}

In a previous, short term study we evaluated the effect of a protonpump-inhibitor (PPI), lansoprazole (Prezal $\left.{ }^{(}\right)$, on fecal fat excretion and body composition, in children with Cystic Fibrosis (CF). One of the main issues in CF disease is exocrine pancreatic insufficiency, resulting in a shortage of both enzymes and bicarbonate secretion. The lack of pancreatic bicarbonate results in a poor duodenal neutralization of gastric acid and a duodenal $\mathrm{pH}$ below the $\mathrm{pH}$ optimum (5.5) of pancreatic enzymes activity. Fat digestion will be hampered, resulting in steatorrhea and malnutrition. Based on the results of our "pilot" study, increasing duodenal luminal $\mathrm{pH}$ through the use of a PPI could be expected to decrease fecal fat excretion and enhance body composition. Additional effects that might be expected are a decrease of the abnormally elevated intestinal permeability (IP) characteristic of CF patients, and secondarily also improvements of the essential fatty acids status and lung function. Finally PPIs might induce side effects, like vitamin $B_{12}$ deficiency.

Therefore, the aim of this study was to investigate whether or not during a pharmacological intervention with PPIs in children with CF any of these predictable effects occur. Secondly, this study was also intended to provide data to perform a power analysis for possible future, placebo-controlled studies. For both purposes an observational study, in children with CF and ongoing pancreatic insufficiency, was performed.

\subsection{SUBJECTS}

\section{STUDY POPULATION}

Children with a confirmed diagnosis of $C F$ involving the respiratory tract and gastro-intestinal tract were eligible for the study. All children received standard therapy, including several pharmacological interventions (described in 2.3) and hyper alimentation (described in 2.4), as part of their regular management before the start of the study. A total of 14 patients entered the study, all completing a one year treatment protocol. All but one patient continued the use of the PPI for 3 years allowing us to study long term effects. Approval of the medical ethical committee of the university hospital of Maastricht and informed consent of the parents and patients older than 11 years was obtained. 
TABLE 2.1. Nutritional daily recommendations for children with CF

\begin{tabular}{ll}
\hline Energy & RDA $\times(1.2-1.5)$ \\
Protein & RDA $\times(1.2-1.5)$ \\
Fat & $35-40 \%$ of energy \\
Essential fatty acids & $5 \%$ of energy \\
Sodium chloride & Infants $1 \mathrm{~g} / \mathrm{d}$, children $3-6 \mathrm{~g} / \mathrm{d}$ (compensation for sweat losses) \\
Fat soluble A & $2500-5000$ IU in water-soluble form \\
Vitamins: $\quad$ D & $800 \mathrm{IU}$ \\
$\quad$ E & $5-10 \mathrm{mg} / \mathrm{kg}$ (max. $300 \mathrm{mg}$ ) tocopheryl acetate \\
$\quad$ K & not defined (probably $1 \mathrm{mg} / \mathrm{kg} /$ day) \\
Water soluble B group & RDA $\times 2$ \\
Vitamins: $\quad$ B12 & RDA unless ileal resection \\
$\quad$ C & RDA $\times 2$ \\
$\quad$ Iron, Zinc & RDA (suppletion only if deficient)
\end{tabular}

$\mathrm{RDA}=$ recommended daily allowance (for healthy children)

CRITERIA WHICH ALL HAD TO BE FULFILLED, BEFORE INCLUSION.

1. The diagnosis of CF had to be confirmed by sweat test according to the method by Gibson and Cooke [1] (chloride of more than $60 \mathrm{mMol} / \mathrm{L}$ ) or by DNA analysis.

2. The patients had to be able to perform lung function measurements adequately and their pre-study $\mathrm{FEV}_{1}$, in the preceding year, had to be over $70 \%$ of mean values for normal children with the same height and sex (predicted).

3. The patients had to demonstrate ongoing pancreatic insufficiency, despite an intake of at least 2000 IU lipase/ $\mathrm{kg}$ body weight, as indicated by a pre-study stool acid steatocrit (an index of fecal fat excretion) over $25 \%$ in the preceding year.

4. The patients had to receive the recommended daily nutritional requirements for $\mathrm{CF}$ patients, as outlined in table 2.1 .

5. The patients had to receive the recommended medical and physiotherapeutical treatment and they should not have used PPIs in the preceding year.

6. No participation in any trial was allowed within the previous 3 months.

\section{CRITERIA LEADING TO EXCLUSION FROM THE STUDY}

1. Hospital admission in the 3 months preceding the study or administration of (oral) antibiotics at home during one month preceding the study (infectious exacerbation).

2. Other metabolic disorders including diabetes mellitus and thyroid disease, which might confound interpretation of the study results or clinically significant cardiovascular, renal, central nervous or musculo-skeletal system disorders.

3. Severe malnutrition requiring daily enteral (by nasal tube or gastrostomy) or parenteral nutritional supplementation, in addition to that described in table 2.1.

4. Considered by the investigator to be unsuitable for the study for reasons of non-compliance or inability to follow instructions correctly. 
TABLE 2.2. Patient characteristics at start $(N=14)$

\begin{tabular}{llrrrr}
\hline Item & & Mean & SD & Range \\
\hline Age & (year) & 9.74 & 3.38 & $4.6 / 17.2$ \\
Height & $(\mathrm{cm})$ & 133.9 & 16.6 & $107.0 / 162.3$ \\
& $(\mathrm{SDS})$ & -1.068 & 0.590 & $-2.166 /+0.003$ \\
Weight & $(\mathrm{kg})$ & 27.7 & 9.9 & $15.5 / 52.3$ \\
& $(\mathrm{SDS})$ & -1.270 & 0.739 & $-2.393 /+0.272$ \\
Acid Steatocrit & $(\%)$ & 33.3 & 17.7 & $5.4 / 65.7$ \\
FEV & $(\%$ predicted & 83.9 & 17.2 & $58 / 112$ \\
FVC & (\% predicted) & 86.6 & 13.0 & $64 / 109$ \\
\hline
\end{tabular}

\subsection{MEDICAL TREATMENT}

During one year lansoprazole (Prezal ${ }^{\circledR}$ ) was administered at a dose of $15 \mathrm{mg}$ once daily, 30 minutes before breakfast. All other medication used before the start of the study was continued in the same dose and frequency. All patients used nebulized saline daily, with or without mucolytics, while four also used nebulized DNAse (Pulmozyme ${ }^{\circledR}$ ). All patients performed regularly sputum mobilization exercises as instructed and controlled by their physiotherapist. Three patients were on ursodeoxycholic acid, while no patient was on daily antibiotics. New medication was permitted, if necessary, according to standard protocols for CF care. Infectious exacerbations, as occurred in 4 children once, were treated according to the usual protocol, with antibiotics for at least 2 weeks. During the whole study year, only one child was admitted because of complaints of his previously demonstrated gastro-intestinal fistula.

\subsection{DIET AND PANCREATIC ENZYMES}

A free but constant diet, similar to that used before the study, according to recommendations (table 2.1.), was prescribed to each patient during the study. The only difference was that during the study the dietary intake was analyzed extensively, every 6 months, instead of once a year. For that purpose at start and after 6 and 12 months, parents and their children held, for three consecutive days, a detailed record of both nutrient intake and pancreatic enzymes doses. This was analyzed and computed by one dietary consultant. For each 6 months period and for each different meal, changes in nutrients, energy and lipase intake were analyzed. 


\subsection{STUDY SCHEME}

(Months)

Visits

Clinical evaluation

+ Anthropometry

Dietary evaluation

Body composition

DEXA

\section{Resting energy expenditure}

Ventilated Hood

\section{Gastro-intestinal function}

3 sugars permeability test

Fecal fat content

Urinary $\mathrm{NO} /$ creatinine-ratio

\section{Lung function}

- F/V-curves, bodybox

- PEF

\section{Laboratory assesments}

Fatty Acids status

Vitamin $\mathrm{B}_{12}$-homocysteine

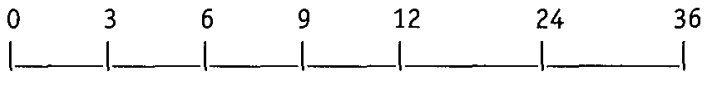

$\begin{array}{lllllll}x & x & x & x & x & x & x \\ x & & x & & x & x & x\end{array}$

$x$

$x$

$x$

$x$

$x \quad x \quad x \quad x$

$\begin{array}{lllll}x & & & & x \\ x & x & x & x & x \\ x & x & x & x & x\end{array}$

$x \quad x \quad x \quad x \quad x \quad x$

4 times daily - 1 week/month

\section{6}

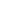

$\times$




\section{ASSESSMENT OF ANTHROPOMETRIC PARAMETERS}

Clinical evaluation: Every 3 months the patients were seen at the out-patient clinic for a routine systematic physical examination covering all body systems, including ENT, respiratory, gastro-intestinal, cardiovascular, neurological, muscles, skeletal, and skin. All medication was checked and prescribed for the following 3-month period.

Weight and Height: At visits in the out-patient clinic, weight and height, as mean of three separate measurements, was assessed, by one single investigator (Hendriks), with the subjects barefoot and dressed in underwear. The same instruments, a Harpenden stadiometer (Holtain Ltd., Crymych, D Y Fed. UK) and an electronic weight scale (Seca Delta, Model 707) were used during the study period. Body mass index (BMI) was computed as weight/height ${ }^{2}$ in $\left(\mathrm{kg} / \mathrm{m}^{2}\right)$. Weight, height and BMI are expressed as standard deviation scores (SDS) for age and sex. We used Dutch reference values, as recorded by Gerver and de Bruin [2,3]. Expression in SDS changes is a prerequisite for pediatric studies, as absolute changes in weight and height with time are age and sex dependent and would be uninterpretable in a group of children of different ages and sexes.

\section{BODY COMPOSITION BY TOTAL BODY DUAL ENERGY X-RAY}

\section{ABSORPTIOMETRY (DEXA)}

This is a non-invasive method, which is used for an easy and rapid ( $<30$ minutes) evaluation of the body composition and bone mineral status. During one assessment total body fat (TBF), fat mass (FM), fat free mass (FFM), bone mineral content (BMC) and bone density (BMD) can be measured. A pediatric software program (Paediatric Beta Software: Lunar 1.5) was used. The radiation dose of this examination is very low $(<5 \mathrm{mRem})$ when compared with the standard yearly background radiation exposure ( $82 \mathrm{mRem} /$ year). This method is considered to be the method of choice for measuring body composition in young children. Because the children are in a normal growth process, results were compared with those of a large $(n=403)$, normal Dutch reference group, matched for age and sex, and expressed as SDS [4].

\section{RESTING ENERGY EXPENDITURE (REE)}

Basal metabolic rate or REE was measured by indirect calorimetry (ventilated hood) and compared to Schofield's age-related normal values for children [5,6]. The principle of a ventilated hood system is that a stream of air is forced to pass across the face of a subject and mixes with the expired air, which is collected by a transparent plexiglas hood $(30 \mathrm{~L})$ placed over the subject's head. The rate of REE was calculated by determining the amount of air flowing through the hood and by measuring the oxygen and the carbon dioxide concentrations in the in and out coming air. The assessments were performed after an overnight fast in the morning, during tidal breathing in supine position for 15 minutes, at complete rest. 


\section{GASTRO INTESTINAL FUNCTIONS}

Fecal Fat Content: Steatorrhea was monitored by measuring the fecal acid steatocrit as previously described [7]. According to this method results are measured as fat / fat + solid layer and expressed in percentage. Fecal acid steatocrit has been shown to correlate well with chemical analyses of fecal fat $(r=0.83)$. We chose this method in order to monitor intensively and easily fecal fat content, allowing us to obtain regular recordings during the study. Before the start ( 3 samples, within 2 weeks) and every two weeks during the entire study a small stool sample was taken, placed in a container, wrapped in aluminum foil, stored in the refrigerator at home at $-18^{\circ} \mathrm{C}$ and taken to the hospital during visits. The upper normal limit for acid steatocrit in children older than 0.5 years is $20 \%$, as described elsewhere $[8,9]$.

Intestinal Permeability (IP): IP was measured before and after one year treatment with lansoprazole, by the 3-sugars permeability test (3-SPT), according to Miki et al [10]. After an overnight fast, the first urine of the day was discarded and the patients ingested $100 \mathrm{ml}$ of an isotonic test solution (osmolality $330 \mathrm{mMol} / \mathrm{L}$ ) containing 1 gram Mannitol (M), 1 gram L-Rhamnose (Rh) and 5 gram Lactulose (L). Only water intake was allowed after the first half-hour of this study, while food and sugar containing fluid intake were withheld for 4 hours. Urine was collected for 5 hours for determination of these 3 sugars by high-performance liquid chromatography. Results were expressed as percentage of intake. Sugar excretion ratios were determined by dividing the percentage of urinary recovery of the large sugar $(L)$ by that of the smaller sugars $(M+R h)$. This simple and non-invasive test is a reproducible index of IP in children [11]. The use of ratios eliminates potentially confounding factors such as delayed gastric emptying, delayed or rapid gut transit, or impaired renal clearance.

\section{LUNG FUNCTION}

An experienced lung function technician performed the lung function tests, using a Jaeger Masterlab pneumotachograph and bodybox. Calibration of the apparatus was performed twice daily. Only lung function data with FVC variability of less than $5 \%$, on 3 consecutive maneuvers, were accepted. Lung function parameters were expressed as \% of predicted $(100 \%$ is the mean of normal children, with the same height and sex) according to the Zapletal reference values [12]. The following lung function parameters were used:

Static and Dynamic lung volumes

Flow Volume curves: (particularly)

- Forced Expiratory Volume in 1 second $\left(\mathrm{FEV}_{1}\right)$

- Forced Vital Capacity (FVC)

- Peak Expiratory Flow (PEF) 
Single body box:

Total Lung Capacity (TLC)

Residual Volume (RV)

* Intra Thoracic Gas Volume (ITGV)

(specific) Airway Resistance and Conductance (Raw, sRaw, Gaw, sGaw)

Respiratory muscle function: As representative of respiratory muscle function, maximal mouth pressures were measured at residual volume (RV) for maximal inspiratory pressure (PImax) and at total lung capacity (TLC) for maximal expiratory pressure (PEmax), according to the method of Black and Hyatt [13]. As there are no normal values for children, the exact data are given.

Peakflow (PEF) variability and Bronchial Lability (BL): In asthmatics, bronchial hyperresponsiveness $(B H R)$ can be increased due to both recurrent infections or gastro esophageal reflux (GER). Because of a different patho-physiology in CF and because of drawbacks of the PEF measurements, it is perhaps better to describe it as bronchial lability (BL). Although GER is known to be present in many (young) CF patients, the existence of BL and the effect of PPI on this BL has never been examined in these patients. Daily PEF variability is an easy and commonly used lung function assessment, especially in normal daily life conditions. In the present study PEF was measured at home four times daily, using a "Personal Best" PEF meter (Respironics HealthScan Products, Europe, Belgium). Instruction was given about the correct technique and reading of the PEF meter. In order to detect an incorrect use, three consecutive maneuvers were performed and recorded, while only the best of these 3 measurements was used for data management. In order to measure changes in $\mathrm{BL}$, several PEF characteristics were calculated from the diary records performed for an one week period every month, during the first year of the study [14]:

- Mean diurnal variability (in L/min), 7 days with 4 data per day.

- Maximal diurnal variability: the difference between the worst (morning) and the best (evening) PEF of that week (expressed as \% of recent (that week) best PEF).

- Minimal morning PEF (expressed as \% of recent best PEF).

- The difference between the best morning and the best evening PEF (in L/min).

\section{MUCOSAL INFLAMMATION}

Mucosal inflammation has been shown to be present in CF patients $[15,16]$. Urinary nitric-oxide products $\left(\mathrm{NO}_{x}\right)$ are markers of cytokine-induced increase of mucosal $\mathrm{NO}$-synthesis. Like others we could show that $\mathrm{NO}_{x}$ are increased in acute celiac disease $[17,18]$. We asked the patients to collect their urine before and at 3 months intervals during this study, in order to evaluate this marker in CF. Twenty-four hours prior to a visit, the CF patients collected urine, after using a nitrate-poor diet for 48 hours, before and during the collection period. Patients were free of viral illness or CF exacerbation during the collection period. Nitrite and nitrate content were determined using a Nitrate/Nitrite colorimetric assay kit (Cayman Chemical Company, Ann Arbor, MI, US). This test uses the Griess reagent assay, which is more accurate than 
the HPLC method [19]. Urinary creatinine was also determined in order to compute the NOx / Creatinine ratio. The data collected in our CF patients were compared with results of urine samples of 25 normal children (mean age 9.0 ( \pm 4.8 ) years).

\subsection{SPECIAL LABORATORY MEASUREMENTS}

Blood was not only taken for routine blood analyses, but also for special assessments. The following investigations were performed.

Fatty Acids: The fatty acid (FA) status was evaluated in 20 CF patients (11 with PPI and 9 without PPI) and in 10 children, submitted to minor surgical procedures (controls). The fatty acid profiles were determined in plasma and red blood cell phospholipids as previously described [20]. Briefly, lipid extracts were prepared from both plasma and RBC samples, and the phospholipid fraction was separated. Then the phospholipid FA were hydrolyzed and transmethylated. The composition of the obtained FA methylesters was determined by capillary gas chromatography using a polar column, with helium as carrier gas and at a pressure of $130 \mathrm{kPa}$. The amount of each fatty acid was quantified by the amount recovered of the internal standard (dinonadecanoyl [19:0]-phosphatidylcholine) added to each sample.

Vitamin $B_{12}$ and Homocysteine: Vitamin $B_{12}$ and homocysteine blood levels were measured in 20 CF patients (11 with PPI and 9 without PPI) and in 10 children, submitted to minor surgical procedures (controls). Total homocysteine concentration in plasma was measured by HPLC, as previously described [21], and vitamin $B_{12}$ by a competitive protein binding assay (Perkin-Elmer, Turku, Finland).

\subsection{STATISTICS}

As our aim was to evaluate possible effects of PPIs, all measured parameters were analysed in two ways. Firstly, in order to maximize the chance to find a possible effect, we compared the mean of the whole intervention period to the pre-trial (baseline) values whenever possible. In that way, the power of the test is optimized, since measurement errors and within-subject variation tends to cancel out. A second advantage of this method is that we avoided doing 4 different tests for essentially the same hypothesis, which would inflate the type-I error probability beyond the nominal $5 \%$. By performing this procedure a Bonferroni correction is not necessary and, according to Altman, this is advised as one of the five possibilities to avoid a repeated measurements design [22]. Secondly, as this procedure will show a less detailed picture, we also looked for trends within the study period. Furthermore, by using the non-parametric Wilcoxon signed ranks test, we avoided to make the assumption of normality, which is untestable with only 14 subjects. Differences with respect to baseline were considered significant when the two-sided $P$-value was 0.05 or less. The 
statistical package SPSS (version 9.0 and 10.0 for Windows, 1998) was used for data management and analysis.

\subsection{REFERENCES}

1. Gibson LE, and Cooke RE. A test for concentration of electrolytes in sweat in CF of the pancreas utilising pilocarpine by iontophoresis. Pediatrics 1959;23:545-549.

2. Gerver WJM and Bruin de R. Paediatric Morphometrics a Reference Manual. In Bunge, Utrecht, the Netherlands 1996.

3. Gerver WJM, Bruin de R. Body composition in children based on anthropometric data. A presentation of normal values. Eur J Pediatr 1996;155:870-876.

4. Boot $A M$ et al. Determinants of body composition by DEXA in Dutch children and adolescents. Am.J.Clin.Nutr. 1997 Aug; 66(2):232-238.

5. Kaplan AS, Zemel BS, Neiswender KM and Stallings VA. Resting Energy Expenditure in clinical pediatrics: measured versus prediction equations. J Pediatr 1995;127:200-5.

6. Schofield WN. Predicting basal metabolic rate, new standards and review of previous work. Hum Nutr Clin Nutr 1985;39c(1s):5-42.

7. Tran TMD, Forget PPh, Van den Neucker AM, Strik J, Kreel van B and Kuijten RH. The acid steatocrit: a much improved method. J Pediatr Gastroenterol Nutr 1994;19:299-303.

8. Van den Neucker AM, Forget PPh, Veneberg JA, Schutten BJ and Kreel van B. Acid Steatocrit during infancy. Acta Paediatr. 1996;85:1153-1155.

9. Van den Neucker AM, Pestel N, Tran TMD, Forget PPh, Veeze HJ, Bouquet J and Sinaasappel M. Clinical use of acid steatocrit. Acta Paediatr. 1997:86:466-469.

10. Miki K, Butler R, Moore D, Davidson G. Rapid and simultaneous quantification of rhamnose, mannitol and lactulose in urine by HPLC for estimating IP in pediatric practice. Clin Chem 1996;42:71-75.

11. Elburg van RM, Uil JJ, Kokke FTM, Mulder AM, Broek van de WGM, Mulder ChJ, Heymans HSA. Repeatability of the sugar-absorption test, using lactulose and mannitol, for measuring intestinal permeability for sugars. J Pediatr Gastroenterol Nutr 1995;20:184-188.

12. Zapletal $A$, Samanek $M$ and Paul T. In Lung function in children and adolescents. Methods, reference values. In Progress in Respiration Research Nr.22. Editor: Herzog H. Karger Basel, 1987.

13. Black LF and Hyatt RE. Maximal respiratory pressures: normal values and relationship to age and sex. Am.Rev.Respir.Dis. 1969;99:696-702.

14. Reddel HK, Salome CM, Peat JK, Woolcock AJ. Which index of PEF is most useful in the management of stable asthma? Am.J.Respir.Crit.Care Med. 1995;151:1320-1325.

15. Smyth RL, Croft NM, O'Hea U, Marshall TG. Intestinal inflammation in CF. Arch Dis Child 2000;82:394-399. 
16. Raia V, Maiuri L, De Ritis G, De Vizia B, Vacca L, Conte R, Auricchio S and Londei M. Evidence of chronic inflammation in morphologically normal small intestine of $C F$ patients. Pediatr Res 2000;47:344-350.

17. Sundqvist T, Laurin P, Falth-Magnusson K, Magnusson KE, Stenhammar L. Significantly increased levels of nitric oxide products in urine of children with celiac disease. $J$ Pediatr Gastroenterol Nutr 1998;27:196-198.

18. Straaten EA, Koster-Kamphuis L, Bovee-Oudenhoven IM, Meer van der R, Forget PPh. Increased urinary nitric oxidation products in children with active coeliac disease. Acta Paediatr 1999;88:528-531.

19. Tsikas D, Fuchs I, Gutzki FM, Frolich JC. Measurement of nitrite and nitrate in plasma, serum and urine by HPLC, the Griess assay, chemiluminescense and gas chromatography- mass spectrometry: interference by biogenic amines and $N(G)$-nitro-L-arginine analogs. J Chromatogr B Biomed Sci Appl 1998;715:441-444.

20. Otto SJ, Foreman-v. Drongelen MM, Houwelingen ACv, Hornstra G. Effects of storage on venous and capillary blood samples: the influence of deferoxamine and butylated hydroxytoluene on the fatty acid alterations in red blood cell phospholipids. Eur J Clin Chem Clin Biochem 1997;35:907-13.

21. Spaapen LJM, Waterval WAH, Bakker JA, Luijckx GJ, Vles JSH. Detectie van hyperhomocysteïnemie bij vroegtijdige cerebrovasculaire ziekte. Tijds NVKC 1992;17:194-9.

22. Altman DG. In Practical statistics for medical research. Chapman and Hall, London 1991:429-431. 



\section{CHAPTER THREE}

\section{Longitudinal growth of children with Cystic Fibrosis: a longitudinal retrospective study}

Han Hendriks, Femke Schuurmans, Willem-Jan Gerver, Philippe Forget

Department of Pediatrics, University Hospital Maastricht, The Netherlands. Translated in Dutch it will be submitted to the Ned Tijdschrift voor Geneesk

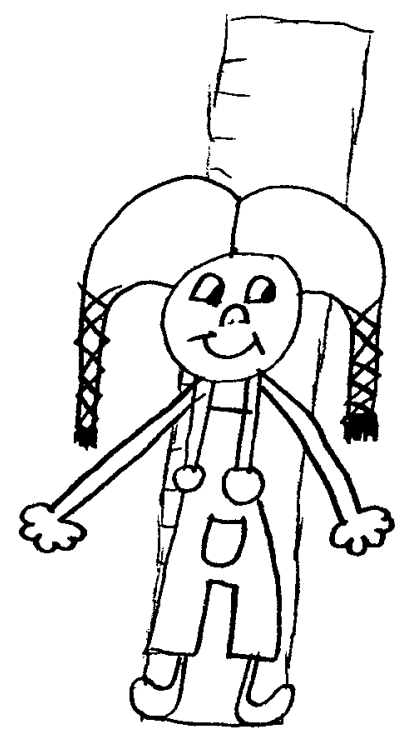




\subsection{ABSTRACT}

Background: Studies of growth in children with Cystic Fibrosis (CF) used crosssectional data and showed a retarded growth pattern in CF. We plotted the growth data of 27 children with cystic fibrosis longitudinal, in order to define growth patterns in children with CF.

Methods: Mean Standard Deviation Scores (SDS) and $95 \%$ confidence intervals for height, weight and weight-for-height were plotted for age intervals. Patients were followed up to the age of 120 months. Non-parametric two-samples tests (Mann-Whitney-U-test) were used in order to compare SDS results between boys and girls at various time intervals.

The Pearson correlation coefficient was used for studying the relationship between catch-up growth and the severity of the initial growth failure.

Results: Compared to normal children, both boys and girls initial showed a severe decrease in mean SDS for weight (boys -3.28; girls -2.84), height (boys -2.88; girls -1.84) and weight-for-height (boys -1.11; girls -1.02). Catch-up growth in CF patients occurred in the first year after diagnosis and resulted in normalising of the SDS for each parameter at the age of two years. A strong correlation was found between catch-up growth for height, weight and weight-for-height and the severity of the initial growth failure. A slight decrease in both mean weight and height SDS occurred when children grew older while weight-for-height remained normal.

Conclusions: Growth patterns show stunting more than wasting, making the use of weight-for-age growth charts preferable to that of weight-for-height in these patients. These data further support the need for CF screening programs as initial growth was in $80 \%$ severely decreased (less than - 2 SD) and early intervention could prevent stunting in these patients. 


\subsection{INTRODUCTION}

Cystic Fibrosis (CF) as a chronic disease is a known cause of growth retardation [1-13]. In CF, growth failure may result from insufficient energy intake, malabsorption and increased catabolism [4,5,9-13]. After making the diagnosis and starting therapy, catch-up growth is known to occur and has been achieved by treating the two main underlying disease entities malnutrition and chronic airway infection. Therefore, besides antibiotics, nutritional support with high-energy diets and by optimising pancreatic supplementation is very important $[1-7,10,11,13]$. Early detection by screening and treatment in $\mathrm{CF}$ centres further improved the outcome of $\mathrm{CF}$ patients. In these settings, CF patients experienced significantly fewer and shorter hospital stays in the first year of life and malnutrition in many patients was prevented $[7,11]$. Catch-up growth for height in children with $C F$ has been reported to be incomplete $[3-5,7,9,12,13]$ and may be also one of the reasons why CF patients start in about one year later with their pubertal growth spurt [14]. Catch-up growth for weight has also been reported to be incomplete, except for one study where weight and height catch-up growth was reported to be complete within 12 months [6].

When studying growth disturbances in childhood the indices of stunting and wasting are used. Stunting and wasting were previously defined as chronic and acute malnutrition respectively. The present definition of wasting is that of a deficit in weight-for-height, while stunting is defined as being a deficit in height-for-age [15]. The first aim of the present retrospective study was to evaluate long term longitudinal growth of children with CF. The second aim was to study the catch-up growth pattern in these patients. Answers to both of these questions could help resolve the dilemma "to screen or not te screen" for this condition.

\subsection{SUBJECTS AND METHODS}

\section{PATIENTS}

Follow-up growth data of 27 CF patients (11 females) were available for our study. The patients were born between 1977 and 1996, therefore patients had variable follow-up periods. Only patients diagnosed before the age of 4 months were included and diagnosis was confirmed by repeated sweat tests. Mean present age (SD) was $11.7(4.0)$ years for girls and 9.3 (5.2) years for boys. Twenty-four patients were pancreatic insufficient, while three were pancreatic sufficient.

\section{METHODS}

Weight and height measurements were obtained from the charts of the out-patient department of Pediatrics of the University Hospital Maastricht. The children were measured using standard anthropometric techniques, using the same instruments, a Harpenden stadiometer (Holtain limited, Crymych, D Y Fed., UK) and an electronic weight scale (Seca delta, modell 707). The data were expressed as SDS, making use of the normal pediatric Dutch reference values, collected by Gerver and de 
Bruin [16]. SDS is defined as the number of standard deviations from the mean. These SDS were calculated for height, weight and weight-for-height. The patient mean and $95 \%$ confidence interval SDS were plotted for different age periods. The study period was divided in six months periods up to 120 months, except for the first year of life where three periods of each 4 months were used.

Growth data have been studied for girls and boys separately and, due to the lack of significant sex differences, as well as the use of SDS, have been pooled together in the figures.

Catch-up growth was defined as the difference between the best SDS, between 18 and 36 months of age, when SDS had most often normalised, and the worst SDS at diagnosis, at the age of 0 to 8 months. The relationship between catch-up growth and the severity of growth failure at the start was evaluated by correlating catch-up growth with the worst initial SDS.

\section{STATISTICAL ANALYSIS}

Parametric tests were used for the calculation of mean values and confidence intervals. A significant difference was considered to exist between the reference population and our data when the mean value of the data set differed from 0 at the 0.05 confidence level. Non-parametric two-sample tests (Mann-Whitney-U-test) were used in order to compare SDS results between boys and girls at various time intervals. The Pearson correlation coefficient was used for studying the relationship between catch-up growth and the severity of the initial growth failure.

The SPSS 7.5 for Windows statistical package was used for data management.

\subsection{RESULTS}

Mean SDS for height, weight and weight-for-height for the different age periods are shown in table 3.1. The initial mean height SDS were evidently decreased for

TABLE 3.1. Height, weight and weight-for-height SDS for female and male CF patients.

\begin{tabular}{llrrrrrr}
\hline Age periods & \multicolumn{2}{c}{ Sex } & \multicolumn{2}{c}{ Height SDS } & \multicolumn{2}{c}{ Weight SDS } & \multicolumn{2}{c}{ Weight-for-height SDS } \\
& & N & \multicolumn{2}{c}{ Mean \pm SD } & N & Mean \pm SD & \multicolumn{2}{c}{ N } & Mean \pm SD \\
\hline 0-4 months & f & 5 & $-1.84 \pm 1.73$ & 5 & $-2.84 \pm 1.17$ & 5 & $-1.02 \pm 0.80$ \\
& m & 9 & $-2.88 \pm 1.67$ & 9 & $-3.28 \pm 1.37$ & 9 & $-1.11 \pm 0.76$ \\
18-24 months & f & 7 & $-0.45 \pm 0.82$ & 7 & $-0.95 \pm 1.26$ & 7 & $-0.47 \pm 1.06$ \\
& m & 10 & $-0.23 \pm 0.99$ & 10 & $-0.32 \pm 0.70$ & 10 & $-0.21 \pm 0.72$ \\
$60-66$ months & f & 6 & $-1.48 \pm 0.97$ & 6 & $-1.19 \pm 0.95$ & 6 & $-0.53 \pm 0.47$ \\
& m & 8 & $-1.50 \pm 0.54$ & 8 & $-1.79 \pm 0.84$ & 8 & $-1.16 \pm 1.09$ \\
$102-108$ months & f & 6 & $-1.61 \pm 0.81$ & 6 & $-1.49 \pm 0.54$ & 6 & $-0.61 \pm 0.42$ \\
& m & 4 & $-0.65 \pm 0.47$ & 4 & $-0.48 \pm 1.00$ & 4 & $0.40 \pm 1.71$ \\
\hline
\end{tabular}




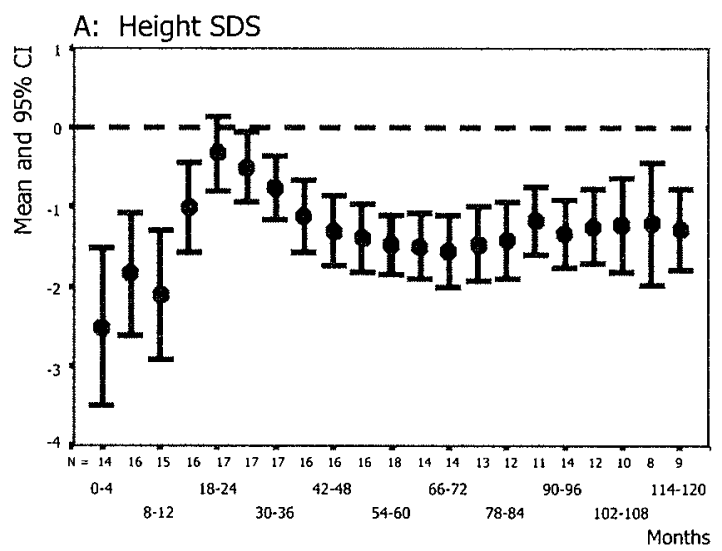

B: Weight SDS

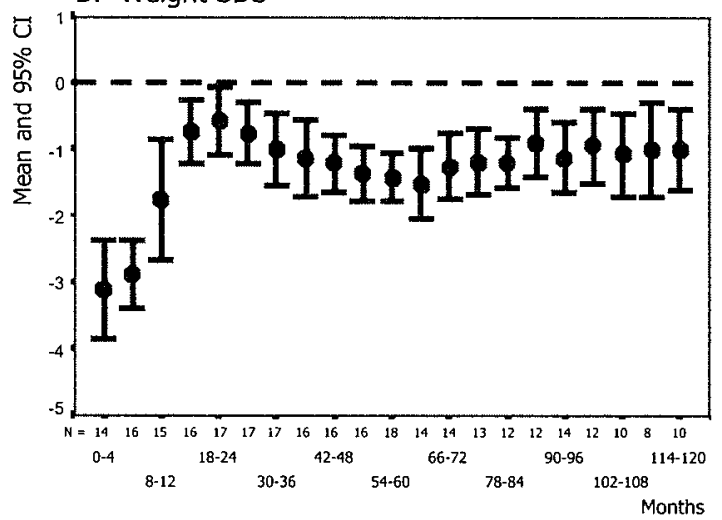

C: Weight-for-height SDS

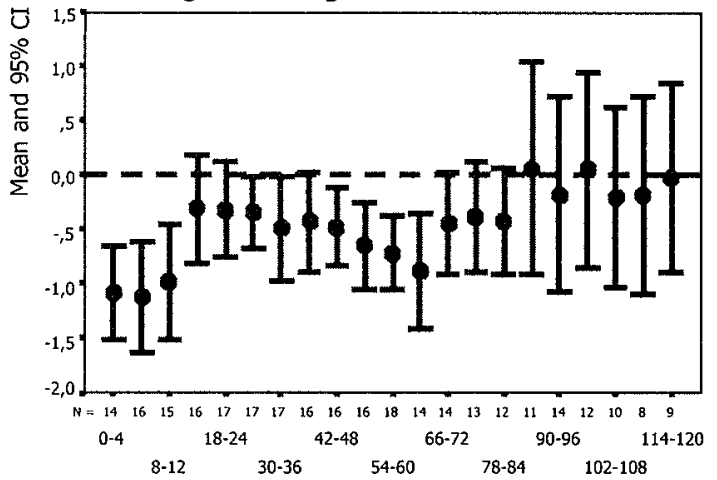

Months

FIG 3.1. A-C. Mean and 95\% confidence intervals for height SDS (a), weight SDS (b) and weight-for-height SDS (c) in CF patients from 0 up to 120 months. 


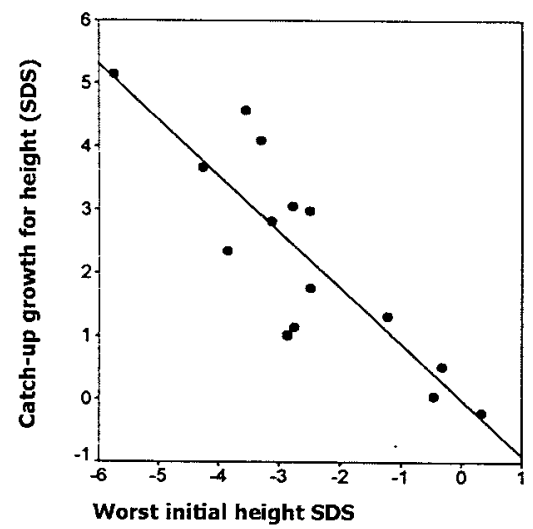

$2 a$.

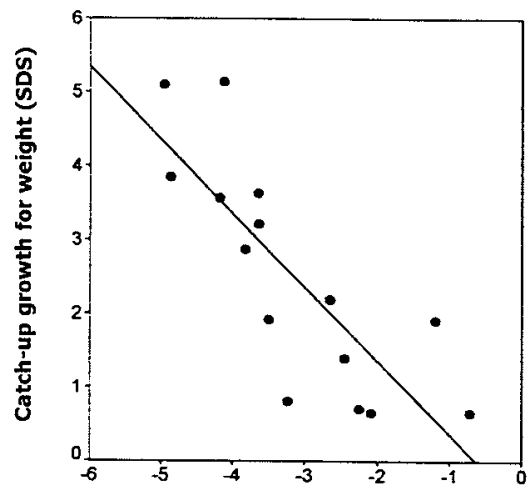

$2 b$.

Worst initial weight SDS

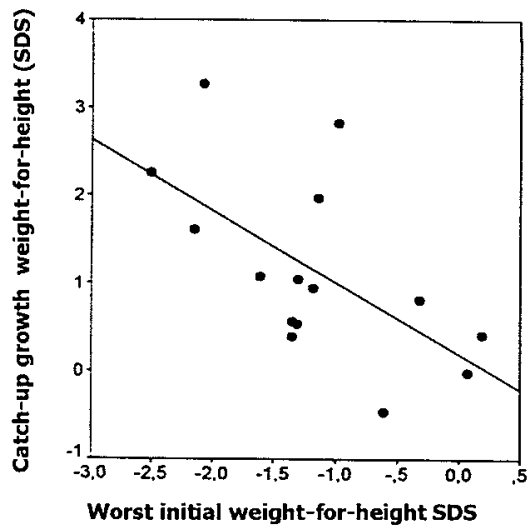

2c.

FIG 3.2. A-C. Correlations between catch-up growth for height (a), weight (b) and weight-for-height (c) with severity of initial growth failure expressed as worst initial SDS for height, weight and weight-for-height. 
female and male CF patients ( -1.84 and -2.88 respectively). Beyond the age of 2 years the mean height SDS was nearly normal ( -0.45 and -0.23 respectively). Weight SDS followed the same pattern with even worse initial SDS. The slight height and weight SDS differences between boys and girls were not significant. Female and male patients showed similar initial weight-for-height SDS (- 1.02 and - 1.11 respectively). The mean weight-for-height SDS of male patients increased up to 0.40 in the 102-108 months period and was by that even better than in normal Dutch boys. While the mean weight-for-height SDS $(-0.61)$ of female patients remained slightly, but not significantly, below mean values for normal girls.

figure 3.1a-c shows the mean and 95\% confidence intervals for height, weight and weight-for-height SDS for boys and girls taken together during the study period. The height SDS started at a very low value, increased to the normal range at the age of two years, but subsequently decreased again, reaching a plateau of - $1.5 \mathrm{SD}$ at the age of 5-10 years. Weight SDS had an identical pattern with a plateau of - 1 SD at the age of 3-10 years. Initially weight-for-height was much less decreased and, besides a short period around $4-5$ years, it was from 1.5 years on in the normal range compared to Dutch children.

A strong positive correlation was found between catch-up growth and the severity of initial growth failure in our patients. Correlation coefficients $(r)$ for height, weight and weight-for-height were resp. $-0.86(P<0.001),-0.80(P<0.001)$ and $-0.60(P<0.05)$ (figure 3.2). While catch-up growth for weight and height were significantly related to each other $(r=0.78, P<0.01)$.

\subsection{DISCUSSION}

Also in our small but longitudinal study, at time of diagnosis (before 4 months of age in all our patients) we demonstrated, in both boys and girls with CF, an obvious decreased height and weight SDS, while weight for height SDS was only slightly decreased. In our study mean height, weight and weight-for-height SDS normalised at the age of 18-24 months, and subsequently decreased somewhat at the age of about five years. Previous studies in CF patients have shown subnormal initial height and weight SDS [1-7, 11-13]. Compared to the latter reported data, our patients showed a more severe initial growth retardation. This could partly be due to the fact that there is no standard screening-program for CF in the Netherlands. On the other hand diagnosis was clear before the age of four months in all of our patients. Important to notice is the almost complete catch-up growth in the first 2 years after diagnosis, which implicates that this growth retardation was reversible.

Karlberg et al. [4] evaluated linear growth in children with CF from birth to 8 years of age. Height SDS were reported to be subnormal up to one year of age, improved up to a height of -0.3 SD at five years of age and even became positive between 5 and 8 years of age. These findings only differ from ours, concerning the partly reverse of catch-up growth found in our patients at about 5-10 years. In a cross-sectional British study, reporting cross sectional growth of 3056 children with CF, showed also a plateau in 
growth, between 1 and 10 years. The plateau was approximately 0.5 SD below the population mean. Before the age of one, both weight and height were below those of the general population, normalized by two years of age and did not change thereafter. After the age of 10 years the SDS declined [12]. The improvement after the age of one year was partly explained by inclusion of late diagnosed mild cases in older cohorts and partly reflected catch-up growth after effective treatment. These cross-sectional study results do perfectly agree with our own longitudinal data. Because of the early diagnosis in all our cases we excluded the possible bias due to the inclusion of later diagnosed mild cases.

Our results show that in CF patients, catch-up growth was strongly related with the severity of the initial growth failure for both weight and height. For weight-for-height SOS this relationship was less impressive: in a previous study reporting catch-up growth of children with congenital heart disease (VSD, Fallot), we showed in severely growth retarded patients only catch-up growth for height to be linearly related to the severity of the initial growth retardation [17].

In the present study, catch-up growth for weight and height were strongly related to each other. The latter finding could be expected as weight and height are interrelated and it also can be explained as a regression to the mean.

As expected weight-for-height is only slightly abnormal pointing to the presence of stunting more than wasting in our patients. Stunting is defined as height-for-age two or more standard deviations below the median and implies chronic malnutrition. Wasting is defined as a low weight-for-height and implies acute malnutrition $[15,18,19]$. Especially the "catch-down" period found in CF patients of 5-10 years old, consists mainly of "stunting" as weight-for-height remained perfectly normal in most patients.

In conclusion, catch-up growth for weight, height and weight-for-height in our CF patients occurs in the first years after diagnosis and results in normalisation of SDS for each parameter around the age of two years. A slight decrease in both weight and height SDS occurs later on while weight-for-height remains normal.

Our results show "wasting" to be a rare event in the evaluation of these patients growth disturbances. Consequently, both height-for-age and weight-for-age are more appropriate than weight-for-height growth charts for the nutritional follow-up of this chronic disease.

Furthermore we think that these findings support the use of a screening program for CF, in order to prevent stunting at an early and sensitive age period. 


\subsection{REFERENCES}

1. Ghosal S, Taylor CJ, Pickering M, McGaw J. Head growth in cystic fibrosis following early diagnosis by neonatal screening. Arch Dis Child 1996;75:191-193.

2. Ghosal S, Taylor CJ, Pickering M, McGaw J, Beckles-Willson N, Wales JKH. Disproportionate head growth retardation in cystic fibrosis. Arch Dis Child 1995;72:150-152.

3. Zemel BS, Kawchack DA, Cnaan A, Zhao H, Scantin TF, Stallings VA. Prospective evaluation of resting energy expenditure, nutritional status, pulmonary function, and genotype in children with cystic fibrosis. Pediatr Res 1996;4:578-586.

4. Karlberg J, Kjellmer I, Kristiansson B. Linear growth in children with cystic fibrosis. Acta Paediatr Scand 1991;80:508-514.

5. Haeusler G, Frisch H, Waldhör T, Götz M. Perspectives of longitudinal growth in cystic fibrosis from birth to adult age. Eur J Pediatr 1994;153:158-163.

6. Greer R, Shepherd R, Cleghorn G, Bowling FG, Holt T. Evaluation of growth and changes in body composition following neonatal diagnosis of cystic fibrosis. J Pediatr Gastroenterol Nutr 1991;13:52-58.

7. Chatfield $\mathrm{S}, 0$ wen $\mathrm{G}$, Ryley $\mathrm{HC}$, et al. Neonatal screening for cystic fibrosis in Wales and the West Midlands: clinical assessment after five years of screening. Arch Dis Child 1991;66:29-33.

8. Byard PJ. The adolescent growth spurt in children with cystic fibrosis. Ann Hum Biol 1994;21:229-240.

9. Lai H, Kosorok MR, Sondel SA, et al. Growth status in children with cystic fibrosis based on the National Cystic Fibrosis Patient Registry data: Evaluation of various criteria used to identify malnutrition. J Pediatr 1998;132:478-85.

10. Gaskin KJ, Waters DL, Baur LA, Soutter VL, Gruca MA. Nutritional status, growth and development in children undergoing intensive treatment for Cystic Fibrosis. Acta Paediatr Scand (suppl.) 1990;366:106-110.

11. Farrel PM, Kosorok MR, Laxova A, et al. Nutritional benefits of neonatal screening for cystic fibrosis. N Engl J Med 1997;337:963-9.

12. Morison S, Dodge JA, Cole TJ, et al. Height and weight in Cystic Fibrosis: a cross sectional study. Arch Dis Child 1997;77:497-500.

13. Kawchak DA, Zhao H, Scanlin TF, Tomezsko JL, Cnaan A, Stallings VA. Longitudinal, prospective analysis of dietary intake of children with cystic fibrosis. J Pediatr 1996;129:119-129.

14. Byard PJ. The adolescent growth spurt in children with CF. Ann Human Biol 1994;21:229-240.

15. Victora CG. The association between wasting and stunting: An international perspective. J Nutr 1992;122:1105-1110.

16. Gerver and De Bruin. Paediatric Morphometrics. Utrecht: Wetenschappelijke uitgeverij Bunge, 1996. 
17. Schuurmans FM, Pulles-Heintzberger CFM, Gerver WJM, Kester ADM, Forget P-Ph. Long-term growth of children with congenital heart disease: a retrospective study. Acta Paediatr Scand 1998;87:1250-5.

18. Martorell R, Kettel Khan L, Schroeder DG. Reversibility of stunting: epidemiological findings in children from developing countries. Eur J Clin Nutr 1994;48:S45-57.

19. Walker SP, Grantham-MCGregor SM, Himes JH, Powell CA. Relationships between wasting and linear growth in stunted children. Acta Paediatr Scand 1996;85:666-9. 


\section{CHAPTER FOUR}

\section{Potential short and long term effects of lansoprazole on body composition in children with Cystic Fibrosis}

Han Hendriks MD1, Estelle Rekkers ${ }^{1}$, Inge van der Sluis MD², Guido Heidendal MD, $\mathrm{PhD}^{3}$, Arnold Kester $\mathrm{PhD}^{4}$, and Philippe Forget MD, $\mathrm{PhD}^{1}$

Departments of Paediatrics ${ }^{1}$, Nuclear Medicine ${ }^{3}$, and Methodology \& Statistics ${ }^{4}$ University Hospital \& University of Maastricht, and Department of Paediatrics ${ }^{2}$ Sophia Children's Hospital Rotterdam, the Netherlands.

Submitted

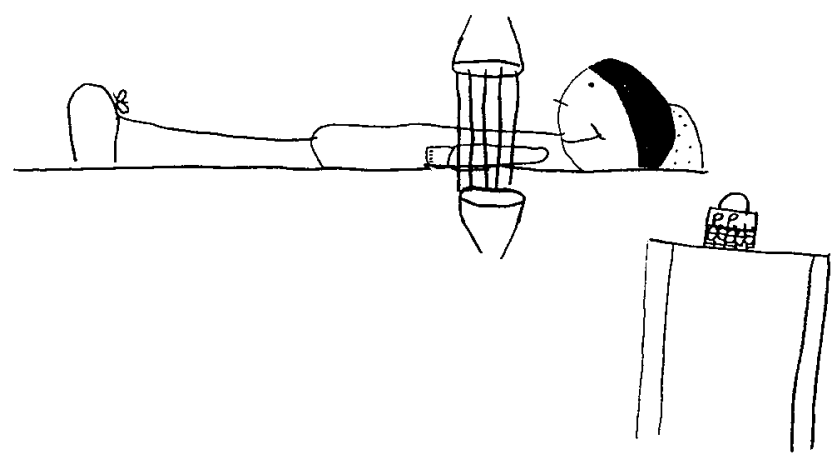




\subsection{ABSTRACT}

Background: In a previous, short-term, study on the additional effect of a proton pump inhibitor (PPI) in Cystic Fibrosis (CF) patients, we were able to demonstrate an improvement in fat absorption and total body fat (TBF), but not fat free mass (FFM).

Objective: The present study was performed to evaluate both the short-term (1 yr) and long-term ( 3 yrs) effects of adjuvant therapy with a PPI on body composition in CF.

Design: In this prospective, observational study $14 \mathrm{CF}$ patients with pancreas insufficiency used lansoprazole, $15 \mathrm{mg}$ daily for 3 years, as adjuvant treatment. Body composition was assessed at the start of the study and at 6,12 and 36 months by dual energy $X$-ray absorptiometry (DEXA). Results were expressed as SD scores (SDS), using a large group of normal Dutch children. Non-parametric tests (Wilcoxon) were used.

Results: The decreased TBF, bone mineral content (BMC) and bone mineral density (BMD) SDS increased significantly ( $P$ values: $0.006,0.022$, and 0.013 respectively) at one year, while FFM did not change ( $P=0.551$ ). After 3 years all three parameters regressed and were not different from starting values anymore.

Conclusion: The addition of a PPI to the standard treatment of young CF patients showed an improvement of TBF, BMC and BMD at one year, whereas its levels after 3 years returned to starting values. As this study was not controlled, it only suggests that, at least temporarily, besides TBF also BMC and BMD might improve during adjuvant therapy with PPIs in CF. Furthermore we advocate that regular assessment of body composition by DEXA in CF allows a better monitoring of the nutritional condition. 


\subsection{INTRODUCTION}

Cystic Fibrosis (CF) is an autosomal recessive inherited disorder, characterized by a defect in the chloride and bicarbonate transport regulating channel at the luminal side of exocrine cells, the cystic fibrosis transmembranous conductance regulator protein (CFTR). One of the most serious consequences of this defect is pancreatic insufficiency, which induces mainly fat malabsorption. This pancreatic insufficiency is only partially corrected by exogenous pancreatic enzymes [1]. In two, separate, studies we have shown that lansoprazole, a proton pump inhibitor (PPI), used as adjuvant therapy, significantly improved both steatorrhea and the nutritional status of $\mathrm{CF}$ patients after 3 months [2] and one year [3] use of lansoprazole, a PPI. At the same time lung hyperinflation decreased in those CF patients [3]. The purpose of a PPI is to improve fat absorption by decreasing gastric acid production resulting in a lower acid duodenal $\mathrm{pH}$ [4-6]. This is necessary because of decreased pancreatic ductular bicarbonate secretion, resulting in a low duodenal buffering capacity and a low luminal $\mathrm{pH}$ of the intestine.

Malabsorption in CF enhances the poor nutritional status, while a relationship between nutritional status, growth and lung function has been demonstrated in these patients [7-12]. The present study was performed primarily to evaluate short-term (0-1 year) and long-term ( 3 years) effects of adjuvant therapy with PPIs on body composition (TBF, FFM, BMC and BMD) as measured by DEXA in young CF patients treated in a standard way according to the Dutch "CBO consensus" [13].

The Medical Ethical Committee of the University Hospital of Maastricht approved the study protocol and informed consent from the parents and from children older than 11 years of age was obtained before onset of the study.

\subsection{PATIENTS AND METHODS}

\section{PATIENTS}

14 CF patients ( 9 males and 5 females), with pancreatic insufficiency and mild lung disease, were included in a prospective study. In all patients the diagnosis of CF was confirmed by sweat testing (Chloride more than $60 \mathrm{mmol} / \mathrm{l}$ ) and all demonstrated persistent steatorrhea despite regular pancreatic enzyme replacement therapy. Except for one patient, the oldest one, all subjects were studied during 3 years of adjuvant therapy with $15 \mathrm{mg}$ lansoprazole daily. Diet and exogenous pancreatic enzymes were adjusted before the study, and checked by our dietary consultant. All other therapy was standardized, according to the Dutch "CBO consensus" [13]. As this study was an open study, the patients were used as their own control, and changes were expressed as changes in standard deviation scores (SDS). Therefore anthropometric data of our patients (height, weight and BMI) were expressed as SDS using a large healthy Dutch reference population $[14,15]$. To include only stable patients, inclusion criteria for this study were no recent infection or exacerbation, and a forced expiratory volume in 1 second $\left(\mathrm{FEV}_{1}\right)$ of more than $70 \%$ of predicted in the preceding 
TABLE 4.1. Patient characteristics at start $(\mathrm{N}=14)$

\begin{tabular}{|c|c|c|c|c|c|}
\hline Item & & Mean & Median & SD & Range \\
\hline Age & $(y r)$ & 9.74 & 8.60 & 3.38 & $4.6 / 17.2$ \\
\hline \multirow[t]{2}{*}{ Height } & $(\mathrm{cm})$ & 133.9 & 131.5 & 16.6 & $107.0 / 162.3$ \\
\hline & (SDS) & -1.07 & -1.11 & 0.59 & $-2.17 / 0.00$ \\
\hline \multirow[t]{2}{*}{ Weight } & $(\mathrm{kg})$ & 27.7 & 25.6 & 9.9 & $15.5 / 52.3$ \\
\hline & (SDS) & -1.27 & -1.44 & 0.74 & $-2.39 / \quad 0.27$ \\
\hline Acid Steatocrit & $(\%)$ & 33.3 & 32.7 & 17.7 & $5.4 / 65.7$ \\
\hline $\mathrm{FEV}_{1}$ & (\% predicted) & 83.9 & 85.0 & 17.2 & $58 / 112$ \\
\hline FVC & (\% predicted) & 86.6 & 87.0 & 13.0 & $64 / 109$ \\
\hline
\end{tabular}

SDS $=$ standard deviation score

year. But the most important inclusion criterion was a mean pre-study stool acid steatocrit (an index of steatorrhea) of more than 25\% (normal $<20 \%$ ), despite an intake of at least $2000 \mathrm{IU}$ lipase $/ \mathrm{kg}$ body weight/day (mean use $4020 \mathrm{IU} / \mathrm{kg} /$ day). Patient characteristics at inclusion are summarized in table 4.1.

\section{FECAL FAT CONTENT}

steatorrhea was monitored by measuring fecal acid steatocrit as previously described $[16,17]$. Here results of fecal fat content are expressed as percentage of fat layer of the addition sum of fat and solid layer. Fecal acid steatocrit has been shown to correlate well with chemical analyses of fecal fat $(r=0.83)$ [18]. We chose this method in order to repetitively and easily monitor fecal fat content, which was measured every 2 weeks during the first year of PPI therapy and at 3 years.

\section{BODY COMPOSITION PARAMETERS}

Body composition was assessed by dual energy $X$-ray absorptiometry (DEXA). This non-invasive method allows an easy and rapid (20 minutes) evaluation of body composition. During one assessment, total body fat (TBF), fat free mass (FFM), bone mineral content (BMC) and bone mineral density (BMD) are measured. A software pediatric program (Pediatric Beta Software: Lunar 1.5) was used. The radiation dose of this examination is very low ( $<5 \mathrm{mRem}$ ) when compared with the standard background radiation exposure ( $82 \mathrm{mRem} / \mathrm{year}$ ), and is therefore considered to be the method of choice to measure body composition in young children. Results were compared with those of a large $(n=403)$ healthy Dutch reference group matched for age and sex and expressed as SDS [19]. In the latter study the variation in TBF was 4\%, which is twice the variation of adults. DEXA results were evaluated at start, after 6,12 and 36 months use of a PPI. 


\section{STATISTICS}

Non-parametric tests (Mann-Whitney, Wilcoxon) were used to compare SDS of our patient group with those of the reference populations at start and at different intervals. By using a Non-parametric test, we avoided making an assumption of normality, which cannot be tested in only 14 subjects. Differences with respect to baseline were considered significant when the two-sided $P$-value was 0.05 or less. The statistical package SPSS (version 10.0 for Windows, 1999, SPSS Inc., Microsoft, Chicago, IL) was used for data management and analysis.

\subsection{RESULTS}

\section{FECAL FAT CONTENT}

Shortly after the addition of lansoprazole a significant decrease in fecal fat content (acid steatocrit) was noticed. As a group, mean acid steatocrit decreased from $33.3 \%( \pm 17.8)$ at the start to $23.7 \%( \pm 11.0)$ at 3 months $(P<0.01)$ and remained at that level thereafter. The mean value during the first year of treatment was $24.0 \%( \pm 9.8 ; P<0.05)$. After use of a PPI for 3 years, mean acid steatocrit was still $23.4 \%( \pm 11.8)$.

\section{ANTHROPOMETRY}

Box plots for height and weight SDS during 3 years treatment with a PPI are shown in figure 4.1. The mean (SD) bodyweight SDS changed slightly but not significantly from $-1.27( \pm 0.74)$ before to $-1.12( \pm 0.82)$ at 1 year and $-1.28( \pm 0.95)$ at 3 years. Mean (SD) height SDS hardly changed from $-1.07( \pm 0.59)$ before the study to $-1.02( \pm 0.61)$ at 1 year and $-1.05( \pm 0.82)$ at 3 years all NS. Table 4.2. shows the mean and median values of the BMI, in girls and boys separately. Mean (SD) BMI at the start of the study was somewhat decreased compared to values of normal children. During the first year it showed an increase of $0.5 \mathrm{~kg} / \mathrm{m}^{2}$ or $0.15 \mathrm{SDS}$, which is exactly what could be expected in healthy children [20]. At 3 years, however, hardly any further increase of BMI was assessed, whereas a further increase of $1.2 \mathrm{~kg} / \mathrm{m}^{2}$ is normal in this age group, resulting in SDS values comparable with starting values. Remarkable is the discrepancy between both sexes, favouring boys.

\section{BODY COMPOSITION}

Means (SD) and medians (range) for body composition data are shown in table 4.3. and in figure 4.2. After using a PPI for 6 months a significant increase in SDS of TBF was found $(P=0.035)$. It is worth mentioning that TBF in grams increased by $32.6 \%$ and, although a part of this increase will be normal growth, it is far beyond the $4 \%$ of variation in the measurement. After 1 year SDS of TBF, BMC and BMD all increased significantly, $(P=0.006,0.022$, and 0.013 respectively), while SDS of FFM did not change. All parameters at 3 years decreased and were not significantly different from starting values. 
TABLE 4.2. Mean and median Body Mass Index during 3 years treatment with lansoprazole, in $\mathrm{kg} / \mathrm{m}^{2}$ and SDS, of the $14 \mathrm{CF}$ patients, with separate numbers for both sexes.

\begin{tabular}{|c|c|c|c|c|c|c|c|c|c|}
\hline \multirow[b]{2}{*}{ Sex } & & \multicolumn{2}{|l|}{ At start } & \multicolumn{2}{|c|}{ At 6 months } & \multicolumn{2}{|c|}{ At I year } & \multicolumn{2}{|c|}{ At 3 years } \\
\hline & & $\mathrm{kg} / \mathrm{m}^{2}$ & SDS & $\mathrm{kg} / \mathrm{m}^{2}$ & SDS & $\mathrm{kg} / \mathrm{m}^{2}$ & SDS & $\mathrm{kg} / \mathrm{m}^{2}$ & SDS \\
\hline \multirow[t]{4}{*}{$\mathrm{F}$} & Mean & 15.86 & -1.24 & 15.95 & -1.29 & 16.37 & -1.21 & 15.89 & -1.38 \\
\hline & SO & 2.40 & 0.64 & 2.32 & 0.60 & 2.49 & 0.61 & 1.62 & 0.71 \\
\hline & Median & 14.55 & -1.21 & 15.37 & -1.21 & 15.37 & -1.24 & 15.23 & -1.36 \\
\hline & Range* $^{*}$ & 5.64 & 1.61 & 5.84 & 1.64 & 6.09 & 1.58 & 3.44 & 1.90 \\
\hline \multirow[t]{4}{*}{ M } & Mean & 14.45 & -1.00 & 14.96 & -0.66 & 14.90 & -0.77 & 15.39 & -0.90 \\
\hline & SD & 1.29 & 1.05 & 1.75 & 1.33 & 1.59 & 1.20 & 2.17 & 1.35 \\
\hline & Median & 14.13 & -1.22 & 14.44 & -1.05 & 14.47 & -0.81 & 14.73 & -1.45 \\
\hline & Range & 3.86 & 3.30 & 5.18 & 4.24 & 4.90 & 3.90 & 6.76 & 4.42 \\
\hline \multirow[t]{4}{*}{ Total } & Mean & 14.95 & -1.09 & 15.32 & -0.88 & 15.43 & -0.93 & 15.54 & -1.08 \\
\hline & SD & 1.81 & 0.91 & 1.95 & 1.14 & 1.99 & 1.03 & 1.97 & 1.15 \\
\hline & Median & 14.31 & -1.21 & 14.48 & -1.16 & 14.71 & -0.92 & 14.86 & -1.41 \\
\hline & Range & 7.25 & 3.30 & 6.89 & 4.25 & 7.19 & 3.90 & 6.76 & 4.48 \\
\hline
\end{tabular}

*Range is given in one number (highest - lowest value).

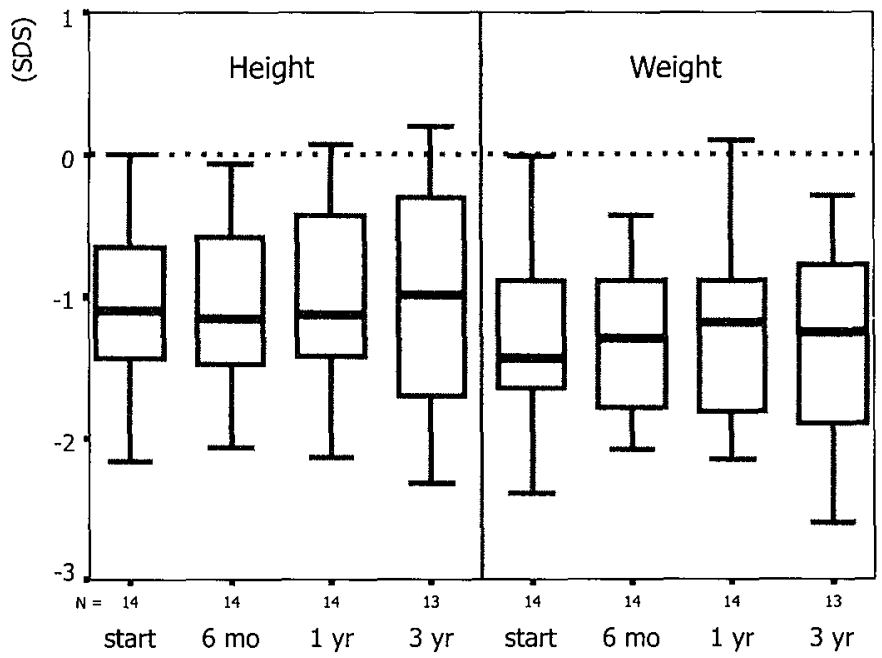

FIGURE 4.1. Box plots (medians and 95\%) of height and weight SDS, during 3 years treatment with lansoprazole in CF patients. 
TABLE 4.3. Mean (SD) and Median (Range) of SDS DEXA body composition parameters, before and during 3 years use of lansoprazole in CF patients.

\begin{tabular}{llllll}
\hline SD scores & $\begin{array}{l}\text { At start } \\
(\mathrm{n}=14)\end{array}$ & $\begin{array}{l}\text { At 6 months } \\
(\mathrm{n}=14)\end{array}$ & $\begin{array}{l}\text { At 1 year } \\
(\mathrm{n}=14)\end{array}$ & $\begin{array}{l}\text { At 3 years } \\
(\mathrm{n}=13)\end{array}$ \\
\hline Age & Mean (SD) & $9.7(3.4)$ & $10.2(3.4)$ & $10.7(3.4)$ & $12.3(2.8)$ \\
& Median (range) & $8.6(12.6)$ & $9.1(12.6)$ & $9.6(12.6)$ & $11.9(9.6)$ \\
FFM & Mean (SD) & $-1.82(0.67)$ & $-1.90(0.78)$ & $-1.78(0.63)$ & $-2.33(0.83)$ \\
& Median (range) & $-1.93(2.54)$ & $-1.93(3.31)$ & $-1.83(2.25)$ & $-2.52(2.61)$ \\
TBF & Mean (SD) & $-0.97(0.49)$ & $-0.73(0.73)^{*}$ & $-0.68(0.70)^{*}$ & $-1.03(0.74)$ \\
& Median (range) & $-0.95(1.73)$ & $-0.88(2.57)^{\star}$ & $-0.85(2.35)^{*}$ & $-1.32(2.82)$ \\
BMC & Mean (SD) & $-1.78(0.76)$ & $-1.71(0.82)$ & $-1.55(0.85)^{*}$ & $-1.80(1.01)$ \\
& Median (range) & $-2.03(2.35)$ & $-1.89(2.67)$ & $-1.72(2.65)^{*}$ & $-1.62(3.14)$ \\
BMD & Mean (SD) & $-0.99(1.12)$ & $-0.95(1.17)$ & $-0.67(1.18)^{\star *}$ & $-0.91(1.48)$ \\
& Median (range) & $-0.88(3.55)$ & $-0.92(4.18)$ & $-0.65(3.71)^{\star *}$ & $-0.92(4.54)$ \\
\hline
\end{tabular}

SDS standard deviation score ( $=\mathrm{Z}$ score)

Range is given in one number (highest - lowest value).

All interval numbers (except age) are compared with starting values, by Wilcoxon rank sum test; 2 sided, 2 related: * $P$ value $<0.05,{ }^{* *} P$ value $<0.01$

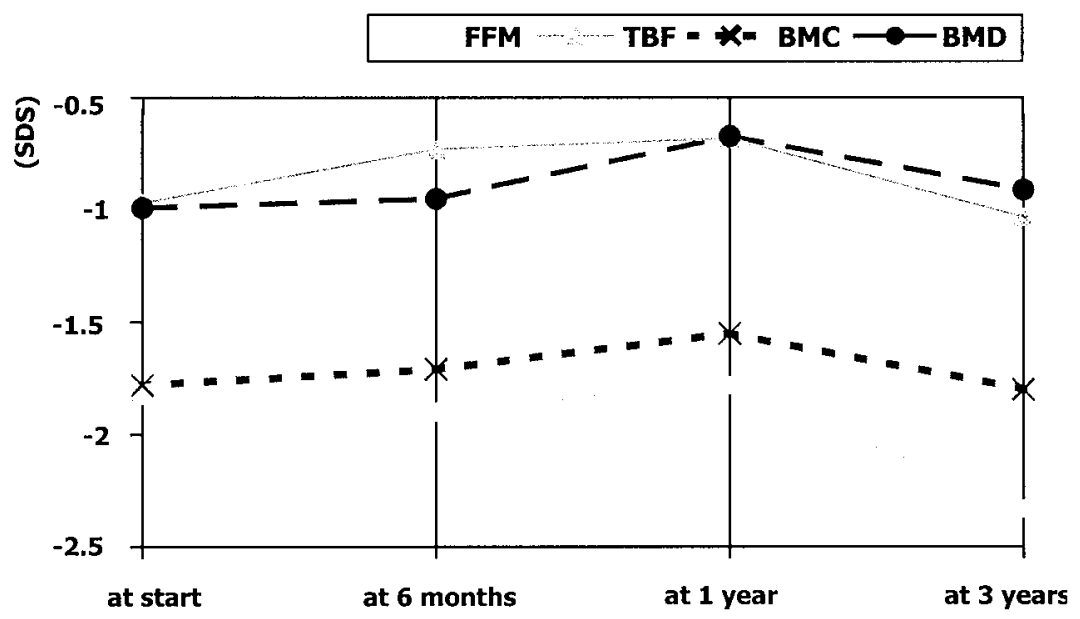

FIGURE 4.2. Changes in SDS for body composition parameters by DEXA during 3 years treatment with lansoprazole in CF patients. 


\subsection{DISCUSSION}

In this observational study, the addition of a PPI demonstrated effects, which were not all expected. The short-term (1 year) effects on fecal fat content (acid steatocrit), and body composition (BMI, TBF, BMC and BMD) suggest a beneficial effect, but on the long-term ( 3 years) this was not confirmed and values dropped back to starting values. Furthermore no effect on body height, weight and FFM was shown. Although malnutrition is common knowledge in CF, we wondered why the starting values of body height and weight were decreased so much, and more than expected. First, our CF population is from the southern part of the Netherlands, where adults, like children, have been shown to be at least $5 \mathrm{~cm}$ shorter than in the northern part where our reference growth data come from. Second, CF patients are known to have a delayed maturation and, as a mean, enter puberty with a delay of about 1 year [21]. Both explanations will result in an overestimation of our patients' growth deficit, and therefore in an underestimation of the body composition parameters.

A decrease in fecal fat content during the use of a PPI is not unknown: besides our earlier reports in children [2,3], it has also been demonstrated previously by Heijerman et al in adults [22]. Therefore the demonstrated favourable and persistent effect of the use of PPIs on fecal fat content, as measured by the acid steatocrit, was expected. The demonstration of an improvement in body fat and bone mass during the first year with the apparent loss at 3 years is much more difficult to interpret, as this is not a controlled study. A placebo effect could also be responsible for the observed changes. However, we could demonstrate the same changes in body composition in two separate studies. The natural course of CF disease shows a decrease in weight and peak bone mass during the second decade [23-27]. Recently, in a 3-year longitudinal study, Stettler et al. [11] showed growth of boys 5-10 years old to be impaired not only for height and weight, but also for FFM and TBF. For girls in that age group these changes are less striking. Therefore during the 3 years of follow up we might have expected a continued decrease in body weight and height, and body composition parameters like BMI, TBF, FFM, BMC and BMD. As we could not demonstrate this expected decrease in 3 years in our patients whose body composition data were similar to their starting values, the addition of a PPI might suggest a delay in the expected decay of weight and bone acquisition over 3 years. According our dietician during the addition of a PPI either the diet and the use of pancreatic enzymes did not change significantly [28]. Furthermore we could demonstrate an improvement in skinfold measurements too. Both the suprailiacal skinfold, and the sum of four skinfolds improved significantly $(P<0.05)$ and correlated very well with TBF as measured by DEXA $\left(r^{2}=0.86\right)[29]$. As we have to interpret all these results cautiously, we therefore only suggest that the use of PPIs in young CF patients might have some effects on body composition.

More remarkably is the improvement in bone mineral status during PPI treatment, which was unexpected. A high prevalence of bone disorders, such as osteoporosis with an increased risk for bone fractures, has been reported in CF patients. Several explanations have been suggested such as malnutrition, especially vitamin D and calcium malabsorption, but also relative inactivity, hormonal alterations and increasing age of 
CF patients. Bone metabolism is not static but a dynamic process, being the result of bone formation and resorption. Evaluation of bone turnover markers in CF patients, have shown an imbalance between bone formation and resorption [30]. Bone mineralization in CF patients has been related to age, pubertal stage, body mass, energy expenditure, illness severity, glucocorticoid therapy and gonadal function. Changes in each of these factors because of the disease can therefore cause a poor bone mineral status [27,31]. Previous studies have shown that serum parathyroid hormone and calcium, carbohydrate intake and activity had limited predictive value, while daily calcium intake and CFTR-genotype had no predictive value on bone mineral status. In many studies a correlation between bone mineral content and body composition, in particular fat-free mass has been demonstrated. However, it might be too simple to explain the defective bone mineral status by either malnutrition or malabsorption since it was also found in patients with completely normal stature and even in pancreatic sufficient patients. In the present study we demonstrated in young pancreas insufficient CF patients, evaluated by DEXA, a significant improvement in BMC and BMD, during adjuvant therapy with a PPI. As height SDS did not change, the increase in BMD might be real and not due to improved growth. The response was not immediate, but occurred between the sixth and the twelfth month of treatment, while malabsorption improved within 3 months. The delay in effect on BMC and BMD explainable by seeing bone turnover as a cyclic process, lasting for about 120 days. The first 20 days there is a bone resorption phase, followed by bone formation for some 100 days [32]. Therefore it is likely that more time is needed to reflect improvements in bone mineral status, and one cycle might be too short to show significant changes. Improvement of BMC and BMD point to a potential beneficial effect of PPI on bone formation. Possible explanations are increased absorption of minerals and fat soluble vitamins, like vitamin $D$ and K. Particularly vitamin K deficiency, a co-factor in the carboxylation of osteocalcin (OC) a marker of bone formation, might play a role in the decreased bone mineral status in CF patients. In order to elucidate the relation between vitamin $\mathrm{K}$ and bone turnover markers we performed a study in our department. Preliminary results point to such an under-carboxylation of $O C$ in CF (to be published separately).

In conclusion, adjuvant therapy with a PPI in young CF patients revealed that potential short term (1 year) improvements returned to starting values in the long term ( 3 years). The effect of PPIs on fecal fat content seems not to be temporary, as acid steatocrit values at 3 years were still as low as at 1 year. It might be that comparison of CF patients, having a delayed puberty, with a healthy population resulted in an apparent decrease of body composition SDS at 3 years compared to pre-pubertal starting values. Another possibility might be that the natural course of CF in 3 years of follow-up is delayed somewhat. Therefore one might conclude that PPIs have a positive, undetected, long-term effect on body composition, but due to its design this statement cannot be proven by the present study. To elucidate further the role of PPIs in improving body composition and bone mineral abnormalities in CF, more placebo-controlled studies are necessary. 


\subsection{REFERENCES}

1. Robinson P, Sly P. High dose pancreatic enzymes in cystic fibrosis. Arch Dis Child 1990;65:311-2.

2. Tran TMD, Van den Neucker A, Hendriks JJE, Forget P, Forget P-Ph. Effects of a proton-pump inhibitor in cystic fibrosis. Acta Paediatr 1998;87:553-8.

3. Hendriks JJE, Kester ADM, Donckerwolcke R, Forget PPh, Wouters EFM. Changes in pulmonary hyperinflation and bronchial hyperresponsiveness following treatment with lansoprazole in children with cystic fibrosis. Ped. Pulmon 2001;31:59-66.

4. Robinson PJ, Smith AL, Sly PD. Duodenal $\mathrm{pH}$ in $\mathrm{CF}$ and its relationship to fat malabsorption. Dig Dis Sci 1990;35:1299-304.

5. Barraclough M, Taylor CJ. 24 Hour ambulatory gastric and duodenal pH profiles in CF: effect of duodenal hyperacidity on pancreatic enzyme function and fat absorption. $]$ Pediatr Gastroenterol Nutr 1996;23:45-50.

6. DiMagno EP. Gastric acid suppression and treatment of severe exocrine pancreatic insufficiency. Baillieres Best Pract Res Clin Gastroenterol 2001;15:477-86.

7. Dodge JA. Gastrointestinal tract and nutrition in cystic fibrosis: pathophysiology. J R Soc Med 1986;12(suppl):27-31.

8. Tomezsko JL, Scantin TF, Stallings VA. Body composition of children with CF with mild clinical manifestations compared with normal children. Am $\mathrm{J}$ Clin Nutr 1994;59:123-128.

9. Benabdesalam H, Garcia I, Bellon G, Gilly R, Revol A. Biochemical assessment of the nutritional status of CF patients treated with pancreatic enzyme extracts. Am J Clin Nutr 1998;67:912-918.

10. Ionescu AA, Nixon LS, Evans WD, Stone MD, Lewis-Jenkins V, Chatham K, Shale DJ. Bone density, body composition, and inflammatory status in CF. Am J Respir Crit Care Med 2000;162:789-794.

11. Stettler N, Kawchak DA., Boyle LL, Propert KJ, Scanlin TF, Stallings VA. Prospective evaluation of growth, nutritional status, and body composition in children with CF. Am 3 Clin Nutr 2000;72:407-413.

12. Zemel BS, Jawad AF, FitzSimmons S, Stallings VA. Longitudinal relationship among growth, nutritional status, and pulmonary function in children with CF: Analysis of the CFFNCFPR. J Pediatr 2000;137:374-380.

13. Laag van der J, Sinaasappel M, Heijerman HGM. Diagnostiek en behandeling van CF: CBO Consensusbijeenkomst.Van Zuiden Communications B.V. Alphen aan den Rijn 1998.

14. Gerver WJM and Bruin de R. Paediatric Morphometrics a Reference Manual. In Bunge, Utrecht, the Netherlands 1996.

15. Gerver WJM, Bruin de R. Body composition in children based on anthropometric data. A presentation of normal values. Eur.J.Pediatr. 1996;155:870-876. 
16. Tran TMD, Forget PPh, Van den Neucker AM, Strik J, Kreel van B and Kuijten RH. The acid steatocrit: a much improved method. J.Pediatr.Gastroenterol.Nutr. 1994;19:299-303.

17. Van den Neucker AM, Forget PPh, Veneberg JA, Schutten BJ and Kreel van B. Acid steatocrit during infancy. Acta Paediatr. 1996;85:1153-1155.

18. Van den Neucker AM, Pestel N, Tran TMD, Forget PPh, Veeze HJ, Bouquet $\mathrm{J}$ and Sinaasappel M. Clinical use of acid steatocrit. Acta Paediatr. 1997:86:466-469.

19. Boot AM, Bouquet J, Ridder de MAJ, Krenning EP, de Muinck Keizer-Schrama SMPF. Determinants of body composition, measured by DEXA, in Dutch children and adolescents. Am J Clin Nutr 1997;66:232-238.

20. Maynard LM, Wisemandle W, Roche AF, Chumlea WC, Guo SS, Siervogel RM. Childhood body composition in relation to Body Mass Index. Pediatrics 2001;107:344-50

21. Byard PJ. The adolescent growth spurt in children with CF. Ann Human Biol 1994;21:229-240.

22 Heijerman HGM, Lamers CBHW, Bakker W. Omeprazole enhances the efficacy of pancreatin (pancrease) in CF. Ann Intern Med 1991;114:200-201.

23. Karlberg J, Kjellmer I, Kristiansson B. Linear growth in children with cystic fibrosis. Acta Paediatr Scand 1991;80:508-514.

24 Haeusler G, Frisch H, Waldhör T, Götz M. Perspectives of longitudinal growth in cystic fibrosis from birth to adult age. Eur J Pediatr 1994;153:158-163.

25 Lai H, Kosorok MR, Sondel SA, et al. Growth status in children with CF based on the National CF Patient Registry data: Evaluation of various criteria used to identify malnutrition. J Pediatr 1998;132:478-85.

26 Morison S, Dodge JA, Cole TJ, et al. Height and weight in Cystic Fibrosis: a cross sectional study. Arch Dis Child 1997;77:497-500.

27. Bhudhikanok GS, Wang WC, Marcus R, Harkins A, Moss RB, Bachrach LK. Bone acquisition and loss in children and adults with CF: A longitudinal study. J Pediatr 1998;133:18-27.

28. Ploeg EMC van der, Van den Neucker AM, Forget PP, Wesseling GJ, Hendriks JJE. Variation in dietary lipase/fat ratio in young CF patients. The Neth. J. Of Med. 1999;54 Suppl.2:S64 (156).

29. Hendriks JJE, Jannink HJA, Sluis van der IM, Forget PP. Adjuvant therapy with a proton pump inhibitor improves body composition by total body DEXA and skinfolds in pancreatic insufficient children with CF. Ped Pulm 1998;26 (suppl.17) A. 544 (360-361)

30. Baroncelli GI, De Luca F, Magazzu G, Arrigo T, Sferlazzas C, Catena C, et al. Bone demineralization in CF: evidence of imbalance between bone formation and degradation. Pediatr Res 1997;41:397-403.

31. Bhudhikanok GS, Lim J, Marcus R, Harkins A, Moss RB, Bachrach LK. et al. Correlates of osteopenia in patients with CF. Pediatrics 1996;97:103-111.

32. Rosen $\mathrm{CJ}$. and Tenenhouse $\mathrm{A}$. The bone remodeling cycle. Postgraduate Medicine 1998;104:101-114. 



\section{CHAPTER FIVE}

\section{Changes in pulmonary hyperinflation and bronchial hyperresponsiveness following treatment with lansoprazole in children with Cystic Fibrosis}

Han Hendriks ${ }^{1} M D$, Arnold Kester ${ }^{2}$ PhD, Raymond Donckerwolcke ${ }^{1} M D$, PhD, Philippe Forget 1 MD, PhD and Miel Wouters ${ }^{3}$ MD, PhD.

Departments of Paediatrics ${ }^{1}$, Methodology \& Statistics ${ }^{2}$ and Pulmonology ${ }^{3}$ University Hospital \& University of Maastricht, the Netherlands

Published in: Ped Pulm 2001;31: 59-66.

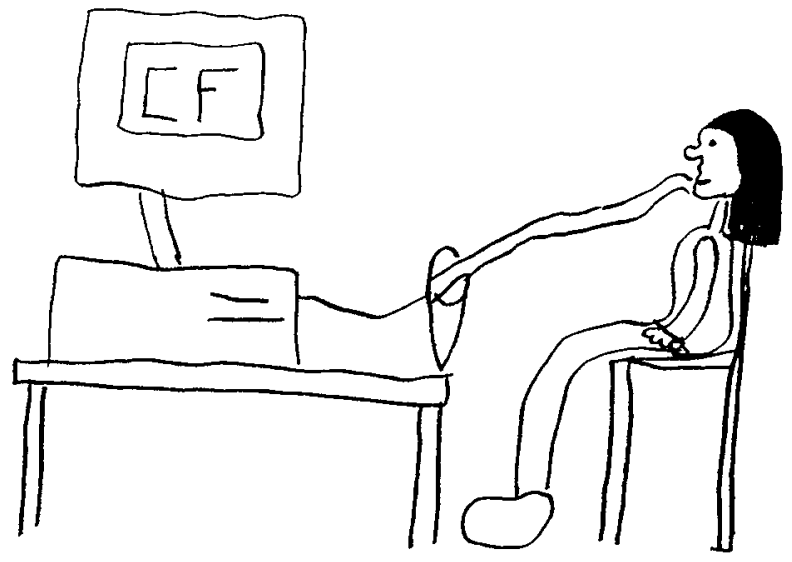




\subsection{ABSTRACT}

Background: In this prospective, preliminary, open study in 14 children with Cystic Fibrosis (CF), we evaluated the effect of one year adjuvant therapy with lansoprazole, a proton pump inhibitor (PPI), on growth, fecal fat losses, body composition and lung function parameters.

Methods: Only stable patients with pancreas insufficiency were included and all their data were compared to those of large Dutch pediatric normal reference populations.

Results: During the use of a PPI mean weight and height did not change significantly, while body mass index improved significantly $(P<0.05)$. An immediate significant and persistent reduction of fecal acid steatocrit $(P<0.05)$ was demonstrated. Compared to normal Dutch children the CF patients showed significantly decreased SD-scores (SDS) for total body fat (TBF; -0.966) and fat free mass (FFM; -1.826). Under lansoprazole, TBF improved significantly $(P<0.05)$ while mean FFM remained unchanged. Meanwhile a significant improvement of total lung capacity (TLC; $P<0.05$ ), residual volume (RV; $P=0.055$ ), and maximal inspiratory mouth pressure (PImax; $P=0.002$ ) was demonstrated. These findings confirm the presence of hyperinflation in $C F$, which seems to decrease during the use of a PPI. Daily recordings of peak expiratory flow (PEF) showed a maximal diurnal variability of $28 \%$ of recent best PEF and minimal morning PEF of $72 \%$ of recent best PEF, which confirms that bronchial hyperresponsiveness (BHR) is increased in CF.

Conclusion: We conclude that adjuvant therapy with lansoprazole in our young CF patients with persistent fat malabsorption, decreased fat losses and improved total body fat. Meanwhile lung hyperinflation decreased, which can partly explain the inspiratory muscle performance improvement. The coincidence between improvement of bodycomposition and lung hyperinflation might suggest a relationship between these two parameters. Further research is necessary in order to confirm a relationship and to elucidate the mechanisms involved. 


\subsection{INTRODUCTION}

CF is the most common lethal hereditary disease amongst Caucasians. The CF gene is located on chromosome 7 and sofar more than 900 mutations of this single gene have been reported. The basic defect is a dysregulation of the chloride channels resulting in dehydration of the luminal surface of exocrine cells. In the lungs this leads to an increase of mucus viscosity, inhibiting normal ciliary clearance. Bacterial colonization, infection and chronic pulmonary inflammation develop subsequently. Pulmonary complications account for most of the morbidity and mortality in CF patients. Besides the respiratory complications, gastroenterological abnormalities give rise to significant morbidity. In children with $\mathrm{CF}$, fat malabsorption leads to malnutrition and growth failure, often associated with increased catabolism. Exogenous administration of pancreatic enzymes improves, but does not reverse fat malabsorption completely. It has been hypothesized that the use of a PPI could improve the effectiveness of the administered pancreatic enzymes. The aim of adding these drugs is to decrease gastric acid production. This is necessary in CF because of a decreased buffering capacity of the pancreatic juices, due to decreased or absent bicarbonate. If duodenal $\mathrm{pH}$ is less than 5 early dissolving of the enteric coating of the administered enzyme capsules is hindered, because this only takes place at a duodenal $\mathrm{pH}$ above 5.5. $[1,2]$ In addition this low pH may also inactivate pancreatic enzymes. Both processes result in suboptimal functioning of these enzymes, accompanied by incomplete absorption of nutrients like fat.

A favourable effect of PPI on fat absorption in adult CF patients was demonstrated by Heijerman et al. [3] We confirmed this favourable effect in a pilot study in children [4]. In the latter short-term (3 months) study, the use of lansoprazole led to a significant increase of TBF or fat mass while FFM or lean body mass did not improve. Although it has frequently been suggested that changes in body composition can affect lung function and especially respiratory mechanics, this has, until now, hardly been proven in CF patients. Research to support this hypothesis is sparse. Steinkamp and von der Hardt [5] demonstrated that nocturnal tube feedings improved nutritional status and lung function in malnourished CF patients. More recently Ionescu et al. [6] demonstrated that in the last stages of CF, survival was negatively associated with a $B M I<20 \mathrm{~kg} / \mathrm{m}^{2}$ and low FFM, while sustained maximum inspiratory pressure seemed to be more impaired than peak maximum inspiratory pressure.

By impairing lung growth, suboptimal increase of body cell mass has also been suggested to be associated with progressive lung dysfunction in CF [7].

Apart from its effect on fat absorption and body composition, a PPI could have a favourable influence on BHR by decreasing gastroesophageal reflux (GER), possibly justifying its use in CF patients. 


\subsection{AIMS OF THE STUDY}

The present open study was performed in 14 children with stable CF, and primarily designed in order to investigate the effect of long term addition of a PPI on body composition. Secondly the relation between changes in body composition and changes in lung function of dynamic and static lung function as well as respiratory muscle parameters, were examined. Thirdly we evaluated the effect of decreased acid secretion and possibly decreased GER on BHR.

\subsection{MATERIALS AND METHODS}

\section{PATIENTS}

14 stable CF patients ( 9 males) with pancreatic insufficiency and mild lung disease were studied before and during one year of treatment with $15 \mathrm{mg}$ lansoprazole daily. Diet and exogenous pancreatic enzymes did not change during the intervention. We conducted an open study for practical reasons and because we preferred to use our patients as their own control, as every patient is unique and not exactly comparable to any other CF patient. We therefore compared them to large normal (Dutch) populations and expressed changes as changes of SD-scores. In order to reduce a possible placebo effect only stable patients were included in the study, demonstrated by the high pre-study $\mathrm{FEV}_{1}$, which was not different from the baseline $\mathrm{FEV}_{1}$. Criteria for inclusion in the study were a mean prestudy stool acid steatocrit (an index of fat absorption) of more then $25 \%$ (normal $<20 \%$ ), despite an intake of at least 2000 IU lipase $/ \mathrm{kg}$ bodyweight (mean use $4020 \mathrm{IU} / \mathrm{kg}$ ). Further our CF patients had to be able to perform reliable lung function tests and in the prestudy year their $\mathrm{FEV}_{1}$ had to be above $70 \%$ of predicted (mean prestudy year $\mathrm{FEV}_{1}$ was $85.2 \pm 13.6 \%$ of predicted). Finally they had to be able to use a Peakflow meter and fill-in diary cards correctly. Verbal and written informed consent was obtained before onset of the study and the study

TABLE 5.1. Patient characteristics at start

\begin{tabular}{llrcc}
\hline Item & & Mean & SD & Range \\
\hline Age & $(\mathrm{yr})$ & 9.74 & 3.38 & $4.6 / 17.2$ \\
Height & $(\mathrm{cm})$ & 133.9 & 16.6 & $107.0 / 162.3$ \\
& $(\mathrm{SDS})$ & -1.068 & 0.590 & $-2.166 / 0.003$ \\
Weight & $(\mathrm{kg})$ & 27.7 & 9.9 & $15.5 / 52.3$ \\
& $(\mathrm{SDS})$ & -1.270 & 0.739 & $-2.393 / 0.272$ \\
Acid Steatocrit & $(\%)$ & 33.3 & 17.7 & $5.4 / 65.7$ \\
FEV & $(\%$ predicted $)$ & 83.9 & 17.2 & $58 / 112$ \\
FVC & $(\%$ predicted $)$ & 86.6 & 13.0 & $64 / 109$ \\
\hline
\end{tabular}

For abbreviations see list of abbreviations (page 6). 
protocol was approved by the medical ethical committy of the university hospital of Maastricht. Patient characteristics at baseline are given in Table 5.1.

\section{ANTHROPOMETRY}

Anthropometric measurements were performed in triple by one single investigator using the same instruments, a Harpenden stadiometer (Holtain limited, Crymych, D Y Fed., UK) and an electronic weight scale (Seca delta, modell 707). Results are expressed as SDS using Dutch reference values collected by Gerver and de Bruin $[8,9]$. The subjects were all measured barefoot and dressed in underwear.

\section{FECAL FAT CONTENT}

steatorrhea was monitored by measuring the fecal acid steatocrit as previously described $[10,11]$, where results are expressed as fat / fat+solid layer in \%. Fecal acid steatocrit has been shown to correlate well with chemical analyses of fecal fat ( $r=$ 0.83 ) [12]. We chose for this method in order to repetitively and easily monitor fecal fat content during the study.

\section{BODY COMPOSITION}

Body composition was assessed by DEXA [13]. This non-invasive method allows an easy and rapid (20 minutes) evaluation of body composition. During one assessment TBF, FFM, BMC and TBD are measured. A software pediatric programme (Paediatric Beta Software: Lunar 1.5) was used. The radiation dose of this examination is very low $(<5 \mathrm{mRem})$ when compared with the standard background radiation exposure ( $82 \mathrm{mRem} / \mathrm{year})$, and is therefore considered to be the method of choice to measure body composition in young children. Results were compared with those of a large $(n=403)$ age matched normal Dutch reference group [14] and expressed as SDS.

\section{LUNG FUNCTION}

Lung function tests were performed by an experienced lung function technician, using a Jaeger Masterlab pneumotachograph and bodybox. Calibration of the apparatus was performed twice daily. Only lung function data with FVC variability of less than $5 \%$, on 3 consecutive manoeuvres, were accepted for data management. Lung function parameters were expressed as \% of predicted (= mean of normal children, for height and sex) according to the Zapletal reference values [15]. Maximal mouth pressures were measured at RV for inspiratory pressure (PImax) and at TLC for expiratory pressure (PEmax) according the method of Black and Hyatt [16].

\section{BRONCHIAL HYPERRESPONSIVENESS}

PEF was measured at home, using a "Personal Best" PEF meter (Respironics HealthScan Products, Europe, Belgium) four times daily. Instruction was given about the correct technique and reading of the PEF meter. Three consecutive manoeuvres were carried out and recorded, but only the best of these 3 was used for data management (also in the so-called minimal morning PEF!). In order to measure changes in 
BHR several PEF characteristics were calculated for each weekly recordings every month [17]:

- Mean diurnal variability (in L/min).

- Maximal diurnal variability: the difference between the worst morning and best evening PEF of that week (expressed as \% of recent (that week) best PEF).

- Minimal morning PEF (expressed as \% of recent best PEF).

The difference between the best morning and the best evening PEF (in L/min).

\section{RESTING ENERGY EXPENDITURE (REE) AND DIET}

Basal metabolic rate or REE was measured by indirect calorimetry [18] (ventilated hood), and compared to Schofields age related normal values for children [19]. Dietary evaluation was carried out using an extensive booklet for three days recording of the diet of these CF patients. From the recorded data lipase intake (FIP-E), dietary fat (gram/day), protein (gram/day) and energy ( $\mathrm{KJ} /$ day) content were calculated.

\section{EXPERIMENTAL PROTOCOL}

The following measurements were obtained over a period of one year, according to the protocol. Before start and at each 3 monthly visit, anthropometric data were obtained $(5 x)$. Three faecal samples before start of the study and two samples were taken monthly during the 12 months study period, providing 27 specimens for analysis of acid steatocrit.

Totalbody DEXA was performed every 6 months $(3 x)$. Lung function tests: Flow Volume curve, Bodybox and PI/ PE-max were performed at each visit ( $5 x$ ) and REE was measured every 6 months $(3 x)$. Diary cards with PEF were recorded during one week, monthly (13x). The dietary intake was recorded before start, at 6 and 12 months (3x).

\section{STATISTICS}

Data are presented in tables as means and standard deviations, while in the figures medians and quartiles are presented as changes from baseline. We tested the response to the treatment for all measured parameters. To maximize the power of the tests, we compared the mean of the whole intervention period to the pre-trial (baseline) values. In that way, the power of the test is optimized, since measurement errors and within-subject variation tends to cancel out. A second advantage of this method is that we avoided doing 4 different tests for essentially the same hypothesis, which would inflate the type-I error probability beyond the nominal $5 \%$ [20]. The price to pay is superficially a less detailed picture of trends within the trial period. However, with a small trial as the present one, we would not have any real power to detect such trends. If a clear trend is visible we noted them in the results and the figures show some of these trends. By using the non-parametric Wilcoxon signed ranks test, we furthermore avoided to make the assumption of normality, which is untestable with only 14 subjects. All data are summarized in the Tables 5.2-4. Differences with respect to baseline were considered significant when the two-sided $P$-value 
was 0.05 or less. The statistical package SPSS (version 7.5 for Windows, 1996) was used for data management and analysis.

\subsection{RESULTS}

\section{ANTHROPOMETRY}

Mean $( \pm S D)$ bodyweight SDS increased from $-1.270( \pm 0.739)$ to -1.085 $( \pm 0.827)$ at 9 months $(P<0.05)$. However the mean value during the study was -1.118 $( \pm 0.817 ;$ NS). Mean height SDS showed a slight, but not significant, increase from $-1.068( \pm 0.590)$ before to $-1.017( \pm 0.608)$ mean during the study. BMI was considerably decreased before the study $14.95\left( \pm 1.81 \mathrm{~kg} / \mathrm{m}^{2}\right)$ but improved significantly to $15.38\left( \pm 1.92 \mathrm{~kg} / \mathrm{m}^{2} ; P<0.05\right)$ (Table 5.2$)$.

\section{FECAL FAT CONTENT}

An immediate and significant decrease in fecal fat content (acid steatocrit) was noticed, shortly after the addition of lansoprazole. The mean acid steatocrit decreased from $33.3 \%( \pm 17.8 \%)$ at the start to $23.7 \%( \pm 11.0 \%)$ at 3 months $(P<0.01)$ and remained at that level thereafter, the mean value during treatment was $24.0 \%$ $( \pm 9.8 \% ; P<0.05)$.

\section{BODY COMPOSITION}

Body fat assessed by DEXA performed at 6 months showed a significant improvement, persisting during the entire study. Mean TBF SDS had increased from -0.966 $( \pm 0.489)$ before to $-0.707( \pm 0.695)$ during PPI $(P<0,05)$. In contrast mean FFM SDS did not change, from $-1.820( \pm 0.673)$ before to $1.843( \pm 0.687 ;$ NS) during PPI (Table 5.2 and Figure 5.1).

\section{LUNG FUNCTION}

Mean TLC decreased from 109.5 ( $\pm 16.6 \%$ of predicted) before to 100.3 $( \pm 7.3 \% ; P<0.05)$ during PPI, mean RV showed a nearly significant decrease from $179.6( \pm 73.1 \%)$ before to $141.5( \pm 29.9 \% ; P=0.055)$ during PPI, mean ITGV decreased from $128.0( \pm 42.9 \%)$ before to $111.0( \pm 13.1 \%$; NS) during PPI and mean ERV increased from $71.9( \pm 15.6 \%)$ to $78.6( \pm 20.6 \%$; NS) during PPI. When ratio's of these static lung volumes were calculated, no significant change was noted, the RV/TLC ratio changed from $40.1( \pm 10.1 \%)$ before to $35.2( \pm 7.2 \%)$ during PPI, while the ITGV/TLC ratio changed from $55.7( \pm 9.2 \%)$ before to $54.0( \pm 4.6 \%)$ during PPI (Table 5.3$)$. Dynamic lungfunction parameters did not change significantly. Mean $\mathrm{FEV}_{1}$ changed from $83.9( \pm 17.2 \%)$ to $81.8( \pm 16.9 \%$; NS) during PPI, mean FVC from $86.6( \pm 13.0 \%)$ to 87.6 ( $\pm 13.1 \%$; NS) during PPI. Mean sGAW did not change, from $0.8641 / \mathrm{kPa} . \mathrm{s}$ $( \pm 0.257)$ to $0.854( \pm 0.219 ; N S)$. Also mean pneumotachographic PEF did not change, from $90.6( \pm 18.7 \%)$ to $87.9( \pm 15.4 \%$; NS) during PPI (Table 5.3). 
TABLE 5.2. Mean values and statistics of anthropometry, REE, body composition and diet parameters before and during PPI.

\begin{tabular}{lrrrrr}
\hline Parameter & $\begin{array}{l}\text { Mean (SD) } \\
\text { Before PPI }\end{array}$ & \multicolumn{2}{l}{$\begin{array}{l}\text { Mean (SD) } \\
\text { During PPI }\end{array}$} & \multicolumn{1}{l}{$\begin{array}{l}\text { Wilcoxon } \\
P=\end{array}$} & Number \\
\hline Weight (SDS) & $-1.270(0.739)$ & $-1.118(0.817)$ & 0.177 & 14 \\
Height (SDS) & $-1.068(0.590)$ & $-1.017(0.608)$ & 0.198 & 14 \\
BMI (kg/m2) & $14.95(1.81)$ & 15.38 & $(1.92)$ & 0.035 & 14 \\
Acid Steatocrit (\%) & $33.3(17.8)$ & 24.0 & $(9.8)$ & 0.030 & 14 \\
TBF (SDS) & $-0.966(0.489)$ & -0.707 & $(0.695)$ & 0.011 & 14 \\
FFM (SDS) & $-1.820(0.673)$ & $-1.843(0.687)$ & 0.826 & 14 \\
REE (\% pred.) & $111.7(12.1)$ & 110.7 & $(9.1)$ & 0.778 & 14 \\
Lipase intake (IU/kg) & $4020(970)$ & 3580 & $(880)$ & 0.198 & 14 \\
Fat intake (gr/d) & $90.5(18.8)$ & 81.9 & $(17.0)$ & 0.056 & 14 \\
Energy intake (kJ/d) & $9713(1966)$ & 9181 & $(1913)$ & 0.056 & 14 \\
\hline
\end{tabular}

For abbreviations see list of abbreviations (page 6).

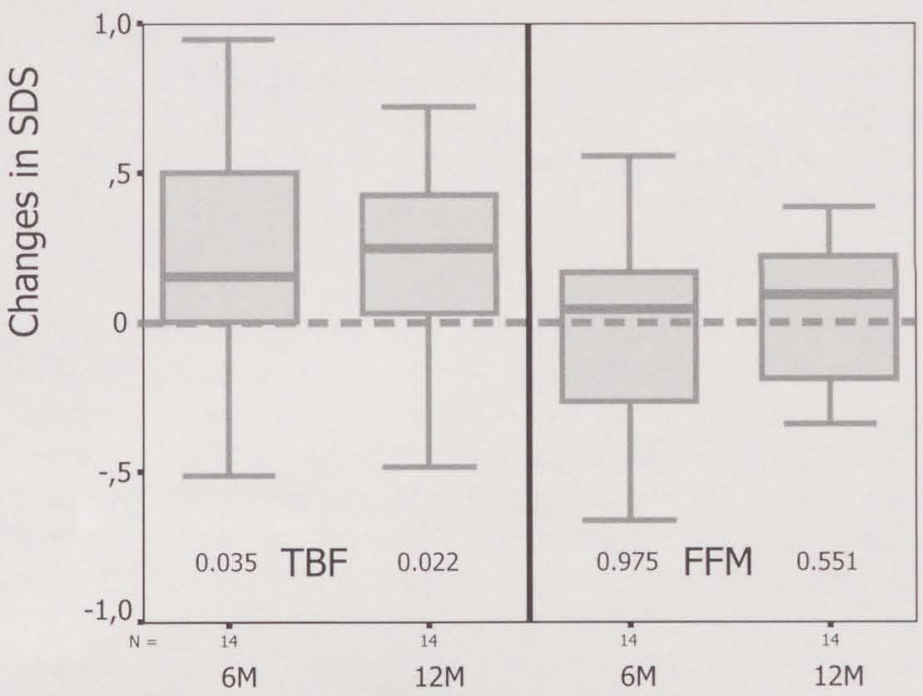

FIGURE 5.1. Box plots showing changes in SD-score for Total Body Fat and Fat Free Mass, 6 and 12 months after starting treatment with a PPI compared to the baseline value (at to $\rightarrow Y=0)$, ( $P$-values by Wilcoxon). 
TABLE 5.3. Mean values and statistics of static and dynamic lung function and respiratory muscle parameters before and during PPI.

\begin{tabular}{|c|c|c|c|c|}
\hline \multirow{3}{*}{$\begin{array}{l}\text { Parameter } \\
\text { TLC (\% pred.) }\end{array}$} & \multirow{2}{*}{$\begin{array}{l}\text { Mean (SD) } \\
\text { Before PPI }\end{array}$} & \multirow{2}{*}{$\begin{array}{l}\text { Mean (SD) } \\
\text { During PPI }\end{array}$} & \multirow{3}{*}{$\begin{array}{l}\text { Wilcoxon } \\
P= \\
0.025\end{array}$} & \multirow{3}{*}{$\begin{array}{l}\text { Number } \\
13\end{array}$} \\
\hline & & & & \\
\hline & $109.5 \quad(16.6)$ & $100.3 \quad(7.3)$ & & \\
\hline RV (\% pred.) & $179.6 \quad(73.1)$ & $141.5 \quad(29.9)$ & 0.055 & 13 \\
\hline ITGV (\% pred.) & $128.0 \quad(42.9)$ & $111.0 \quad(13.1)$ & 0.209 & 13 \\
\hline ERV (\% pred.) & $71.9 \quad(15.6)$ & $78.6 \quad(20.6)$ & 0.133 & 13 \\
\hline RV/TLC (\% pred.) & $40.1 \quad(10.1)$ & $35.2 \quad(7.2)$ & 0.173 & 13 \\
\hline ITGV/TLC (\% pred.) & $55.7 \quad(9.2)$ & $(4.6)$ & 0.753 & 13 \\
\hline $\mathrm{FEV}_{1}$ (\% pred.) & $83.9 \quad(17.2)$ & $81.8 \quad(16.9)$ & 0.234 & 14 \\
\hline FVC (\% pred.) & $86.6 \quad(13.0)$ & $87.6 \quad(13.1)$ & 0.950 & 14 \\
\hline MEF25\%FVC (\% pred.) & $56.6 \quad(53.7)$ & $34.8 \quad(16.6)$ & 0.103 & 14 \\
\hline $\operatorname{PImax}\left(\mathrm{cmH}_{2} \mathrm{O}\right)$ & $-66.3 \quad(18.9)$ & $-81.3 \quad(18.7)$ & 0.002 & 13 \\
\hline $\operatorname{PEmax}\left(\mathrm{cmH}_{2} \mathrm{O}\right)$ & $75.9 \quad(15.8)$ & $83.7 \quad(18.4)$ & 0.069 & 13 \\
\hline MIF50\%FVC (\% pred.) & $47.3 \quad(14.9)$ & $47.6 \quad(13.8)$ & 0.925 & 14 \\
\hline sGAW (1/kPa.s) & $0.864(0.257)$ & $0.854(0.219)$ & 0.807 & 13 \\
\hline PEF (\% pred.) & $90.6 \quad(18.7)$ & $87.9 \quad(15.4)$ & 0.177 & 14 \\
\hline
\end{tabular}

For abbreviations see list of abbreviations (page 6).

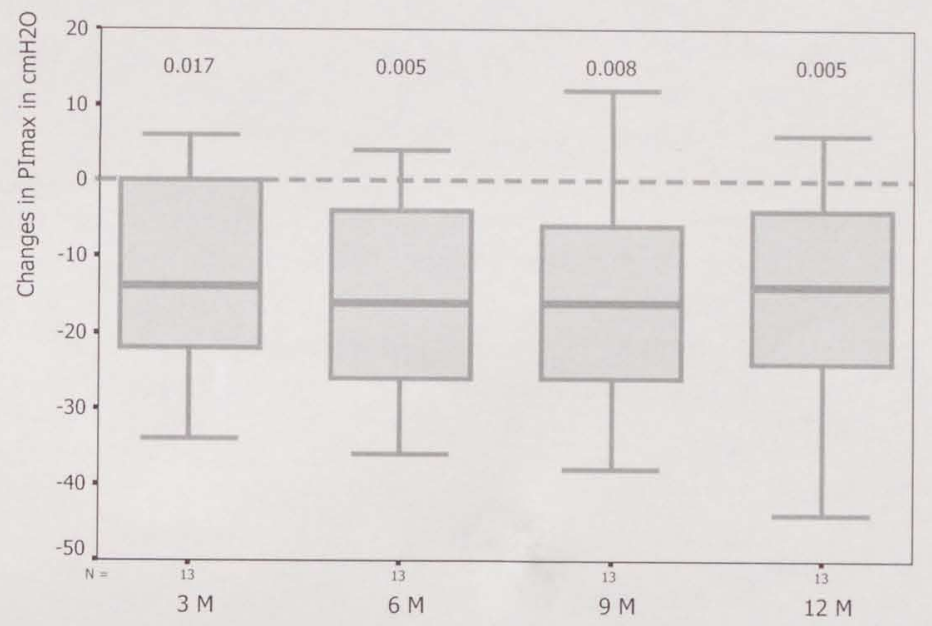

FIGURE 5.2. Box plots showing changes in Maximal Inspiratory Pressure (PImax) comparing each 3 month period, during treatment with a PPI, with the baseline value (at to $\rightarrow \mathrm{Y}=0)$, ( $P$-values by Wilcoxon). 
TABLE 5.4. Mean values and statistics of the home recordings of Peak expiratory flow (= PEF) parameters before and during PPI.

\begin{tabular}{|c|c|c|c|c|c|c|}
\hline \multirow{3}{*}{$\begin{array}{l}\text { Parameter } \\
\text { Mean diurnal variability }(\mathrm{l} / \mathrm{min})\end{array}$} & \multirow{2}{*}{\multicolumn{2}{|c|}{$\begin{array}{l}\text { Mean (SD) } \\
\text { Before PPI }\end{array}$}} & \multirow{2}{*}{\multicolumn{2}{|c|}{$\begin{array}{l}\text { Mean (SD) } \\
\text { During PPI }\end{array}$}} & \multirow{3}{*}{$\begin{array}{l}\text { Wilcoxon } \\
P= \\
0.722\end{array}$} & \multirow{3}{*}{$\begin{array}{l}\text { Number } \\
14\end{array}$} \\
\hline & & & & & & \\
\hline & \multirow{2}{*}{$\begin{array}{l}24.6 \\
27.6\end{array}$} & $(16.7)$ & \multirow{2}{*}{$\begin{array}{l}26.6 \\
21.3\end{array}$} & $(15.6)$ & & \\
\hline Maximal diurnal variability (\%) & & (12.3) & & $(4.4)$ & 0.041 & 14 \\
\hline Minimal morning PEF $(\%)$ & 72.4 & (12.3) & 78.4 & $(4.2)$ & 0.056 & 14 \\
\hline Mean difference PEF $(\mathrm{l} / \mathrm{min})$ & 5.9 & $(27.6)$ & 16.5 & (19.3) & 0.106 & 14 \\
\hline
\end{tabular}

For abbreviations see list of abbreviations (page 6).

Respiratory muscle parameters especially mean PI/PEmax improved markedly. PImax changed from $66,3\left( \pm 18,9 \mathrm{cmH}_{2} 0\right)$ to $81.3( \pm 18.7 ; P=0.002)$ during PPI and PEmax from $75.9\left( \pm 15,8 \mathrm{cmH}_{2} 0\right)$ to $83.7( \pm 18.4 ; P=0.069)$ during PPI, while MIF50\%VCin did not change during PPI, from $47.3( \pm 14.9 \%$ ) to 47.6 ( $\pm 13.8 \%$; NS) (Table 5.3 and Figure 5.2).

\section{BRONCHIAL HYPERRESPONSIVENESS}

The monthly recordings at home with the Personal Best PEF meter demonstrated variable changes. While mean diurnal variability even slightly increased from 24.6 $( \pm 16.7 \mathrm{~L} / \mathrm{min}$ ) before to $26.6( \pm 15.6 \mathrm{~L} / \mathrm{min} ; \mathrm{NS})$ during PPI, maximal diurnal variability decreased significantly from 27.6 ( $\pm 12.3 \%$ of recent best) before to $21.3( \pm 4.4 \%$; $\mathrm{p}<0.05)$ during PPI. Minimal morning PEF increased from $72.4( \pm 12.3 \%)$ before to $78.4( \pm 4.2 \%)$ during PPI $(P=0.056)$. Mean difference between best evening and best morning PEF increased from $5.9( \pm 27.6 \mathrm{~L} / \mathrm{min})$ before to $16.5( \pm 19.3 ; \mathrm{NS})$ under PPI (Table 5.4).

\section{RESTING ENERGY AND DIET}

REE did not change during PPI, from $111.7 \%$ of reference values ( $\pm 12.1 \%$ ) to $110.7( \pm 9.1 \%$; NS). Dietary parameters did not change significantly. Mean fat intake decreased from 90.5 ( $\pm 18.8 \mathrm{gram} /$ day) to 81.9 ( $\pm 17.0 ; \mathrm{NS}$ ) during PPI and total daily energy intake decreased from 9713 ( $\pm 1966 \mathrm{~kJ} /$ day) to 9181 ( \pm 1913 ; NS) during PPI (Table 5.2). The mean intake of lipase decreased from $4020( \pm 970 \mathrm{IU} / \mathrm{kg})$ to 3580 $( \pm 880 ;$ NS) during PPI.

\subsection{DISCUSSION}

In the present study in 14 young CF patients, the effect of lansoprazole on growth, fecal fat losses, body composition, as well as the consequences of possible changes in body composition on lung function parameters and BHR was evaluated. 
The decreased mean SDS for weight, height and BMI in our patients confirms the well known growth retardation of CF patients [21]. The use of a PPI resulted in a better improvement of weight SDS compared to height SDS, however, despite a visible trend, both changes were not significant when averaged for the whole treatment period. BMI, which is derived from weight and height, did improve significantly.

As this study was performed in an open designed fashion, in a small group of CF patients, the results should be interpreted cautiously. But as we in our previous open study [4], concerning the effect of a PPI on stool fat and body composition, showed exactly the same results (decrease of stool fat and increase of TBF, with unchanged FFM) a placebo effect would very unlikely be responsible for these consecutive similar findings. In the present study, performed in only partly the same population and with more than one year no use of a PPI in between, similar changes were measured and confirmed on several occasions during the treatment year. Repeated confirmation and progression of changes in the same direction during one year is more likely to be due to a treatment effect than to a placebo effect.

Our results show a significant and persistent decrease of the mean acid steatocrit during the entire study period. The finding that weight improved more than height can probably be explained by an improved fat absorption and thereby an increased TBF under treatment with a PPI. Our body composition measurements are in line with this statement. Compared to normal Dutch children our CF patients showed significant decreases of both mean TBF and FFM. Under treatment with a PPI and despite a non significant decrease in fat and energy intake, mean TBF improved significantly while mean FFM remained unchanged. The decreased steatocrit values could either be due to this slight decrease of fat intake or to improved fat absorption. Because the lipase intake decreased too, the second hypothesis seems more likely as it also explains the significant increase of body fat and BMI. These results confirm previous findings showing a favourable effect of a PPI on fecal fat losses in CF. An explanation for the diverging results concerning the improvement of FM but not FFM could be the lack of an physical exercise during the study [22].

Despite a lack of improvement of FFM we could demonstrate an improvement of the static lung volumes TLC and RV, and respiratory muscle performance, as shown by improvement of the resultant of expiratory and inspiratory forces, especially PI-max [23]. Although we could demonstrate a significant decrease in TLC and a nearly significant decrease in RV, the ratio RV/TLC appeared not to change significantly. The initial mean ratio of $40 \%$ is, however, significantly increased when compared to that of normal individuals. The lack of a significant change of ITGV is probably related to the large SD at the start. The relation between the decrease of hyperinflation (TLC and RV) and the improvement of respiratory muscle force is more difficult to interpret. Indeed a decrease of hyperinflation can lead to a more favourable starting point for diaphragm muscle contraction, improving the contractile force and therefore maximal mouth pressures [24]. Lands et al. [25] demonstrated in their comparative study, an effect of nutritional status on respiratory muscle strength in CF patients but not in asthmatic and anorexia nervosa patients, indicating that the combination of malnutrition and chronic hyperinflation give rise to inefficient functioning of the diaphragm. The 
prompt decrease of TLC and RV with an increase of PI/PEmax in the present study, points to such a beneficial effect of a PPI on the diaphragm muscles. But, because of the unchanged ITGV, ERV and RV/TLC, we could not demonstrate an improved elastic recoil. In the absence of absolute changes in body FFM, the improvement of PI/PEmax during the intervention period could hypothetically be explained by metabolic adaptations in the respiratory muscles rather than by changes in the mechanical properties of the diaphragm. As ventilatory muscles training was in no way part of the intervention procedure, training effects are expected not to be related to these changes in ventilatory muscle function. Besides the PImax, the sustained maximal inspiratory presure could have clinical significance in CF patients. Further studies are needed to assess the effects of a PPI on endurance of the inspiratory muscles.

The reduction in lung volumes under lansoprazole seems to us clinically relevant in view of the data of Kraemer et al [26], who recently showed in 60 infants with CF that differences in lung function within subgroups of mutations were mainly related to pulmonary hyperinflation. Hyperinflation seems to occur in a very early phase of the disease and may even precede inflammation and infection. This might, at least partly, be influenced by the type of mutation as shown by Kraemer.

Lung hyperinflation in CF patients have been related to surfactant deficiency [27-30]. The improved fat absorption might have a favourable effect on surfactant composition, but the relation between the use of a PPI and improvement of surfactant composition has yet to be demonstrated. Another factor contributing to hyperinflation could be the degree of inflammation, especially of the smaller airways. Bronchial inflammation is known to be present in $\mathrm{CF}$, where it has been demonstrated even in very young $\mathrm{CF}$ patients [31].

The absence of effects on sGAW after a PPI does not exclude changes in these smaller airways. In this respect the increase in TBF under PPI intervention is remarkable. Body fat plays an important role in energy homeostasis by production of the adipocyte-derived leptin. Leptin seems to have a pleotrophic function in the body and its administration has been shown to improve immune function [32]. Further studies are necessary in order to elucidate the relation between leptin metabolism and the observed changes in body composition in CF patients.

From the daily recordings of the PEF at home, maximal diurnal variability and minimal morning PEF are the most important indicators for the presence of BHR [19]. Both the maximal diurnal variability, being nearly $30 \%$ of recent best PEF, and the weekly minimal morning $P E F$, being only $72 \%$ of recent best $P E F$, support the assumption that BHR is increased in CF. When compared to normal children, patients with CF show an increased prevalence of BHR [33]. BHR is directly related to bronchial inflammation, but also to GER. GER is common in CF patients [34], and is often present in infants [35] and toddlers [36]. Administration of lansoprazole might consequently affect both GER and BHR. Assessment of diurnal variability of PEF has been proposed as a surrogate for measuring the degree of BHR in asthmatic patients, even when asymptomatic [37], but its usefullness has been limited because of its rather poor reproducibility [38]. However it is still the only available method to measure diurnal changes of airway obstruction in every day life [39]. We could demonstrate a significant decrease in 
maximal diurnal variability and a nearly significant change in minimal morning PEF. But, on the other hand, the mean diurnal variability did not improve at all, which perhaps indicates the poor reproducibility of this method. The mean differences only slightly increased towards the end of the study, which demonstrated that evening PEF improved more than morning PEF, but this change was not significant. Although our results of PEF recordings do not allow us to conclude definitely that $B H R$ in CF patients is decreased by antacid therapy with a PPI, our results suggest that BHR is present in CF and that GER may contribute to it. More studies are necessary to confirm this finding.

In conclusion we would recommend to assess regularly, even in young CF patients, dynamic as well as static lungvolumes. Further, as our study shows that improvement of body composition and of some lung function parameters, particularly TLC and PImax occur in parallel, we would recommend to make all effort to reduce fat malabsorption in young CF patients. The relationship between body composition and lung function in children with CF should be further studied in order to elucidate the mechanisms involved.

\subsection{REFERENCES}

1. Knauf RE, Adams JA. Duodenal fluid pH in CF. Clin.Chem. 1968;14:477-479.

2. Lenaerts C, Beraud N, Castaigne JP. Pancrease gastroresistance: in vitro evaluation op pH-determined dissolution. J.Paediatr.Gastroenterol.Nutr. 1988;7(suppl.1):S18-S21.

3. Heijerman HGM, Lamers CBHW, Bakker W. Omeprazole enhances the efficacy of pancreatin (pancrease) in CF. Ann.Intern.Med. 1991;114:200-201.

4. Tran TMD, Van den Neucker AM, Hendriks JJE, Forget P, Forget PPh. Effects of a proton-pump inhibitor in CF. Acta Paediatr. 1998;87:553-558.

5. Steinkamp G, Hardt von der $\mathrm{H}$. Improvement of nutritional status and lung function after long-term nocturnal gastrostomy feedings in CF. J.Pediatr. 1994;124:244-249.

6. Ionescu AA, Chatham K, Davies CA, Nixon LS, Enright S, Shale DJ. Inspiratory muscle function and body composition in CF. Am.J.Respir.Crit.Care Med. 1998;158:1271-1276.

7. Thomson MA, Quirk P, Swanson CE, Thomas BJ, Holt TL, Francis PJ, Shephard RW. Nutritional growth retardation is associated with defective lung growth in CF: a preventable determinant of progressive pulmonary dysfunction. Nutrition 1995;11:350-354.

8. Gerver WJM and Bruin de R. Paediatric Morphometrics a Reference Manual. In Bunge, Utrecht, the Netherlands 1996.

9. Gerver WJM, Bruin de R. Body composition in children based on anthropometric data. A presentation of normal values. Eur.J.Pediatr. 1996;155:870-876.

10. Tran TMD, Forget PPh, Van den Neucker AM, Strik J, Kreel van B and Kujiten RH. The acid teatocrit: a much improved method. J.Pediatr.Gastroenterol.Nutr. 1994;19:299-303.

11. Van den Neucker AM, Forget PPh, Veneberg JA, Schutten BJ and Kreel van B. Acid Steatocrit during infancy. Acta Paediatr. 1996;85:1153-1155. 
12. Van den Neucker AM, Pestel N, Tran TMD, Forget PPh, Veeze HJ, Bouquet J and Sinaasappel M. Clinical use of acid steatocrit. Acta Paediatr. 1997:86:466-469.

13. Brunton JA, Weiler HA and Atkinson SA. Improvement in the accuracy of DEXA for whole body and regional analysis of body composition: Validation using piglets and methodologic considerations in infants. Ped. Research 1997;41:590-597.

14. Boot $A M$ et al. Determinants of body composition by DEXA in Dutch children and adolescents. Am.J.Clin.Nutr. 1997 Aug;66(2):232-238.

15. Zapletal $A$, Samanek $M$ and Paul T. In Lung function in children and adolescents. Methods, reference values. In Progress in Respiration Research Nr.22. Editor: Herzog H. Karger Basel, 1987.

16. Black LF and Hyatt RE. Maximal respiratory pressures: normal values and relationship to age and sex. Am.Rev.Respir.Dis. 1969;99:696-702.

17. Reddel HK, Salome CM, Peat JK, Woolcock AJ. Which index of PEF is most useful in the management of stable asthma? Am.J.Respir.Crit.Care Med. 1995;151:1320-1325.

18. Kaplan AS, Zemel BS, Neiswender KM and Stallings VA. Resting Energy Expenditure in clinical pediatrics: measured versus prediction equations. J.Pediatr. 1995;127:200-5.

19. Schofield WN. Predicting basal metabolic rate, new standards and review of previous work. Hum.Nutr.Clin.Nutr. 1985;39c(1s):5-42.

20. Altman DG. In Practical statistics for medical research. Chapman and Hall, London 1991:429-431.

21. Morison S, Dodge JA, Cole TJ, Lewis PA, Coles EC, Geddes D, Russell G, Littlewood JM, Scott MT (the UK CF Survey Management Committee). Height and weight in CF: a cross sectional study. Arch.Dis.Childh. 1997;77:497-500.

22. Meer de K, Gulmans VAM and Laag van der J. Peripheral muscle weakness and exercise capacity in children with CF. Am.J.Respir.Crit.Care Med. 1999;159:748-754.

23. Mier A, Redington A, Brophy C, Hodson M, Green M. Respiratory muscle function in CF. Thorax 1990;45:750-752.

24. Nichols DG. Respiratory muscle performance in infants and children. J. of Pediatrics 1991;118:493-502.

25. Lands L, Desmond KJ, Demizio D, Pavilanes A, Coates AL. The effects of nutritional status and hyperinflation on respiratory muscle strength in children and young adults. Am.Rev.Respir.Dis. 1990;141(6):1506-1509.

26. Kraemer R, Birrer P and Liechti-Gallati S. Genotype-Phenotype association in infants with CF at the time of diagnosis. Ped. Research 1998;44:920-926.

27. Hull J, South M, Phelan P, Grimwood K. Surfactant composition in infants and young children with CF. Am.J.Respir.Crit.Care Med. 1997;156:161-165.

28. Griese M, Birrer P, Demirsoy A. pulmonary surfactant in CF. Eur.Respir.J. 1997;10:1983-1988.

29. Griese M, Bufler P, Teller J, Reinhardt D. Nebulization of a bovine surfactant in CF: a pilot study. Eur.Respir.J. 1997;10:1989-1994.

30. Puchelle E, Bentzmann de S, Zahm JM. Physical and functional properties of airway secretions in CF - therapeutic approaches. Respiration 1995;62 suppl.1:2-12. 
31. Khan TZ, Wagener JS, Bost T, Martinez J, Accurso FJ, Riches DW. Early pulmonary inflammation in infants with CF> Am.J.Crit.Care Med. 1995;151:1075-1082.

32. Lord GM, Matarese G, Howard JK, Baker RJ, Bloom SR, Lechler RI. Leptin modulates the $T$-cell immune respons and reverses starvation-induced immunosuppression. Nature 1998;394(6696):897-901.

33. Sanchez I, Powell RE, Pasterkamp H. Wheezing and airflow obstruction during metacholinechallenge in children with CF and in normal children. Am. Rev. Respir.Dis. 1993;147:705-709.

34. Malfroot A, Dab I. New insights on gastro-oesophageal reflux in CF by longitudinal follow up. Arch.Dis.Child. 1991;66:1339-1345.

35. Vic P, Tassin E, Turck D, Gottrand F, Launay V, Farriaux JP. Frequency of gastraoesofageal reflux in infants and in young children with CF. Arch.Pediatr. $1995 ; 2: 742-746$.

36. Heine RG, Button BM, Olinsky A, Phelan PD, Catto-Smith AG. Gastro-oesophageal reflux in infants under 6 months with CF. Arch.Dis.Child. 1998;78:44-48.

37. Gibson PG, Mattoli S, Sears MR, Dolovich J, Hargreave FE. Increased peak flow variability in children with asymptomatic hyperresponsiveness. Eur.Respir.J. 1995;8:1731-1735.

38. Frischer $T$, Meinert $R$, Urbanek R, Kuehr J. Variability of PEF-rate in children: short and long term reproducibility. Thorax 1995;50:35-39.

39. Konig P, Poehler J, Barbero GJ. A placebo-controlled, double-blind trial of the long-term effects of albuterol administration in patients with CF. Pediatr.Pulmonol. 1998;25:32-36. 

CHAPTER SIX

\section{Effects of therapy with lansoprazole on intestinal permeability and inflammation in young Cystic Fibrosis patients}

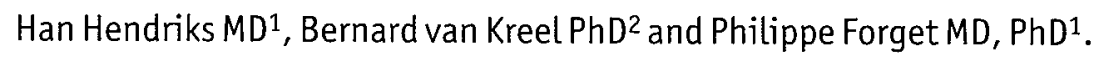
Departments of Paediatrics ${ }^{1}$ and Clinical Chemistry ${ }^{2}$ University and University Hospital Maastricht, the Netherlands

J Ped Gastroenterol Nutr 2001;33:260-265.

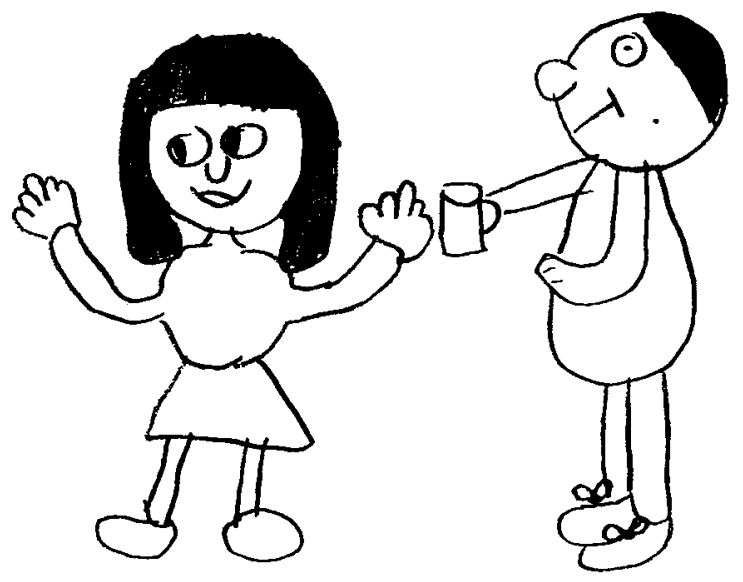




\subsection{ABSTRACT}

Background: Defective pancreatic bicarbonate secretion with low intestinal $\mathrm{pH}$ or intestinal inflammation of any origin increase intestinal permeability in Cystic Fibrosis (CF).

Methods: In this open study the authors evaluated the effect of a proton-pump inhibitor (PPI) on intestinal permeability and inflammation in 14 young, pancreatic insufficient CF patients. Permeability was measured, by a three-sugar permeability test before and after 1 year lansoprazole use, and urinary nitric oxide (NO) oxidation products were assessed before and during that year, as a marker of inflammation.

Results: After 1 year of lansoprazole use, median urinary recovery percentages changed from $2.5 \%$ to $1.7 \%(P=0.064)$, from $24.9 \%$ to $24.5 \%$ (NS) and from $10.5 \%$ to $11.1 \%$ (NS) for lactulose, mannitol and L-rhamnose respectively. Despite the fact that the median urinary excretion ratios decreased from 0.108 to $0.083(P=0.03)$ and from 0.246 to $0.176(P=0.016)$ for lactulose to mannitol and lactulose to L-rhamnose, respectively, they both remained increased. Median urinary N0-products-to-creatinine ratios was 0.287 for CF patients before lansoprazole and 0.130 for healthy controls $(P=0.002)$. Although there was a tendency towards a decrease in NO products-to-creatinine ratio during treatment, this was not significant at the endpoint.

Conclusions: Intestinal permeability is considerably increased in CF patients and is partly corrected after the use of a PPI for one year, which may point to a harmful effect of the acid luminal contents on the tight junctional related paracellular permeability pathway. The start and end values for the NO products-to-creatinine ratio in CF patients were not significantly different, but were considerable increased when compared to control participants $(P=0.002)$. 


\subsection{INTRODUCTION}

Cystic Fibrosis (CF) is the most common lethal hereditary disease among white persons. The CF gene is located on chromosome 7 and so far more than 900 mutations of this single gene, producing the CF transmembrane conductance regulator (CFTR), have been reported. The basic defect is a dysregulation of the chloride channels, resulting in dehydration of the luminal surface of exocrine cells. Apart from respiratory complications, gastroenterologic abnormalities give rise to significant morbidity in children with CF.

Although a severe increase in intestinal permeability (IP) is known to be present in CF patients, the clinical significance of this abnormality is unknown at present $[1,2]$. A recent study in rats, revealed that increases of IP favours the development of intestinal damage associated with excessive pancreatic enzyme administration. The characteristically increased IP in CF similarly could increase vulnerability to fibrosing colonopathy [3]. In a review article a relationship between increased IP, decreased intestinal pH and the pathogenesis of fibrosing colonopathy has been suggested [4]. Although a relationship has been shown to exist between IP and pancreatic insufficiency (PI), of whatever origin [5], patients with CF do show specific IP abnormalities such as increased mannitol xylose and rhamnose permeability $[2,6,7]$. These $C F$ related abnormalities suggest the presence of specific pancreatic dysfunction contributing to the increased IP. One of these abnormalities could be the severe CFTR-associated decrease in ductular bicarbonate secretion [8], resulting in a low duodenal buffering capacity and therefore in a low luminal $\mathrm{pH}$.

In children with $\mathrm{CF}$, exogenous administration of pancreatic enzymes improved but did not reverse fat malabsorption completely. It has been shown that the use of a proton pump inhibitor (PPI) improves the effectiveness of administered pancreatic enzymes $[9,10]$. The purpose of these drugs is to increase duodenal $\mathrm{pH}$ by decreasing gastric acid production. Also, a direct action on the residual pancreatic function is possible [11], which could be more expected in young CF patients. If duodenal $\mathrm{pH}$ is less than 5 , early dissolution of the enteric coating of administered enzyme capsules is hindered because this only occurs at a duodenal $\mathrm{pH}$ above 5.5 [12.13]. In addition this low pH may also inactivate pancreatic enzymes. Both processes result in suboptimal functioning of the enzymes required for the treatment of malabsorption.

Additionally, a low luminal $\mathrm{pH}$ could also have a direct effect on the mucosa of the intestine. As a possible explanation for the increased IP in CF, we hypothesized that the increased acidity of the intestinal contents could affect mucosal integrity. Decreased mucosal integrity could lead to both increased IP and intestinal inflammation (II), both present in CF.

Intesinal permeability is also increased in chronic inflammatory diseases such as celiac disease. In previous studies, we demonstrated an increased expression of inducible nitric oxide synthase (iNOS) in mucosal biopsies of celiac disease patients, resulting in II and high levels of urinary nitric oxide (NO) oxidation products, nitrite, and nitrate $[14,15]$. Prostaglandins and $N 0$ are important mediators of inflammation and there is mounting evidence for a biological relation between prostanoid and NO biosynthesis 
[16]. We therefore hypothesized that $\mathrm{N} 0$ oxidation products could be increased in $\mathrm{CF}$, resulting in an increase of the $\mathrm{N} O$ oxidation products-to-creatinine ratios.

As part of a wider study, the aim of the present study was to investigate the effect of lansoprazole on fat malabsorption and IP and to assess the presence of II by determination of urinary $\mathrm{NO}$ oxidation products excretion, and to find a possible association between Intestinal permeability and inflammation. Informed consent was obtained before onset, as part of a wider study, the protocol of which was approved by the Medical Ethical Committee of the University Hospital of Maastricht.

\subsection{MATERIALS AND METHODS}

\section{PATIENTS}

Fourteen stable CF patients ( 9 males, 5-16 years of age) with PI and mild lung disease, were studied before and during 1 year of treatment with $15 \mathrm{mg}$ lansoprazole (a PPI) daily. Because of this standard dose, we also computed the lansoprazole dose per kilogram of body weight. Diet and exogenous pancreatic enzymes were not changed during the intervention. For inclusion in the study, prestudy stool acid steatocrit (an index of fat losses) had to exceed 25\%, despite an intake of at least 2000 IU lipase $/ \mathrm{kg}$ bodyweight (mean $4020 \mathrm{IU}$ lipase $/ \mathrm{kg}$ ). The genetic mutations have been characterized in only 8 out of $14(57 \%)$ of our patients ( $\triangle \mathrm{F} 508$ mutation in $75 \%$ ). Table 6.1. summarizes the clinical data of our patients.

\section{METHODS}

Intestinal Permeability: (IP) was measured before and after 1 year of treatment with lansoprazole $15 \mathrm{mg}$ daily, by 3-sugar permeability test (SPT) [17]. After an overnight fast the first urine of the day was discarded, CF patients ingested $100 \mathrm{ml}$ of the test solution containing $1 \mathrm{~g}$ mannitol, $1 \mathrm{~g}$ L-rhamnose and $5 \mathrm{~g}$ lactulose. This solution was isotonic (osmolality $330 \mathrm{mmol} / \mathrm{L}$ ). After drinking the test solution, urine was

TABLE 6.1. Patient characteristics at start

\begin{tabular}{|c|c|c|c|c|c|c|}
\hline \multirow{2}{*}{$\frac{\text { Item }}{\text { Age }}$} & \multirow[b]{2}{*}{$(y)$} & \multirow{2}{*}{$\frac{\text { Mean }}{9.74}$} & \multirow{2}{*}{$\frac{\text { Median }}{8.60}$} & \multirow{2}{*}{$\frac{\text { SD }}{3.38}$} & \multicolumn{2}{|c|}{ Range } \\
\hline & & & & & $4.6-$ & 17.2 \\
\hline \multirow[t]{2}{*}{ Height } & $(\mathrm{cm})$ & 133.9 & 131.5 & 16.6 & $107.0-$ & 162.3 \\
\hline & $(S D S)^{*}$ & -1.068 & -1.112 & 0.590 & $-2.166-$ & 0.003 \\
\hline \multirow[t]{2}{*}{ Weight } & $(\mathrm{kg})$ & 27.7 & 25.6 & 9.9 & $15.5-$ & 52.3 \\
\hline & (SDS) & -1.270 & -1.438 & 0.739 & $-2.393-$ & 0.272 \\
\hline Acid Steatocrit & $(\%)$ & 33.3 & 32.7 & 17.7 & $5.4-$ & 65.7 \\
\hline $\mathrm{FEV}_{1}^{\dagger}$ & (\% predicted) & 83.9 & 85.0 & 17.2 & $58-$ & 112 \\
\hline FVC $\neq$ & (\% predicted) & 86.6 & 87.0 & 13.0 & $64-$ & 109 \\
\hline
\end{tabular}

* Standard deviation score or Z score; † Forced expiratory volume in 1 second; $\ddagger$ Forced vital capacity 
collected for 5 hours for determination of these 3 sugars by high-performance liquid chromatography and expressed as percentage of intake. Water intake was allowed after the first half hour in all patients, while, for practical reasons, food and sugar containing fluids intake was delayed for 3 hours. Sugar excretion ratios were determined by dividing the urinary percent recovery of the large sugar (lactulose) by that of the smaller sugars (mannitol + L-rhamnose). This simple and non-invasive test is a reproducible index of IP in children $[17,18]$. The use of ratios correct for potentially confounding factors such as delayed gastric emptying, delayed or rapid gut transit, or impaired renal clearance.

Nitric oxide oxidation products in urine: Nitric oxide oxidation products in urine were determined before and every 3 months during treatment. On the day before a visit, the CF patients collected urine for 24 hours, the 24 hours before and during the collection period these patients used a nitrate poor diet. Patients were free of viral illness or CF exacerbation during the collection period. A Nitrate/Nitrite colorimetric assay kit (Cayman Chemical Company, Ann Arbor, MI, US) determined nitrite and nitrate content. This test uses the Griess reagent assay, which is more accurate than the HPLC method [19]. Urinary creatinine was also determined and the NO oxidation products-to-creatinine ratio computed. The data of the CF patients were compared with urine samples of 25 healthy children (mean age 9,0 year $( \pm 4,8)$, healthy children of staff members).

Fecal Acid Steatocrit: Fecal Acid Steatocrit was used to monitor the steatorrhea as previously described $[20,21]$. Here results are expressed as the fat layer divided by the fat plus solid layer as a percent. Fecal acid steatocrit has been shown to correlate well with chemical analyses of fecal fat $(r=0.83 ; P<0.001)$ [22]. In healthy individuals older than 6 months, the acid steatocrit is less than $20 \%$. We chose for this method to monitor fecal fat content repetitively and easily during the study.

Statistics: In the tables data are presented as means, standard deviations and medians, whereas in the figures the data are presented as box plots with medians and quartiles. Individual values of the 3-SPT are shown in Table 6.2. By using the non-parametric Wilcoxon signed ranks test, we avoided making an assumption of normality, which is untestable with only 14 subjects. Differences with respect to baseline were considered significant when the two-sided $P$-value was 0.05 or less. The statistical package SPSS (version 9.0 for Windows, 1999, SPSS Inc., Microsoft, Chicago, IL) was used for data management and analysis.

\subsection{RESULTS}

INTESTINAL PERMEABILITY

Intestinal Permeability was severely increased in all but one subject before adjuvant therapy with lansoprazole. After 1 year of treatment with lansoprazole, the 
TABLE 6.2. Case Summaries of fat losses (acid steatocrit) and 3 sugar permeability test, before and after lansoprazole for one year

\begin{tabular}{|c|c|c|c|c|c|c|c|c|c|c|c|c|}
\hline \multirow[t]{2}{*}{ Case } & \multicolumn{4}{|c|}{ Steatocrit (\%) L-rec. ${ }^{*}(\%)$} & \multicolumn{2}{|c|}{ M-rec. $\downarrow(\%)$} & \multicolumn{2}{|c|}{ Rh-rec. $\neq(\%)$} & \multicolumn{2}{|c|}{ L/MTI (ratio) } & \multicolumn{2}{|c|}{ L/Rh§ (ratio) } \\
\hline & Start & End & Start & End & Start & End & Start & End & Start & End & Start & End \\
\hline 1 & 42.2 & 39.0 & 2.5 & 1.5 & 18.1 & 21.7 & 7.8 & 8.5 & 0.14 & 0.07 & 0.32 & 0.18 \\
\hline 2 & 31.2 & 23.0 & 7.2 & 1.7 & 7.4 & 8.8 & 9.7 & 7.3 & 0.98 & 0.20 & 0.75 & 0.24 \\
\hline 3 & 38.5 & 26.7 & 2.2 & .5 & 25.1 & 31.9 & 10.6 & 4.0 & 0.09 & 0.02 & 0.21 & 0.12 \\
\hline 4 & 26.3 & 11.6 & 7.4 & 2.2 & 24.8 & 24.8 & 12.8 & 12.4 & 0.30 & 0.09 & 0.58 & 0.18 \\
\hline 5 & 65.7 & 38.6 & 3.2 & 1.9 & 27.6 & 35.2 & 11.8 & 16.8 & 0.12 & 0.05 & 0.27 & 0.11 \\
\hline 6 & 29.0 & 16.4 & 4.6 & 1.9 & 21.4 & 19.8 & 10.5 & 11.0 & 0.21 & 0.10 & 0.43 & 0.17 \\
\hline 7 & 5.4 & 24.6 & 2.4 & 1.7 & 17.0 & 17.6 & 8.9 & 10.8 & 0.14 & 0.10 & 0.27 & 0.16 \\
\hline 8 & 14.1 & 15.8 & .8 & 5.8 & 49.7 & 40.6 & 10.5 & 18.7 & 0.02 & 0.14 & 0.08 & 0.31 \\
\hline 9 & 7.8 & 8.9 & 4.5 & 2.1 & 32.2 & 21.9 & 18.5 & 12.5 & 0.14 & 0.10 & 0.25 & 0.17 \\
\hline 10 & 38.3 & 37.2 & 2.6 & 1.3 & 32.9 & 25.3 & 10.3 & 7.4 & 0.08 & 0.05 & 0.25 & 0.18 \\
\hline 11 & 34.2 & 41.1 & 2.7 & 1.6 & 36.5 & 35.3 & 16.1 & 15.1 & 0.07 & 0.05 & 0.17 & 0.11 \\
\hline 12 & 45.3 & 18.9 & 2.1 & 4.1 & 20.9 & 30.1 & 10.2 & 16.7 & 0.10 & 0.13 & 0.20 & 0.24 \\
\hline 13 & 25.6 & 39.2 & .9 & 1.7 & 12.4 & 21.7 & 5.2 & 9.1 & 0.07 & 0.08 & 0.18 & 0.18 \\
\hline 14 & 62.3 & 35.7 & 1.9 & 1.0 & 26.3 & 24.2 & 11.4 & 11.1 & 0.07 & 0.04 & 0.17 & 0.09 \\
\hline Mean & 33.3 & 26.9 & 3.2 & 2.1 & 25.2 & 25.6 & 11.0 & 11.5 & 0.181 & 0.087 & 0.294 & 0.175 \\
\hline Median & 32.7 & 25.6 & 2.5 & 1.7 & 24.9 & 24.5 & 10.5 & 11.1 & 0.108 & 0.083 & 0.246 & 0.176 \\
\hline SD & 17.8 & 11.4 & 2.0 & 1.3 & 10.7 & 8.3 & 3.3 & 4.2 & 0.240 & 0.048 & 0.180 & 0.059 \\
\hline
\end{tabular}

Normal values $\mathrm{E}$

$0.11-0.678 .1-20.2$

$4.1-10.9$

$0.011-0.0360 .023-0.074$

* Lactulose recovery; $\uparrow$ Mannitol recovery; $\ddagger$ L-rhamnose recovery; 9 Lactulose-to-mannitol ratio; $\S$ Lactulose-to-L-rhamnose ratio; $£$ reference range according to Miki et al (17).

TABLE 6.3. Three-sugar test: change in recovery and excretion ratios after treatment with lansoprazole for 1 year

\begin{tabular}{lccccc}
\hline & $\begin{array}{l}\text { Lactulose } \\
\text { recovery }\end{array}$ & $\begin{array}{l}\text { Mannitol } \\
\text { recovery }\end{array}$ & $\begin{array}{l}\text { Rhamnose } \\
\text { recovery }\end{array}$ & $\begin{array}{l}\text { L/M ratio } \\
\text { (\% recovery) }\end{array}$ & $\begin{array}{l}\text { L/Rh ratio } \\
\text { (\% recovery) }\end{array}$ \\
\hline Mean change & -1.138 & +0.467 & +0.504 & -1.015 & -0.913 \\
Mean \% decrease & 35.4 & -1.9 & -4.5 & 52.0 & 40.5 \\
Median change & -1.174 & +0.310 & +0.132 & -0.707 & -0.670 \\
SD & 2.64 & 6.46 & 4.34 & 1.30 & 0.92 \\
Wilcoxon $(\mathrm{P} \Rightarrow)$ & 0.064 & 0.826 & 0.730 & 0.030 & 0.016 \\
\hline
\end{tabular}

L, lactulose; M, mannitol; Rh, L-rhamnose 


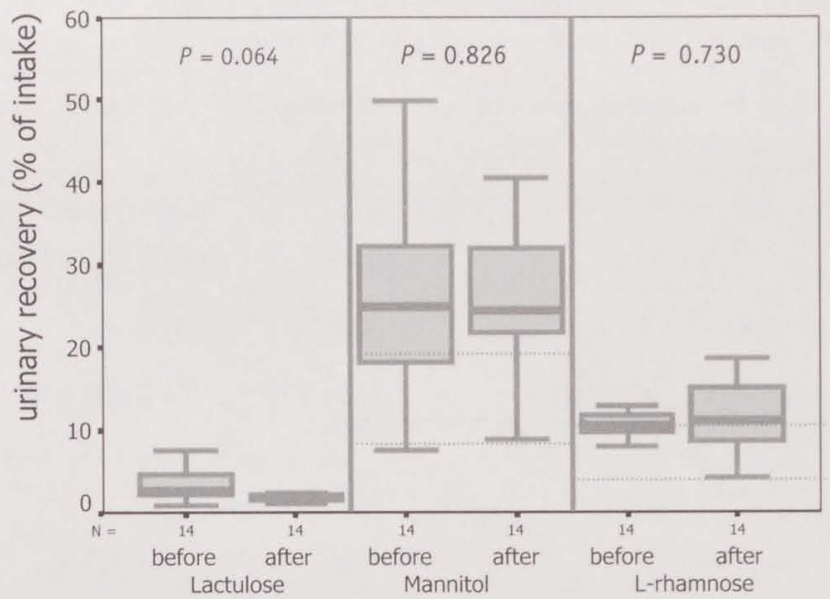

FIGURE 6.1. Box plots of urinary recovery of lactulose, mannitol and L-rhamnose before and after 1 year treatment with a proton-pump inhibitor. expressed in \% of administered dose (dotted lines are reference values). $P$ values were determined by Wilcoxon rank sum test.

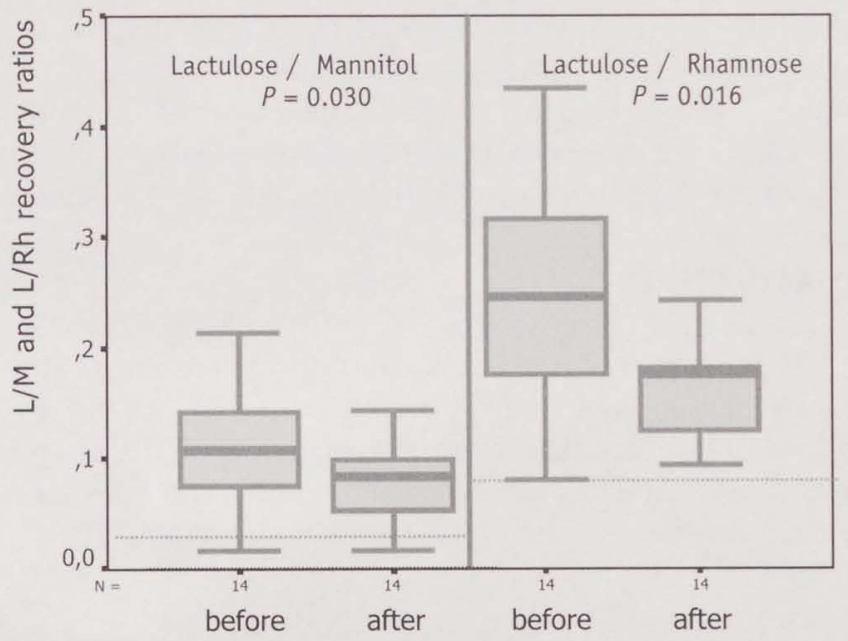

FIGURE 6.2. Box plots of urinary recovery ratios of large (lactulose) versus small sugars (mannitol and rhamnose) before and after 1-year treatment with a proton-pump inhibitor. Dotted lines are maximum of reference values. $P$ values were determined by Wilcoxon rank sum test. 
TABLE 6.4. Significancy of bivariate correlations of lansoprasole/body weight with lactulose recovery, $\mathrm{N} 0$ oxidation products/creatinine, $\mathrm{L} / \mathrm{M}$ and $\mathrm{L} / \mathrm{Rh}$ ratios

\begin{tabular}{lllll}
\hline $\begin{array}{l}\text { Lansoprazole/ } \\
\text { body weight }\end{array}$ & $\begin{array}{l}\text { NO oxidation products/ } \\
\text { creatinine }\end{array}$ & L/M ratio & L/Rh ratio & L recovery \\
\hline start & 0.608 & 0.805 & 0.454 & 0.655 \\
12 months & 0.244 & 0.961 & 0.782 & 0.308 \\
\hline
\end{tabular}

L, lactulose; M, mannitol; Rh, L-rhamnose

TABLE 6.5. Mean and Median values of the nitric oxide oxidation products-to-creatinine ratio $(\mathrm{mmol} / \mathrm{mmol})$ before and during 1 year use of lansoprazole

\begin{tabular}{lllllll}
\hline & Before & 3 months & 6 months & 9 months & 12 months & Controls \\
\hline Mean & 0.330 & 0.326 & 0.261 & 0.216 & 0.270 & 0.166 \\
Median & 0.287 & 0.232 & 0.235 & 0.233 & 0.252 & 0.130 \\
SD & 0.186 & 0.228 & 0.150 & 0.102 & 0.101 & 0.114 \\
P value * & & 0.470 & 0.594 & 0.019 & 0.140 & 0.002 \\
\hline
\end{tabular}

* Wilcoxon rank sum test compared to value at start

mean urinary recovery percentages changed from $3.22 \%$ to $2.08 \%$, from $25.16 \%$ to $25.62 \%$ and from $11.02 \%$ to $11.53 \%$ for lactulose, mannitol, and L-rhamnose, respectively. Lactulose recovery decreased by $35 \%$, from five times to three times the upper reference limit, but the decrease just failed to reach statistical significance ( $P$ $=0.064)$. The urinary excretion ratios decreased from 0.181 to $0.087(P=0.03)$ and from 0.294 to $0.175(P=0.016)$ for lactulose to mannitol and lactulose to L-rhamnose, respectively. Although both ratios decreased by half, they still were more than double the upper reference limit (Tables 6.2. +6.3. , figure 6.1. +6.2. ).

\section{FECAL ACID STEATOCRIT}

Fecal Acid Steatocrit decreased significantly from a mean of $33.3 \%( \pm 17.8 \%)$ at the start to $23.7 \%( \pm 11.0 \%)$ at 3 months $(P<0.01)$ and remained at that level thereafter, the mean value during treatment was $24.0 \%(9.8 \% ; P<0.05)$. Even when converted for body weight, no correlations were found between lactulose recovery, lactulose to mannitol and lactulose to L-rhamnose ratios and the mean fecal acid steatocrit, as an index for persisting fat losses, however (Table 6.4.).

\section{URINARY NITRIC OXIDE OXIDATION PRODUCTS}

Urinary nitric oxide oxidation products expressed as median (SD) NO oxidation products-to-creatinine ratio in CF patients was, at the start of PPI treatment, 0.287 $( \pm 0.186)$ whereas it was $0.130( \pm 0.114)$ for control participants $(P=0.002)$. There was a trend in decrease of the mean NO oxidation products- to-creatinine ratio during the treatment period, with $0.233( \pm 0.102)$ as the lowest value at 9 months $(P=0.019)$, which was still significantly increased compared to the healthy controls 
$(P=0.035)$. The value at the end, however, was increased again and was not different from start values (Table 6.5.).

\subsection{DISCUSSION}

In this open prospective study, we demonstrated that IP was dramatically increased in CF and more pronounced for the lactulose recovery. After the use of lansoprazole for 1 year, the 3-SPT only showed an improvement in the permeability of the large sugar, lactulose. Therefore both ratios lactulose-to-mannitol and lactulose-to-L-rhamnose ratios decreased significantly. During that year, the NO oxidation products-to-creatinine ratio tended to decrease, but was in the end not significantly different from start values. Furthermore, after the use of a PPI for 1 year in these same patients, the fecal acid steatocrit decreased and total body fat improved significantly $(P<0.05)$, whereas free fat mass remained unchanged. SD-scores of height and body weight showed a slight, but non significant, increase [23]. Because this study was performed with an open design in a small group of CF patients, the results should be interpreted cautiously. In the present study, we only tried to determine the change in increased IP before and after 1 year of PPI treatment. For ethical reasons, we did not check IP in the healthy control group, before and after 1 year of lansoprazole use. Although we do not expect that lansoprasole could improve IP by itself, we are not certain about this. Nevertheless we consider the observed improvement in IP likely to be linked to a decrease in luminal acidity.

Although it is well known that IP is increased dramatically in CF [1-7], the cause of this phenomenon is poorly understood. Van Elburg et al. [24] have shown the increased IP in CF to be linked to pancreatic insufficiency and not to the dose of pancreatic enzyme supplementation. However, IP in CF has been related to genotype, and therefore more basic defects[7]. We hypothesized that increased acidity, resulting from the CFTR-associated decreased bicarbonate secretion, might affect the small bowel mucosal integrity. Although our study was not placebo controlled, we could demonstrate after intervention with lansoprazole for 1 year a decrease in IP for the larger sugar lactulose only, whereas the recoveries of the smaller sugars remained unchanged. This contrast in effects leads to a significant decrease of lactulose-to-mannitol $(P=0.03)$ and laculose-to-L-rhamnose $(P=0.016)$ excretion ratios. According to the "pore theory", permeation takes place through paracellular pathways (large pores) and transcellular pathways (small pores) [25]. In the 3-SPT, the sugars permeate via different routes, L-rhamnose and mannitol predominantly transcellularly and lactulose as a large sugar only permeates paracellularly. Because in our patients only lactulose recovery improved, our results indicate in duplo that adjuvant therapy with PPI only affects the paracellular or "tight junctional" pathway. As to the cause of the increased IP in CF, it could be either primary or secondary. Primary tight junctional abnormalities at the level of the pancreas, ileum and trachea in CF patients have been reported previously [26]. A possible direct relation between 
the basic cellular $C F$ defect and the increased intestinal permeability and inflammation has recently been suggested $[27,28]$.

Low intestinal $\mathrm{pH}$ resulting from defective pancreatic bicarbonate secretion or II of any origin belongs to possible secondary causes of increased IP in CF. First, low intestinal $\mathrm{pH}$ either could damage tight junctions directly or be responsible for late opening of the enzyme coating in the small bowel, resulting in elevated luminal proteolytic activity, leading to tight junctional damage and increased IP. In both cases one would expect IP to decrease after use of a PPI, as shown by our results. The increased IP did not normalize probably because PPIs only slightly increase distal duodenal $\mathrm{pH}$, but do not normalize it $[9,10,29]$. Second, II of various origin such as gastroenteritis, inflammatory bowel diseases, and celiac disease, are known to be associated with increased IP and could be responsible for or could aggravate the increased IP in CF [30]. Although the bowel mucosal architecture is usually considered to be normal in patients with CF [31], mucosal inflammation has been shown to be present $[27,28]$. Like other researchers we showed that the urinary N0 oxidation products-to-creatinine ratio was increased in acute celiac disease [14,32]. Therefore we evaluated this marker of cytokine-induced increased NO synthesis by measuring urinary NO oxidation products in our CF patients. The NO oxidation products-to-creatinine ratio found in the CF patients proved to be significantly increased $(P=0.002)$, indicating that inflammation could be present. After use of a PPI for 1 year, this ratio tended to decrease, but this decrease at the end was not significantly different from start values. We checked for possible causes, such as infections, changes in compliance to therapy, increase in weight and diarrhea, that could not explain the observed variations in the NO oxidation products-to-creatinine ratios. Although regression to the mean could be responsible for the apparent variations in NO oxidation products-to-creatinine ratio, these variations could also reflect variations in inflammation at both intestinal and pulmonary levels [33]. Third, although IP improved, it did not normalize, which could reflect persisting II and elevated NO oxidation products-to-creatinine ratios. Fourth the possibility remains that $15 \mathrm{mg}$ lansoprazole daily for 1 year in children with CF is not sufficient to normalize intestinal permeability and inflammation, because it also did not normalize fat malabsorption [23]. Therefore our results do not allow any firm conclusions about the possible relationship between intestinal permeability and inflammation. Further studies are necessary to elucidate this point.

Finally, during the treatment year and in the years thereafter, patients did not report adverse events, such as diarrhoea, constipation, or colitis. No vitamin $B_{12}$ deficiency could be demonstrated, even after 3 years of use of PPI [34].

In conclusion, the use of a PPI as adjuvant therapy in children with CF resulted in improvement of fat malabsorption and IP, linked to a significant decrease of the paracellular permeability pathway only. Because PPI therapy was the only intervention, we consider the increased acidity of intestinal contents to be a likely cause of increased IP. The introduction of a PPI improved but did not normalize IP. We also could demonstrate a significant increase of urinary NO oxidation products-to-creatinine ratios, pointing to the presence of inflammation in our patients, possibly of intestinal origin. But because of lack of difference at the end point, we are 
not able to draw any conclusion about therapy with lansoprazole and a possible link between increased intestinal permeability and inflammation.

\subsection{REFERENCES}

1. Lederq-Foucart J, Forget PP, van Cutsem JL. Lactulose-rhamnose intestinal permeability in children with cystic fibrosis. J Pediatr Gastroenterol Nutr 1987;6:66-70.

2. Leclerq-Foucart J. et al. Intestinal permeability to [51Cr]EDTA in children with cystic fibrosis. J Pediatr Gastroenterol Nutr 1986;5:384-387.

3. Loyd-Still JD, Uhing MR, Arango V, Fusaro A, Kimura RE. The effect of intestinal permeability on pancreatic enzyme-induced enteropathy in the rat. J Pediatr Gastroenterol Nutr 1998;26:489-495.

4. Gregory PC. Gastrointestinal pH, motility/transit and permeability in cystic fibrosis. J Pediatr Gastroenterol Nutr 1996;23:513-523.

5. Mack DR, Flick JA, Durie PR, Rosenstein BJ, Ellis LE, Perman JA. Correlation of intestinal lactulose permeability with exocrine pancreatic dysfunction. I Pediatr 1992;120:696-701.

6. Murphy MS, Sheldon W, Brunetto A, Pearson AD, Laker MF, Eastham EJ, Nelson R. Active and passive sugar absorption in pancreatic insufficiency. $J$ Pediatr Gastroenterol Nutr 1989;8:189-194.

7. Hallberg K, Grzegorczyk A, Larson G, Strandvik B. Intestinal permeability in cystic fibrosis in relation to genotype. J Pediatr Gastroenterol Nutr 1997;25:290-295.

8. Shumaker H, Amlal H, Frizzell R, Utrich CD 2nd, Soleimani M. CFTR drives $\mathrm{Na}-\mathrm{nHCO}-3$ cotransport in pancreatic duct cells: a basis for defective $\mathrm{HCO}-3$ secretion in CF. Am J Physiol 1999;276:C16-25.

9. Heijerman HGM, Lamers CBHW, Bakker W. Omeprazole enhances the efficacy of pancreatin (pancrease) in CF. Ann Intern Med 1991;114;200-201.

10. Tran TMD, Van den Neucker AM, Hendriks JJE, Forget P, Forget PPh. Effects of a proton-pump inhibitor in CF. Acta Paediatr 1998;87:553-558.

11. Heijerman $H G$, Lamers CB, Bakker W, Dijkman JH. Improvement of fecal fat excretion after addition of omeprazole to pancrease in CF is related to residual exocrine function of the pancreas. Dig Dis Sci 1993; 38(1): 1-6.

12. Knauf RE, Adams JA. Duodenal fluid pH in CF. Clin Chem 1968;14:477-479.

13. Lenaerts $C$, Beraud N, Castaigne JP. Pancrease gastroresistance: in vitro evaluation op pH-determined dissolution.J Paediatr Gastroenterol Nutr 1988;7(suppl.1):S18-S21.

14. Straaten EA, Koster-Kamphuis L, Bovee-Oudenhoven IM, Meer van der R, Forget PPh. Increased urinary nitric oxidation products in children with active coeliac disease. Acta Paediatr 1999;88:528-531.

15. Steege ter J, Buurman W, Arends JW, Forget P. Presence of inducible nitric oxide synthethase, nitrotyrosine, CD68, and CD14 in the small intestine in celiac disease. Lab Invest 1997;77:29-36. 
16. Goodwin DC, Landino LM, Marnett LJ. Effects of nitric oxide and nitric oxide-derived species on prostaglandine endoperoxide synthase and prostaglandin biosynthesis. FASEB J 1999;13:1121-1136.

17. Miki K, Butler R, Moore D, Davidson G. Rapid and simultaneous quantification of rhamnose, mannitol and lactulose in urine by HPLC for estimating IP in pediatric practice. Clin Chem 1996;42:71-75.

18. Elburg van RM, Uil JJ, Kokke FTM, Mulder AM, Broek van de WGM, Mulder ChJ, Heymans HSA. Repeatability of the sugar-absorption test, using lactulose and mannitol, for measuring intestinal permeability for sugars. J Pediatr Gastroenterol Nutr 1995;20:184-188.

19. Tsikas D, Fuchs I, Gutzki FM, Frolich JC. Measurement of nitrite and nitrate in plasma, serum and urine by HPLC, the Griess assay, chemiluminescense and gas chromatography- mass spectrometry: interference by biogenic amines and $N(G)$-nitro-L-arginine analogs. J Chromatogr B Biomed Sci Appl 1998;715:441-444.

20. Tran TMD, Forget PPh, Van den Neucker AM, Strik J, Kreel van B and Kuijten RH. The acid steatocrit: a much improved method. J Pediatr Gastroenterol Nutr 1994;19:299-303.

21. Van den Neucker AM, Forget PPh, Veneberg JA, Schutten BJ and Kreel van B. Acid Steatocrit during infancy. Acta Paediatr 1996;85:1153-1155.

22. Van den Neucker AM, Pestel N, Tran TMD, Forget PPh, Veeze HJ, Bouquet J and Sinaasappel M. Clinical use of acid steatocrit. Acta Paediatr 1997;86:466-469.

23. Hendriks JJE, Kester ADM, Donckerwolcke R, Forget PPh, and Wouters EFM. Changes in pulmonary hyperinflation and bronchial hyperresponsiveness in children with cystic fibrosis during treatment with lansoprazole. Ped.Pulmon. 2001;31:59-66.

24. Elburg van RM, Uil JJ, Aalderen van WMC, Mulder ChJJ, Heymans HSA. Intestinal permeability in exocrine pancreatic insufficiency due to cystic fibrosis or chronic pancreatitis. Pediatr Res 1996;39:985-991.

25. Travis S, Menzies I. Intestinal permeability: functional assessment and significance. Clin Sci 1992;82:471-788.

26. Gosden CM, Gosden JR. Fetal abnormalities in CF suggest a deficiency in proteolysis of cholecystokinin. The Lancet 1984;Sep.8:541-546.

27. Smyth RL, Croft NM, O'Hea U, Marshall TG. Intestinal inflammation in CF. Arch Dis Child 2000; 82: 394-399.

28. Raia V, Maiuri L, De Ritis G, De Vizia B, Vacca L, Conte R, Auricchio S and Londei M. Evidence of chronic inflammation in morphologically normal small intestine of $\mathrm{CF}$ patients. Pediatr Res 2000; 47: 344-350.

29. Barraclough M, Taylor CJ. Twenty-four hour ambulatory gastric and duodenal pH profiles in cystic fibrosis: effect of duodenal hyperacidity on pancreatic enzyme function and fat absorption. J Pediatr Gastroenterol Nutr 1996;23:45-50.

30. Miki K, Moore DJ, Butler RN, Southcott E, Couper RTL, Davidson GP. The sugar permeability test reflects disease activity in children and adolescents with inflammatory bowel disease. J Pediatr 1998;133:750-754. 
31. Sbarbati A, Bertini M, Catassi C, Gagliardini R, Osculati F. Ultrastructural lesions in the small bowel of patients with CF. Pediatr Res 1998;43:234-239.

32. Sundqvist T, Laurin P, Falth-Magnusson K, Magnusson KE, Stenhammar L. Significantly increased levels of nitric oxide products in urine of children with celiac disease. $J$ Pediatr Gastroenterol Nutr 1998;27:196-198.

33. Khan TZ, Wagener JS, Bost T et al. Early pulmonary inflammation in infants with CF. Am J Resp Crit Care Med 1995;151:1075-82.

34. Heide ter H, Hendriks JJE, Heijmans H, Menheere PCA, Spaapen LJM, Bakker JA, Forget PP. Are children with CF who are treated with a proton-pump inhibitor at risk for vitamin B12 deficiency? J Pediatr Gastroenterol Nutr 2001;33:342-345. 



\section{CHAPTER SEVEN}

\section{Fatty acid status of plasma and red blood cells phospholipids in Cystic Fibrosis patients treated with and without lansoprazole}

Han Hendriks ${ }^{1}$, Arno Brouwers ${ }^{1}$, Adriana van Houwelingen ${ }^{2}$, Hiltje Heijmans ${ }^{1}$, Henriette ter Heide ${ }^{1}$, Anita Van den Neucker ${ }^{1}$, Arnold Kester $^{3}$, Gerard Hornstra ${ }^{4}$, and Philippe Forget ${ }^{1}$

Departments of Paediatrics ${ }^{1}$, Human Biology ${ }^{2}$, Methodology \& Statistics ${ }^{3}$ and Nutrition and Toxicology Research Institute Maastricht", University Hospital \& University of Maastricht, the Netherlands.

Submitted

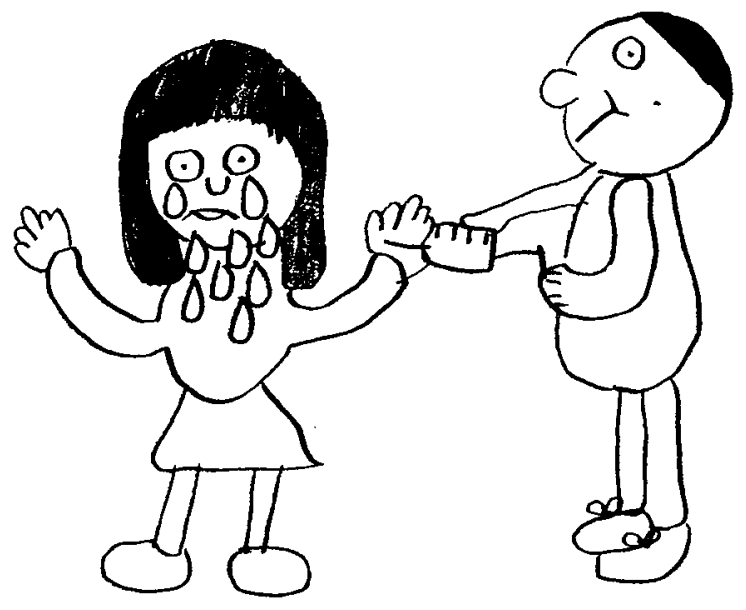




\subsection{ABSTRACT}

Background: In a former study on the additional effect of a proton pump inhibitor (PPI) in Cystic Fibrosis (CF) patients, we were able to demonstrate an improvement in fat absorption.

Objective: The present study was performed to assess the (essential) fatty acid $((E) F A)$ composition of plasma and red blood cells (RBC) phospholipids ( $\mathrm{PL}$ ) in patients with CF. Secondly the effect of longterm treatment with a PPI on the FA status was examined.

Design: This descriptive study compares in a cross-sectional design, $11 \mathrm{CF}$ patients who used lansoprazole ( $15 \mathrm{mg} /$ day) for 3 years (PPI+ group), $9 \mathrm{CF}$ patients on the standard regime (PPI- group) and 10 healthy controls. There was no baseline investigation prior to PPI treatment. Student- $t$ test was used for comparisons of FA results between the 3 groups.

Results: Mean plasma docosahexaenoic acid (DHA) concentrations in the PPIgroup $(14 \mathrm{mg} / \mathrm{L})$ and in the PPI+ group $(21 \mathrm{mg} / \mathrm{L})$, were significantly decreased $(P=0.001$ resp. $P<0.05)$ compared to controls $(33 \mathrm{mg} / \mathrm{L})$. The difference between the two CF groups was significant also $(P<0.05)$. Arachidonic acid (AA)/DHA and mead acid/AA ratios were significantly increased in the PPIgroup $(P<0.01)$. In RBC only the FA status linolenic acid was decreased and eicosatrienoic acid increased, while DHA and AA levels were normal.

Conclusion: Our CF patients showed biochemical signs of EFA deficiency mainly in plasma PL. Although the EFA status of patients receiving a PPI, showed a trend towards normalization, the only significant difference between the two CF groups consisted in a higher plasma DHA level in the PPI+ group. Our results suggest some role for fat malabsorption in the different EFA status of CF patients. 


\subsection{INTRODUCTION}

Cystic Fibrosis (CF) is an autosomal recessive inherited disorder, characterised by a defect in the chloride transport regulating channel at the luminal side of exocrine cells, the cystic fibrosis transmembranous conductance regulator protein (CFTR). One of the most serious consequences in CF patients of this defect is pancreatic insufficiency, which induces malabsorption, especially for fat. This pancreatic insufficiency is only partially corrected by exogenous pancreatic enzymes [1]. The malabsorption in CF enhances the poor nutritional status seen in these patients [2]. Fat nutritional status can be biochemically assessed, for instance by analysing fatty acid (FA) profiles [3]. Several studies have shown the presence of an essential fatty acid (EFA) deficiency or shortage in CF patients [3-7]. However, controversy exists about the origin of this EFA shortage [8-13]. A few reports have been published on the lower EFA status of red blood cell phospholipids (RBCPL)[14-16]. A complete FA profile of RBCPL in CF has not yet been documented in complete detail. Recent studies demonstrated that, in a CFTR knockout mice model, lipid membranes of CF affected organs, such as ileum, pancreas, and lung, show a profound decrease of docosahexaenoic acid (DHA, 22:6n-3) and an increase of arachidonic acid (AA, 20:4n-6). These abnormalities could be reversed by oral administration of DHA $[17,18]$.

Although even in patients with a normal EFA status lung disease will develop, it has been postulated that an EFA shortage could be a predisposing factor for lung disease in CF patients $[19,20]$. An improvement of the nutritional status with optimized EFA status could lead to a decrease of inflammation and an improvement of lung function. In two earlier, studies we have shown that lansoprazole, a proton pump inhibitor (PPI), used as adjuvant therapy, significantly improved both steatorrhea and the nutritional status of CF patients while at the same time lung hyperinflation decreased in those patients with a mean age of 10 years $[21,20]$. The effect of a PPI on the EFA status of CF patients has not been reported so far. The present study was performed primarily to assess the detailed FA composition of plasma and RBCPL in CF patients. In addition, the EFA status of CF patients using a PPI for 3 years was compared to that of CF patients without a PPI and that of control subjects.

\subsection{SUBJECTS}

Twenty CF patients from our out-patient clinic were studied. All patients had the diagnosis confirmed by sweat chloride testing (Chloride more than $60 \mathrm{mmol} / \mathrm{l}$ ) and a persistent steatorrhea which required regular pancreatic enzyme replacement therapy. Eleven of these patients (PPI+ group, 6 males) were recruited earlier for a one-year study evaluating the effects of a PPI on fat malabsorption and body composition. The selection criteria for that study consisted of persisting steatorrhea, a forced expiratory volume in 1 second $\left(\mathrm{FEV}_{1}\right)$ of more than $70 \%$ of predicted, and stable CF disease [22]. The observed improvement was the reason for continuing the PPI therapy. They received lansoprazole treatment in a dose of $15 \mathrm{mg} /$ day for at least 3 
years as adjuvant treatment to the standard regime consisting of exogenous pancreas enzyme replacement therapy, an energy and fat enriched diet, vitamins $A, D, E$ and $K$ supplements, and nebulization of mucolytics and chest physiotherapy. The mean age of this group at the start of lansoprazole therapy was 8.3 years (range: $5.3-14.0$ ) and at the time of FA analysis 11.7 years (8.5-17.4). In this group DNA-analysis had taken place in four patients. Three patients were homozygous for the $\triangle F 508$ mutation. One subject had a $\Delta$ F508/N1303K mutation. The remaining 9 patients (PPI- group, 4 males) received standard treatment as described above. In this group the mean age at the time of FA analysis was 8.2 years (1.8-12.3). DNA-analysis were performed in seven out of these nine patients. Four patients were homozygous for the $\Delta F 508$ mutation. The other 3 patients were heterozygous for $\Delta \mathrm{F} 508$.

All patients were screened for fat malabsorption at the start of the study by measuring faecal acid steatocrit values [23]. Our upper range of normal for acid steatocrit is $20 \%$. In the PPI+ group the mean steatocrit value before PPI treatment was $41.7 \%$ (range: $22.4-65.7 \%$ ) after 3 years, at the time of sampling for FA analysis, the acid steatocrit was significantly decreased to a mean of $28.6 \%( \pm 12.2 \%)$. The PPI- group had a mean steatocrit value of $32.6 \%$ (range: $7.9-67.2 \%$ ). The difference in mean steatocrit values between the two CF groups was not significant. In the PPI+ group 2 patients suffered from a meconium ileus at birth whereas this was the case for 3 patients in the PPIgroup.

The two CF groups described above were compared with a healthy control group consisting of ten preoperative surgical patients (6 males), not suffering from any inflammatory, infectious, digestive or nutritional disease. The mean age of the control group at FA analysis was 9.2 years (3.3-16.2).

Informed consent was obtained from all the parents and from children older than 11 years, before onset of the study. The study protocol was approved by the medical ethical committy of the university hospital of Maastricht.

\subsection{METHODS}

The fatty acid profiles were determined in plasma and RBCPL as previously described [24]. Briefly, lipid extracts were prepared from both plasma and RBC samples, and the phospholipid fraction separated using aminopropyl-BondElut cartridges [9]. The phospholipid FA were hydrolyzed and transmethylated with boron trifluoride in methanol. The composition of the obtained FA methylesters was determined by capillary gas chromatography using a polar column (50 m x $0.25 \mathrm{~mm}$ CPSil 88; Chrompack, Middelburg, the Netherlands), with helium as carrier gas, pressure $130 \mathrm{kPa}$. Both the injection and the detector temperatures were $300^{\circ} \mathrm{C}$. The starting temperature of the column was $160^{\circ} \mathrm{C}$. After $10 \mathrm{~min}$, the temperature increased to $190^{\circ} \mathrm{C}$ with a rate of $3.2^{\circ} \mathrm{C} / \mathrm{min}$. Subsequently, after $15 \mathrm{~min}$, the temperature was further increased to $230^{\circ} \mathrm{C}$ with a rate of $5^{\circ} \mathrm{C} / \mathrm{min}$. The amount of each fatty acid was quantified by the amount recovered of the internal standard (dinonadecanoyl [19:0]-phosphatidylcholine) added to each sample. 


\subsection{STATISTICAL ANALYSIS}

Statiscal analysis of the relative data (expressed as \% of total amount of FA) and the absolute data were not different. Because of the debate whether or not absolute numbers expresses better real life necessity of EFA, we presented them both. In the tables FA composition of plasma and RBCPL are presented as absolute values in $\mathrm{mg} / \mathrm{L}$ (mean SD). Relative concentrations are shown in figure 2, while in figure 3 box plots with medians and quartiles of the absolute concentrations of DHA are presented. Because the FA data distribution did not depart from normality, the separate variances Student t-test was used for comparisons between groups (alpha=0.05, 2-sided). For statistical analysis the SPSS package for windows (version 10.0) was used.

\subsection{RESULTS}

\section{PLASMA PHOSPHOLIPIDS}

FA concentrations of plasma phospholipids (PLPL) of the PPI+ group, the PPIgroup and the control group are shown in table 7.1. and summarised in figure 7.1. In the PPI- group the total FA concentration of PLPL was slightly but significantly $(P<0.05)$ lower compared to the concentrations found in the PPI+ and control groups. As table 1 shows, most items of the FA phospholipids (for PPI- group 14/24, for PPI+ group 6/24) were significantly different from our control results.

PPI- group: Besides the total FA, mean concentrations of palmitic (16:0), linoleic $(18: 2 n-6)$, docosapentaenoic $(22: 5 n-3)$ and docosahexaenoic acid $(22: 6 n-3)$ in PLPL of the PPI- group were lower compared to control subjects. On the other hand, mean concentrations of eicosatrienoic or mead acid $(20: 3 n-9)$ and $\gamma$-linolenic acid $(18: 3 n-6)$ were higher in the PPI- group compared to the control group. We also calculated the sum and ratios of different FA. These results are also shown in table 7.1. The sums of both n-3 and n-6 FA in PLPL were significantly lower, while the long chain polyunsaturated (lcp) n-9 FA was significantly higher in the PPI- group compared to control subjects. Furthermore, significantly lower amounts of saturated FA (SFA) and polyunsaturated FA (PUFA) were observed of PLPL of the PPI- group. The ratio of 20:3n-9/20:4n-6, which is a generally accepted marker for EFA shortage [25], showed to be higher in PLPL of the PPI- group compared to control subjects but the critical value for EFA shortage ( $>0.2$ ) was not reached (figure 7.2 .). The ratio $20: 4 n-6 / 22: 6 n-3$ was also significantly higher.

PPI+ group: In contrast to the results of the PPI- group, the results of the PPI+ group were less different in comparison to the control group. No significant differences were found for mean concentrations of 16:0, 18:2n-6, 20:3n-9, total n-6, total n-9lcp, SFA, PUFA and total FA in PLPL. When compared to concentrations of our control group, the mean concentrations of $18: 3 n-6,22: 5 n-3,22: 6 n-3$, total $n-3$, and the ratios $20: 3 n-9 / 20: 4 n-6$ and $20: 4 n-6 / 22: 6 n-3$ in PLPL were slightly but significantly different, with values between those of the control and the PPI- group. 


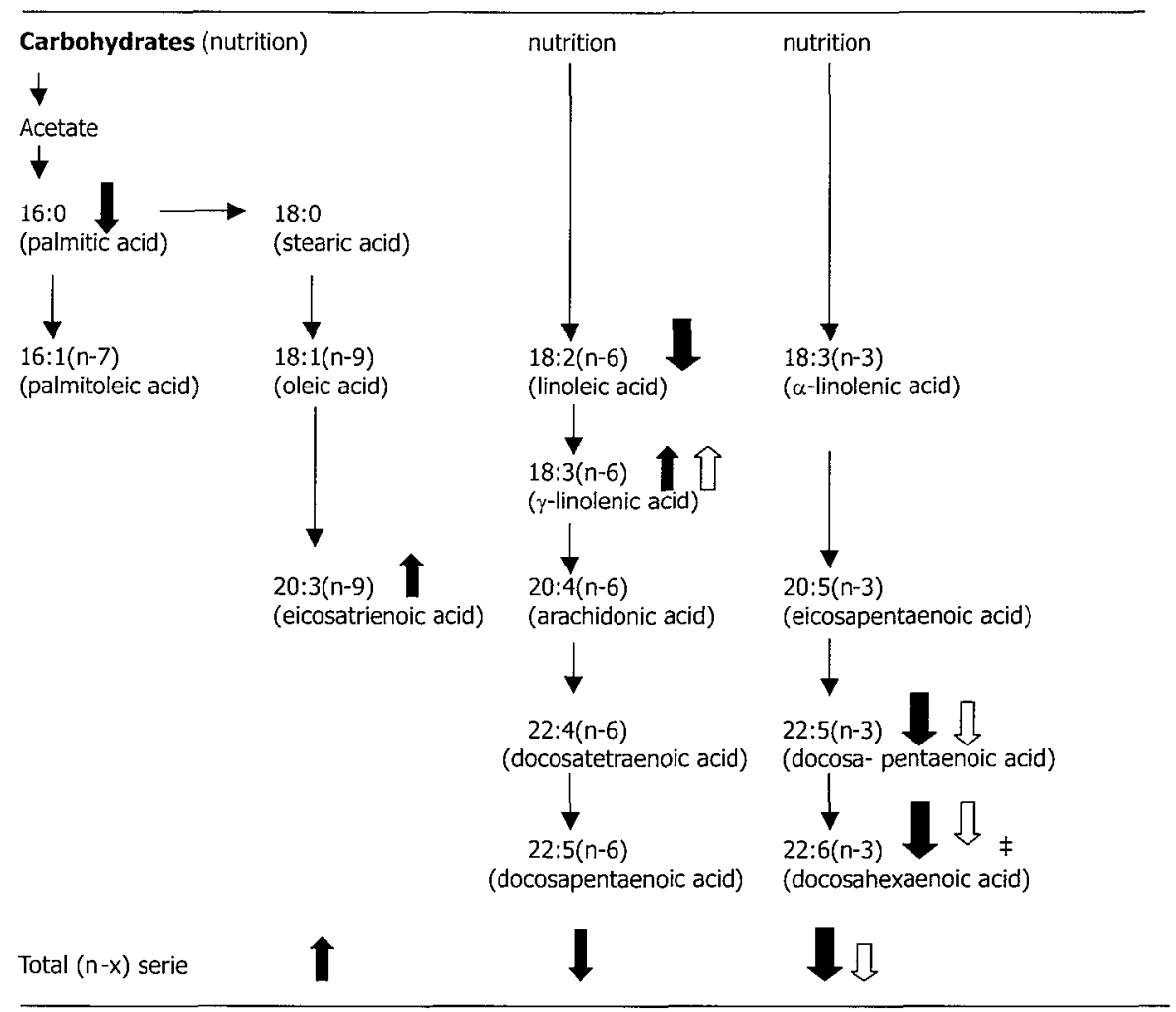

FIGURE 7.1. Schematic view of fatty acid synthesis, showing different findings in plasma phospholipid fatty acids (FA). Black arrows indicate significant changes of FA concentrations in CF patients treated without lansoprazole (PPI-) compared to control subjects. White arrows indicate significant changes of FA concentrations in CF patients treated with lansoprazole (PPI+) compared to control subjects. The significance of differences with the control group are shown by small arrows $(P<0.05)$ and large arrows $(P<0.01)$. Differences between the two CF groups is shown by $\ddagger(P<0.05)$. All data are computed by student t-test.

No differences between the three investigated groups were found in mean concentrations of $16: 1 n-7,18: 0,18: 1 n-9,18: 3 n-3,20: 3 n-6,20: 4 n-6,20: 5 n-3,22: 4 n-6$, 22:5n-6, and MUFA.

When comparing the PPI+ group to the PPI-group only the DHA and AA/DHA proved to be significantly different $(P<0.05)$, while the mead acid/AA ratio, as a marker of EFA deficiency, was not significantly different (table 7.1. and figure 7.2.+7.3.).

\section{RED BLOOD CELL PHOSPHOLIPIDS}

Results of FA analysis of RBCPL are shown in table 7.2. In RBC, FA compositions were less abnormal when compared to plasma findings in both investigated CF groups. Most of the results of the PPI+ group were in between those of the PPI- group 


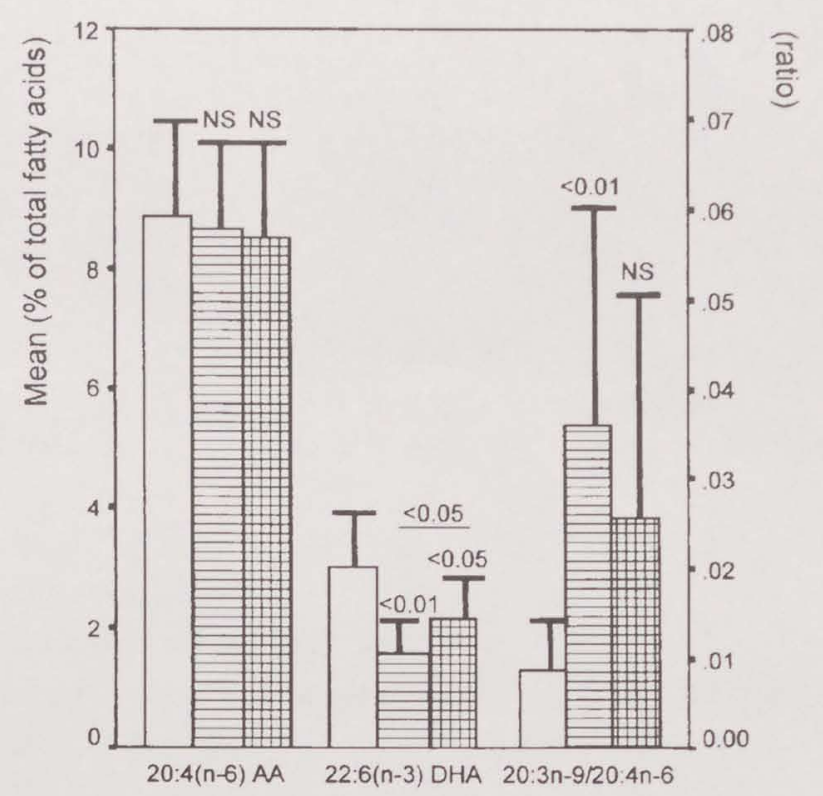

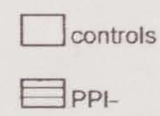

曲冊PPI+

FIGURE 7.2. Mean (+SD) relative plasma: levels of arachidonic acid (AA), docosahexaenoic acid (DHA) and mead acid / arachidonic acid ratio, in CF patients without (PPI-) and with (PPI+) proton pump inhibitor treatment compared to healthy controls. Statistics: both CF groups compared to controls by student t-test. (NS: not significant)

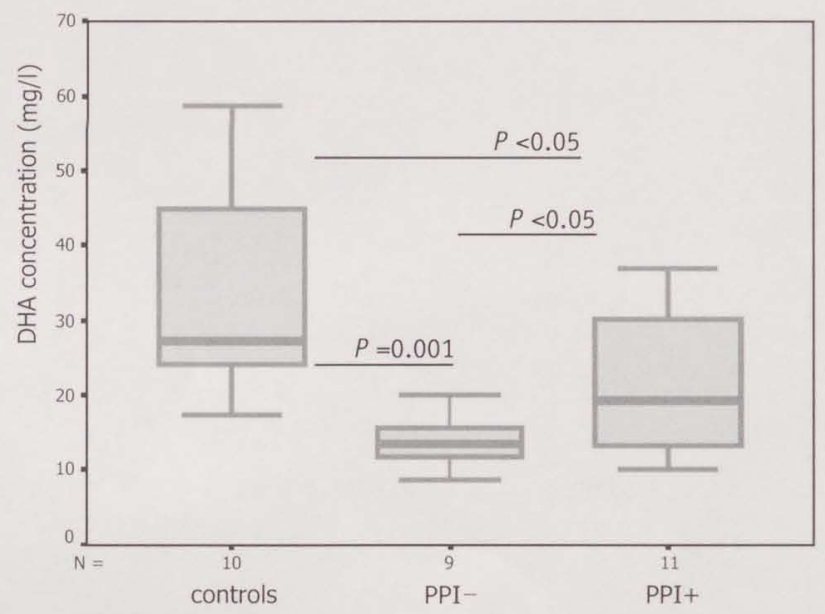

FIGURE 7.3. Box plots in medians and quartiles of absolute docosahexaenoic acid (DHA) concentrations in plasma, in CF patients without PPI (PPI-), with PPI (PPI+) and in healthy controls. Statistics of parametric (Student $t$-test) $=$ non parametric (Wilcoxon) test. 
TABLE 7.1. Mean absolute concentrations ( \pm SD) of Fatty Acids in plasma phospholipids (mg/L)

\begin{tabular}{|c|c|c|c|c|c|c|}
\hline \multirow{3}{*}{$\begin{array}{l}\text { Fatty Acids } \\
\text { Total FA }\end{array}$} & \multirow{2}{*}{\multicolumn{2}{|c|}{$\begin{array}{l}\text { Control subjects } \\
(n=10)\end{array}$}} & \multirow{2}{*}{\multicolumn{2}{|c|}{$\begin{array}{l}\text { CF patients without } \\
\text { lansoprazole (PPI-) } \\
(n=9)\end{array}$}} & \multirow{2}{*}{\multicolumn{2}{|c|}{$\begin{array}{l}\text { CF patients with } \\
\text { lansoprazole }(P P I+) \\
(n=11)\end{array}$}} \\
\hline & & & & & & \\
\hline & 1080.1 & (187.4) & 880.4 & $(154.6)^{3}$ & 971.8 & (283.7) \\
\hline $16: 0$ & 283.6 & $(70.1)$ & 213.6 & $(41.9)^{3}$ & 258.0 & $(98.3)$ \\
\hline $18: 0$ & 146.6 & $(21.4)$ & 134.6 & $(19.7)$ & 132.1 & $(24.2)$ \\
\hline Total SFA ${ }^{1}$ & 482.4 & $(90.8)$ & 383.7 & $(64.9)^{3}$ & 427.8 & (123.9) \\
\hline $16: 1 n-7$ & 4.3 & $(1.5)$ & 5.5 & $(2.6)$ & 6.5 & $(4.1)$ \\
\hline $18: 1 n-9$ & 94.4 & $(19.2)$ & 95.9 & $(25.2)$ & 99.6 & $(39.8)$ \\
\hline $20: 3 n-9$ & 0.9 & $(0.6)$ & 2.6 & $(1.9)^{3}$ & 1.9 & $(2.0)$ \\
\hline Total n-9 $\operatorname{lcp}{ }^{\dagger}$ & 1.6 & $(0.7)$ & 3.7 & $(2.3)^{3}$ & 2.8 & $(2.5)$ \\
\hline $18: 2 n-6$ & 234.7 & $(41.5)$ & 183.4 & $(32.9)^{2}$ & 202.1 & $(71.9)$ \\
\hline $18: 3 n-6$ & 0.6 & $(0.4)$ & 1.5 & $(1.1)^{3}$ & 1.2 & $(0.6)^{2}$ \\
\hline $20: 3 n-6$ & 34.3 & (8.1) & 37.0 & $(11.6)$ & 41.5 & $(19.4)$ \\
\hline $20: 4 n-6$ & 95.8 & $(23.4)$ & 76.6 & $(20.0)$ & 81.1 & $(21.6)$ \\
\hline $22: 4 n-6$ & 4.1 & $(0.7)$ & 4.0 & $(1.4)$ & 3.4 & $(0.7)$ \\
\hline $22: 5 n-6$ & 2.7 & $(1.0)$ & 2.6 & $(1.3)$ & 2.6 & $(1.3)$ \\
\hline Total n-6 & 377.7 & $(63.8)$ & 310.0 & $(53.2)^{3}$ & 337.9 & $(105.5)$ \\
\hline $18: 3 n-3$ & 1.7 & $(0.6)$ & 1.7 & $(1.0)$ & 1.9 & $(1.1)$ \\
\hline $20: 5 n-3$ & 5.7 & $(5.4)$ & 4.1 & $(2.2)$ & 4.3 & $(1.9)$ \\
\hline $22: 5 n-3$ & 9.2 & $(2.1)$ & 5.9 & $(2.0)^{2}$ & 6.6 & $(2.7)^{3}$ \\
\hline $22: 6 n-3$ & 32.9 & $(13.2)$ & 13.8 & $(3.5)^{2, *}$ & 21.4 & $(9.7)^{3, *}$ \\
\hline Total n-3 & 50.7 & $(17.8)$ & 26.5 & $(8.0)^{2}$ & 35.1 & $(12.8)^{3}$ \\
\hline Total MUFA ${ }^{1}$ & 138.6 & $(26.9)$ & 133.3 & $(32.0)$ & 144.9 & $(53.3)$ \\
\hline Total PUFA ${ }^{1}$ & 430.0 & $(75.2)$ & 340.2 & $(60.6)^{3}$ & 375.9 & (114.9) \\
\hline $20: 3 n-9 / 20: 4 n-6$ & 0.009 & $(0.005)$ & 0.036 & $(0.025)^{2}$ & 0.026 & $(0.026)^{3}$ \\
\hline $20: 4 n-6 / 22: 6 n-3$ & 3.1 & $(0.8)$ & 5.7 & $(1.6)^{1, *}$ & 4.2 & $(1.1)^{3, \star}$ \\
\hline $22: 5 n-6 / 22: 4 n-6$ & 0.65 & $(0.15)$ & 0.64 & $(0.22)$ & 0.74 & $(0.25)$ \\
\hline $22: 6 n-3 / 22: 5 n-6$ & 14.3 & $(8.7)$ & 7.9 & $(8.2)$ & 8.8 & $(4.1)$ \\
\hline
\end{tabular}

$\dagger$ lcp: long chain polyunsaturated FA; SFA: saturated FA; MUFA: monounsaturated FA; PUFA: polyunsaturated FA.

${ }_{1-3}$ Differences versus control subjects (student-t: $1 P<0.001,2 P<0.01,3 P<0.05$ ).

* Differences between the two CF groups (student-t: $P<0.05$ ). 
TABLE 7.2. Mean absolute concentrations $( \pm \mathrm{SD}$ ) of Fatty Acids in red blood cell phospholipids (mg/L)

\begin{tabular}{|c|c|c|c|c|c|c|}
\hline \multirow{2}{*}{$\begin{array}{l}\text { Fatty Acid } \\
\text { Total FA }\end{array}$} & \multicolumn{2}{|c|}{$\begin{array}{l}\text { Control subjects } \\
(n=10)\end{array}$} & \multicolumn{2}{|c|}{$\begin{array}{l}\text { CF patients without } \\
\text { lansoprazole (PPI-) } \\
(n=9)\end{array}$} & \multicolumn{2}{|c|}{$\begin{array}{l}\text { CF patients with } \\
\text { lansoprazole (PPI+) } \\
(n=11)\end{array}$} \\
\hline & 1107.8 & $(160.5)$ & 1098.5 & $(89.6)$ & 1069.8 & (152.9) \\
\hline $16: 0$ & 248.5 & $(34.2)$ & 249.3 & $(21.9)$ & 256.4 & $(38.2)$ \\
\hline 18:0 & 97.4 & $(14.8)$ & 94.2 & $(8.7)$ & 83.8 & (15.3) \\
\hline Total SFAs ${ }^{\dagger}$ & 443.2 & $(62.7)$ & 432.0 & $(34.5)$ & 424.6 & $(60.0)$ \\
\hline $16: 1 n-7$ & 3.1 & $(1.1)$ & 4.6 & $(1.6)^{3}$ & 4.8 & $(2.0)^{3}$ \\
\hline $18: 1 n-9$ & 139.6 & $(27.0)$ & 143.6 & $(23.3)$ & 140.1 & $(26.0)$ \\
\hline $20: 3 n-9$ & 0.3 & $(0.3)$ & 1.2 & $(0.7)^{2}$ & 0.7 & $(0.5)^{3}$ \\
\hline Total n-9 lcp ${ }^{\dagger}$ & 0.8 & $(0.3)$ & 1.8 & $(0.8)^{2}$ & 1.2 & $(0.7)$ \\
\hline $18: 2 n-6$ & 129.9 & $(23.4)$ & 110.0 & $(14.2)^{3}$ & 113.8 & $(26.4)$ \\
\hline $18: 3 n-6$ & 0.5 & $(0.4)$ & 0.7 & $(0.3)$ & 0.6 & $(0.3)$ \\
\hline $20: 3 n-6$ & 16.3 & $(4.1)$ & 20.9 & (7.3) & 19.6 & (5.3) \\
\hline $20: 4 n-6$ & 116.4 & $(15.2)$ & 120.7 & (9.1) & 112.1 & (19.1) \\
\hline $22: 4 n-6$ & 30.6 & $(5.5)$ & 32.6 & $(6.3)$ & 27.8 & $(7.2)$ \\
\hline $22: 5 n-6$ & 3.5 & $(1.0)$ & 4.9 & (1.6) & 3.8 & $(1.0)$ \\
\hline Total n-6 & 307.2 & $(42.1)$ & 301.8 & (25.1) & 289.8 & $(46.7)$ \\
\hline $18: 3 n-3$ & 1.4 & $(0.6)$ & 1.4 & $(0.8)$ & 1.3 & $(0.5)$ \\
\hline $20: 5 n-3$ & 3.3 & $(1.5)$ & 3.8 & $(0.9)$ & 3.8 & (1.5) \\
\hline $22: 5 n-3$ & 17.6 & $(3.0)$ & 17.4 & $(2.4)$ & 16.5 & (5.1) \\
\hline $22: 6 n-3$ & 27.7 & $(8.1)$ & 22.2 & (3.9) & 23.6 & $(6.7)$ \\
\hline Total $n-3$ & 50.4 & $(11.1)$ & 45.5 & $(5.5)$ & 45.6 & $(9.1)$ \\
\hline Total MUFAs ${ }^{\dagger}$ & 206.7 & $(38.2)$ & 224.2 & $(43.6)$ & 215.4 & $(42.5)$ \\
\hline Total PUFAs ${ }^{\dagger}$ & 358.3 & $(48.7)$ & 349.1 & $(26.6)$ & 336.6 & $(49.8)$ \\
\hline $20: 3 n-9 / 20: 4 n-6$ & 0.002 & $(0.002)$ & 0.010 & $(0.006)^{2}$ & 0.006 & $(0.005)^{3}$ \\
\hline $20: 4 n-6 / 22: 6 n-3$ & 4.5 & $(1.1)$ & 5.6 & $(1.1)$ & 5.1 & (1.4) \\
\hline $22: 5 n-6 / 22: 4 n-6$ & 0.12 & $(0.03)$ & 0.16 & $(0.05)$ & 0.14 & $(0.05)$ \\
\hline $22: 6 n-3 / 22: 5 n-6$ & 8.9 & $(4.6)$ & 5.1 & $(2.2)$ & 6.5 & $(2.6)$ \\
\hline
\end{tabular}

$\dagger$ lcp: long chain polyunsaturated FA; SFA,: saturated FA; MUFA: monounsaturated FA; PUFA: polyunsaturated FA.

${ }^{1-3}$ Differences versus control subjects: ${ }^{1} P<0.001,{ }^{2} P<0.01,{ }^{3} P<0.05$. 
and the control group. The total RBCPL FA concentration did not differ between the 3 groups.

PPI-group: In RBCPL of the PPI- group a lower concentration of 18:2n-6 was observed. On the other hand, these CF patients showed higher amounts of $16: 1 n-7,20: 3 n-9$ and $n-9 l c p$ FA in RBCPL when compared to control subjects. Further, a higher ratio of 20:3n-9/20:4n-6 was found in RBCPL in the PPI- group.

$P P I+$ group: In the PPI+ group no difference was seen in the concentrations of $18: 2 n-6$ and $n-9$ cp compared to the control group. Only the concentrations of $16: 1 n-7,20: 3 n-9$ and the ratio of $20: 3 n-9 / 20: 4 n-6$ were slightly higher in the PPI+ group when compared to the control group.

When comparing the PPI+ group to the PPI- group no significant differences were observed, neither for separate FA, nor for the various ratios.

\subsection{DISCUSSION}

In agreement with other studies [3-7], our data show a different FA profile in both plasma and RBCPL in CF patients who received the standard treatment. Although the design of the study was not adequate to compare the results of addition of a PPI for 3 years to the standard treatment, the results showed a trend towards normalisation in the PPI+ group for most FA, especially in plasma.

The evidence for an EFA shortage in our PPI- group consists of a higher concentration of 20:3n-9 (mead acid) and the 20:3n-9/20:4n-6 ratio, and lower 18:2n-6, 22:5n-3, 22:6n-3 (DHA), total n-6 FA and total n-3 FA concentrations in PLPL. Although most of our results are in good agreement with data from the literature, some differences were seen. In contrast with our results, a decrease in 20:4n-6 (AA) was demonstrated by Benabdeslam et al [3] in plasma and by Biggemann et al [15] in RBC. Like Biggeman and Freedman $[18,19]$, we could demonstrate a very significantly lowered DHA, especially in the PPI- group ( $P=0.001)$. Moreover, despite a significantly lower plasma DHA in the $\mathrm{PPI}+$ group, compared to the control group, DHA was significantly higher than in the PPI- group $(P<0.05$; see table 7.1. and 7.2., figure 7.1.-7.3.). It is also important to notice that 20:3n-9, a marker of EFA deficiency, was significantly higher in the PPIgroup, both in plasma as well as in RBC. Hubbard et al. [16] also found an increase of 20:3n-9 in RBCPL in pancreatic insufficient but not in pancreatic sufficient CF patients. The FA patterns in plasma and RBC are reasonably comparable to the results of healthy controls, and are suggestive of an EFA shortage. In our PPI+ group, the EFA status remained slightly disturbed, although evidently less than that of the PPI- group. The wide range of concentrations and the small number of patients could be responsible for the fact that the differences in EFA, found between both CF groups, only rarely reached statistical significance.

The less optimal EFA status, observed especially in the PPI- group, is probably due to various causes. The most frequently postulated mechanism is that EFA shortage is secondary to malabsorption of dietary fat due to pancreatic insufficiency [8]. Increased FA oxidation due to elevated energy requirements in CF patients is a plau- 
sible alternative [12]. The EFA shortage could also be explained by a defect in FA metabolism [9], peroxysomal dysfunction [13] or increased lipid turnover in cell membranes [10]. It also has been shown to increase eicosanoid production [11]. Recently it has been suggested that the CFTR itself might play a role in membrane phospholipids differences in ileum, pancreas and lung, organs typically affected in CF. In these studies oral administration of DHA in CF knockout mice reversed these lipid differences $[17,18]$. Differences in EFA status between the PPI- and PPI+ group could be explained in various ways. Lloyd-Still et al [20] showed EFA deficiency to be more pronounced in CF patients who had a meconium ileus at birth. We looked for this confounder and found a similar incidence of meconium ileus in both investigated CF groups, which excludes this potential explanation. Alternatively, it could be explained by a difference in CF pheno- or genotypes between the PPI- and PPI+ group. Unfortunately the genotype was only be determined in about half of our studied CF patients.

Although we should be cautious in drawing definitive conclusions from this unrandomised, descriptive study, our findings show a less severe EFA shortage in the PPI+ group, as shown by the decrease of mead acid and the 20:3n-9/20:4n-6 ratio. This suggests a potential beneficial effect of lansoprazole on the EFA status in pancreatic insufficient CF patients. As lansoprazole significantly improved both steatorrhea and body composition in CF patients $[21,22]$, the present study might support the hypothesis that the marginal EFA status in CF is, at least partly, related to fat malabsorption. This hypothesis is further supported by the finding that the EFA status of CF patients without fat malabsorption is usually better than of patients with fat malabsorption $[8,26,27]$. Despite treatment with pancreatic enzymes, residual fat malabsorption in CF could be explained by a low duodenal $\mathrm{pH}$ associated with CF resulting in either a poor release of enteric coated pancreatic enzymes, a decreased lipolytic activity, or bile acid precipitation [28-30]. Lastly Kalivianakis et al [31] demonstrated a diminished absorption of long-chain FA through the enterocyte in CF independently of lipolytic enzyme activity. By increasing the luminal pH, a PPI could improve the solubilization and absorption of long-chain FA.

In a mouse model of $\mathrm{CF}$, administration of $18: 3 n-3$ resulted in a further decrease in DHA [18]. This suggests that there might be a block in the biosynthesis of $22: 5 n-3$ and 22:6n-3.

In general, when DHA is low, the conversion of $22: 4 n-6$ into $22: 5 n-6$ becomes increased [32]. In our CF patients neither the amounts of 22:5n- 6 nor the ratio between 22:5n-6 and its precursor 22:4n-6 were increased as compared to controls. This suggests a reduced activity of the metabolic processes involved in the endogenous synthesis of both DHA as well of its 'shortage marker' 22:5n-6 from their respective precursors $22: 5 n-3$ and $22: 4 n-6$. This synthetic pathway includes elongation of 22:5n-3 and 22:4n-6, $\Delta 6$-desaturation of the resulting FA (both occurring in the microsomes) and 1 cycle of peroxisomal $\beta$-oxidation [33]. A reduced $\Delta 6$-desaturation is rather unlikely, since in CF patients a lower linoleic acid status is associated with higher amounts of $18: 3 n-6$, the $\Delta 6$-desaturation product of linoleic acid. It can not be excluded, however, that the $\Delta 6$-desaturase activities are mediated by different enzymes, of which one can be defective in CF. A reduced peroxisomal FA oxidation is 
another option to explain the lower DHA status in CF patients without a concomitant reactive increase in 22:5n-6. This hypothesis seems the more attractive since peroxisomal dysfunction has been mentioned as a feature in $\mathrm{CF}$ [13]. If peroxisomal $\beta$-oxidation is reduced in $C F, 24: 5 n-6$ and $24: 6 n-3$ can be expected to appear in the gas chromatogram. However, careful inspection of the chromatograms did not reveal the presence of such peaks. Consequently, the low DHA level without a reactive increase in 22:5n-6 could possibly result from a defective elongation of 22:5n-3 and 22:4n-6. EFA deficiency may contribute to the development of lung disease in CF patients. Studies using EFA deficient rabbits and chickens have suggested that EFA shortage predisposes for lung infection with S. aureus and Ps. aeruginosa, the two most common microorganisms infecting CF patients [34,35]. EFA shortage also seems to be related to different lung surfactant activity in the neonate [36]. Lawrence and Sorrell [37] showed that dietary 20:5n-3 supplementation resulted in a significant reduction in sputum volume and improvement in $\mathrm{FEV}_{1}$ values and vital capacity in CF patients. Gibson et al [19], showed a significant positive correlation between pulmonary function and levels of $18: 2 n-6,20: 4 n-6,22: 4 n-6.22: 5 n-3,22: 6 n-3$ and total $n-3$ FA in CF. In a study performed by Thompson [38] the only FA showing a significant correlation with pulmonary function was 22:6n-3. Recently Schwartz [39] reviewed the role of PUFA in lung disease, where he points to several trials dealing with supplemention of $\mathrm{n}-3$ FA suggesting an improvement in lung disease. The existence of a correlation between EFA shortage and decreased lung function in CF patients, suggest that correction of this deficiency and particularly of $22: 5 n-3$ and 22:6n-3 could lead to an improvement of lung function, just as we demonstrated in one of our studies [22]. Several studies showed that dietary supplementation of CF patients with fish oils with high amounts of the n-3 FA 20:5n-3 and 22:6n-3 leads to a significantly better incorporation of these $F A$ into plasma, $R B C$ and platelet phospholipids [40-42]. Suppletion of $n-3 F A$ revealed also a significant reduction of the serum concentration of leukotriene $\mathrm{B}_{4}$, an inflammatory mediator in CF enhancing the influx of neutrophils into the lung $[37,42]$.

In conclusion, the present study confirmed the presence of a marginal EFA status in pancreatic insufficient CF patients, particularly in plasma PL. This EFA shortage is, amongst others, thought to be a predisposing factor for lung disease in CF patients. The fact that CF patients who received a PPI in addition to the standard treatment showed a less disturbed EFA status compared to CF patients without PPI, suggests that fat malabsorption might, at least partly, be responsible for the EFA deficiency. Because lansoprazole did not normalize steatorrhea completely, we think that additional nutritional supplements of $n-3$ FA could be useful in children with CF. A larger, placebo controlled study, evaluating the effect of a PPI and n-3 FA supplementation on the EFA status and lung function in CF patients could solve this question. 


\subsection{REFERENCES}

1. Robinson P, Sly P. High dose pancreatic enzymes in cystic fibrosis. Arch Dis Child 1990; 65:311-2.

2. Dodge JA. Gastrointestinal tract and nutrition in cystic fibrosis: pathophysiology. J R Soc Med 1986;12(suppl):27-31.

3. Benabdestam H, Garcia I, Bellon G, Gilly R, Revol A. Biochemical assessment of the nutritional status of cystic fibrosis patients treated with pancreatic enzyme extracts. Am J Clin Nutr 1998;67:912-8.

4. Roulet M, Frascarolo P, Rappaz I, Pilet M. Essential FA deficiency in well nourished young cystic fibrosis patients. Eur J Pediatr 1997;156:952-6.

5. Lloyd-Still JD, Johnson SB, Holman RT. Essential FA status and fluidity of PLPL in cystic fibrosis infants. Am J Clin Nutr 1991;54:1029-35.

6. Christophe AB, Warwick WJ, Holman RT. Serum FA profiles in cystic fibrosis patients and their parents. Lipids 1994;29:569-75.

7. Christophe A, Robberecht E. Current knowledge on FA in cystic fibrosis. Prostaglandins, Leukotrienes and Essential FA 1996;55(3):129-38.

8. Hubbard VS, Dewey Dunn G, Di Sant'Agnese PA. Abnormal fatty-acid composition of plasma lipids in cystic fibrosis- a primary or secondary defect? Lancet 1977;2:1302-4.

9. Rivers JPW, Hassam AG. Defective essential FA metabolism in cystic fibrosis. Lancet 1975;2:642-3.

10. Rogiers V, Dab I, Michotte Y. Abnormal FA turnover in the PL of the red blood cell membranes of the cystic fibrosis patients. Pediatr Res 1984;18:704-8.

11. Strandvik B, Brönnegard M, Gilljam H, Carlstedt-Duke J. Relation between defective regulation of arachidonic acid release and symptoms in cystic fibrosis. Scand $J$ Gastroenterol 1988;23 (Suppl 143):1-4.

12. Parsons HG, O'Loughlin, Forbes D, Cooper D, Gall G. Supplemental calories improve essential FA deficiency in cystic fibrosis patients. Pediatr Res 1988;24:353-6.

13. Lepage $\mathrm{G}$, Kneepkens CMF, Roy CC. Peroxysomal dysfunction associated with essential FA deficiency. Med Sci 1993;9:571-6.

14. Rogiers V, Crokaert R, Vis HL. Altered phospholipid composition and changed FA pattern of the various phospholipid fractions of red cell membranes of cystic fibrosis children with pancreatic insufficiency. Clin Chim Acta 1980;105:105-15.

15. Biggemann B, Laryea MD, Schuster A, Griese M, Reinhardt D, Bremer HJ. Status of plasma and EM FA and vitamin $A$ and $E$ in young children with cystic fibrosis. Scand J Gastroenterol 1988;23 (Suppl 143):134-41.

16. Hubbard VS, Dewey Dunn G. FA composition of RBCPL from patients with cystic fibrosis. Clin Chim Acta 1980;102:115-8.

17. Freedman SD, Katz MH, Parker EM, Laposata M, Urman MY, Alvarez JG. A membrane lipid imbalance plays a role in the phenotypic expression of cystic fibrosis in cftr(-/-)mice. Proc Natl Acad Sci USA 1999;96:13995-14000. 
18. Freedman SD, Shea JC, Blanco PG, Alvarez JG. Fatty acids in cystic fibrosis. Curr Opin Pulm Med 2000 Nov; $6(6): 530-2$.

19. Gibson RA, Teubner JK, Haines K, Cooper DM, Davidson GP. Relationships between pulmonary function and plasma FA levels in cystic fibrosis patients. $J$ Pediatr Gastroenterol Nutr 1986;5:408-15.

20. Lloyd-Still JD, Bibus DM, Powers CA, Johnson SB, Holman RT. Essential FA deficiency and predisposition to lung disease in cystic fibrosis. Acta Paediatr 1996;85:1426-32.

21. Tran TMD, Van den Neucker A, Hendriks JJE, Forget P, Forget P-Ph. Effects of a proton-pump inhibitor in cystic fibrosis. Acta Paediatr 1998;87:553-8.

22. Hendriks JJE, Kester ADM, Donckerwolcke R, Forget PPh, Wouters EFM. Changes in pulmonary hyperinflation and bronchial hyperresponsiveness following treatment with lansoprazole in children with cystic fibrosis. Ped. Pulmon 2001; 31: 59-66.

23. Tran $M$, Forget $P$, Van den Neucker A, Strik J, van Kreel B, Kuijten R. The acid steatocrit: A much improved method. J Pediatr Gastroenterol Nutr 1994;19:299-303.

24. Otto SJ, Foreman-v. Drongelen MM, Houwelingen ACV, Hornstra G. Effects of storage on venous and capillary blood samples: the influence of deferoxamine and butylated hydroxytoluene on the fatty acid alterations in red blood cell phospholipids. Eur J Clin Chem Clin Biochem 1997;35:907-13.

25. Holman RT. The ratio of trienoic:tetraenoic acids in tissue lipids as a measure of essential FA requirement. J Nutr 1960;70:405-10.

26. Galabert C, Filliat M, Chazalette JP. FA composition of serum lecithins in cystic fibrosis patients without steatorrhea. Lancet 1978;i:903.

27. Farrell PM, Mischler EH, Engle MJ, Brown DJ, Lau SM. FA abnormalities in cystic fibrosis. Pediat Res 1985;19:104-9.

28. Regan P, Malagelada J, Dimagno E, Go V. Reduced intraluminal bile acid concentrations and fat maldigestion in pancreatic insufficiency: Correction by treatment. Gastroenterology 1979;77:285-9.

29. Zentler-Munro P, Fitzpatrick W, Batten J, Northfield T. Effect of intrajejunal acidity on aqueous phase bile acid and lipid concentrations in pancreatic steatorrhea due to cystic fibrosis. Gut 1984;25:500-7.

30. Zentler-Munro P, Fine D, Batten J, Northfield T. Effect of cimetidine on enzyme inactivation, bile acid precipitation, and lipid solubilisation in pancreatic steatorrhea due to cystic fibrosis. Gut $1985 ; 26: 892-901$.

31. Kalivianakis M, Minich DM, Bijleveld CMA, Aalderen van WMC, Stellaard F, Laseur M, Vonk RJ and Verkade $H J$. Fat malabsorption in CF patients receiving enzyme replacement therapy is due to impaired intestinal uptake of long-chain fatty acids. Am J Clin Nutr 1999; 69: 127-134.

32. Sprecher H, Luthria DL, Mohammed BS, Baykousheva SP. Reevaluation of the pathways for the biosynthesis of polyunsaturated fatty acids. J Lipid Res 1995; 36: 2471-77.

33. Neuringer M, Connor WE, Lin DS, Barstad L, Luck S. Biochemical and functional effects of prenatal and postnatal $\omega 3$ fatty acid deficiency on retina and brain in rhesus monkeys. Proc Natl Acad Sci USA 1986; 83: 4021-25. 
34. Harper TB, Chase HP, Henson J, Henson PM. Essential FA deficiency in the rabbit as a model of nutritional impairment in cystic fibrosis: In vitro and in vivo effects on lung defence mechanisms. Am Rev Respir Dis 1982;126:540-7.

35. Craig-Schmidt MC, Faircloth SA, Teer PA, Weete JD, Wu CY. The essential FA deficient chicken as a model for cystic fibrosis. Am J Clin Nutr 1986;44:816-24.

36. Friedman Z, Rosenberg A. Abnormal lung surfactant related to essential FA deficiency in a neonate. Pediatrics 1979;63:855-9.

37. Lawrence $R$, Sorrell T. Eicosapentaenoic acid in cystic fibrosis: evidence of a pathogenetic role for leukotriene B4. Lancet 1993;342:465-9.

38. Thompson GN. Relationships between essential FA levels, pulmonary function and fat absorption in pre-adolescent cystic fibrosis children with good clinical scores. Eur J Pediatr 1989;148:327-9.

39. Joel Schwartz. Role of polyunsaturated fatty acids in lung disease. Am J Clin Nutr 2000; 71 (suppl): 393S-6S.

40. Henderson WR, Astley SJ, McCready MM, et al. Oral absorption of omega-3 FA in patients with cystic fibrosis who have pancreatic insufficiency and in healthy control subjects. J Pediatr 1994;124:400-8.

41. Clandinin MTh, Zuberbuhler P, Brown NE, Kielo ES and Goh YK. Fatty acid pool size in plasma lipoprotein fractions of cystic fibrosis patients. Am J Clin Nutr 1995; 62: 1268-75.

42. Kurlandsky LE, Bennink MR, Webb PM, Ulrich PJ, Baer LJ. The absorption and effect of dietary supplementation with omega-3 FA on serum leukotriene B4 in patients with cystic fibrosis. Pediatr Pulmonol 1994;18:211-7. 


\section{.}




\section{CHAPTER EIGHT}

\section{Are children with Cystic Fibrosis treated with a proton pump inhibitor at risk for vitamin B12 deficiency?}

Henriëtte ter Heide ${ }^{1}$, Han Hendriks ${ }^{1}$, Hiltje Heijmans ${ }^{1}$, Paul Menheere ${ }^{2}$, Leo Spaapen ${ }^{3}$, Jaap Bakker ${ }^{3}$, Philippe Forget ${ }^{1}$

Department of ${ }^{1}$ Pediatrics, ${ }^{2}$ Clinical Chemistry and ${ }^{3}$ Stichting Klinische Genetica Z.O.N., University Hospital Maastricht, The Netherlands.

J Ped Gastroenterol Nutr 2001; 33: 342-345.

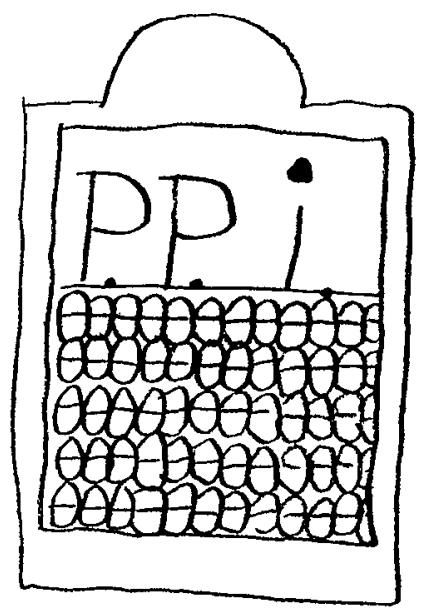




\subsection{ABSTRACT}

Background: In a recent study, the authors demonstrated the beneficial effect of proton-pump inhibitors (PPI) on fat malabsorption and bone mineral content in children with cystic fibrosis (CF). Prolonged use of PPI could result in vitamin $B_{12}$ deficiency as a consequence of impaired release of vitamin $B_{12}$ from food in a nonacid environment. The aim of this study was to evaluate the vitamin $B_{12}$ status of CF patients either treated with a PPI or not by measuring vitamin $B_{12}$ and homocysteine blood levels, the latter being a sensitive indicator of vitamin $\mathrm{B}_{12}$ deficiency.

Methods: The study population consisted of $20 \mathrm{CF}$ patients, 11 patients treated with a PPI for at least 2 years and 9 CF patients not treated with a PPI, and 10 healthy, age matched control participants. Homocysteine blood levels were measured by high-performance liquid chromatography, and vitamin $B_{12}$ levels were measured by a competitive protein-binding assay.

Results: Vitamin $B_{12}$ levels were significantly higher in both CF groups compared with the control participants (PPI+, $P=0.02$; PPI-,$P=0.009$ ). There was no significant difference in vitamin $B_{12}$ levels between both $C F$ groups. Homocysteine levels were normal and similar in all groups.

Conclusions: Cystic Fibrosis patients treated with a PPI for at least 2 years show no signs of vitamin $B_{12}$ deficiency. 


\subsection{INTRODUCTION}

Binding to gastric intrinsic factor is the central event in the absorption of vitamin $B_{12}$. Several steps, however, must occur before this binding can take place. First, food-bound vitamin $B_{12}$ must be released, mediated by pepsin and acid in the stomach, after which vitamin $\mathrm{B}_{12}$ binds to salivary haptocorrin. At the acid gastric $\mathrm{pH}$ environment, the affinity of vitamin $B_{12}$ for haptocorrin is much higher than for intrinsic factor. Second, in the more alkaline intestinal pH environment, pancreatic enzymes degrade the haptocorrin vitamin $B_{12}$ complex, and vitamin $B_{12}$ is transferred to intrinsic factor. Finally, the intrinsic factor-vitamin $B_{12}$ complex is absorbed in the terminal ileum by phagocytosis after attachment to specific membrane receptors. After absorption vitamin $B_{12}$ is bound to transcobalamin II in the circulation and subsequently transported intracellularly. Only $6 \%$ to $20 \%$ of plasma vitamin $B_{12}$ are attached to the transport protein transcobalamin II. This is the metabolically active fraction that ensures the internalization of vitamin $B_{12}$ into the body cells, where it acts as a cofactor for the enzymes methionine synthase and methylmalonyl-CoA mutase [1]. Impairment of these enzymatic reactions can result in hyperhomocysteinemia and increased methylmalonic acid blood levels, and clinical manifestations such as anemia and neuropathy $[2,3]$. The vitamin $B_{12}$ malabsorption seen in pancreatic insufficient cystic fibrosis (CF) patients has been suggested to be the result of the trypsin-related impaired release of vitamin $B_{12}$ from haptocorrin. Lindemans et al. [4] showed that the addition of trypsin resulted in an improvement of vitamin $B_{12}$ absorption in most, but not all, CF patients.

In a recent study, we demonstrated that the use of a proton-pump inhibitor (PPI) in children with CF decreases fat malabsorption and increases body fat and bone mineral content [5]. We were concerned that long-term use of PPIs could result in vitamin $B_{12}$ deficiency as a result of the impaired release of vitamin $B_{12}$ from food in a nonacid gastric environment. The purpose of this study was to evaluate the vitamin $B_{12}$ status of our $C F$ patients by both vitamin $B_{12}$ and homocysteine blood levels, the latter being a sensitive indicator of vitamin $B_{12}$ deficiency [3].

\subsection{PATIENTS AND METHODS}

Twenty CF out-patients from the University Hospital Maastricht were recruited. All children were known to have pancreatic insufficiency on the basis of steatorrhea associated with low fecal chymotrypsin activity. The control group consisted of children admitted to our hospital for minor surgical interventions, for example, orchidopexy and hypospadias. The study was approved by the Ethical Committee of our hospital, and informed patient and parental consent were obtained.

We measured vitamin $\mathrm{B}_{12}$ and homocysteine blood levels in $11 \mathrm{CF}$ patients (mean age, 11.7 years; range, $5.5-17.4$ years) treated with a PPI (PPI+), in 9 CF patients (mean age, 8.1 years; range, $1.8-12.3$ years) without a PPI (PPI-), and in 10 healthy, age-matched controls (mean age, 9.2 years; range, $3.3-16.2$ years). The prescribed 
PPI was lansoprazole in a dosage of $15 \mathrm{mg} /$ day orally for at least 2 years. Total homocysteine concentration in plasma ( $\mathrm{tHcy}$ ) was measured by high-performance liquid chromatography [6] and vitamin $B_{12}$ by a competitive protein binding assay (Perkin-Elmer, Turku, Finland).

\subsection{STATISTICS}

All data were analyzed using the SPSS statistic program (version 9.0, SPSS Inc., Macintosh, Chicago, IL). Data are presented as mean and range. Vitamin $B_{12}$ and homocysteine were compared between groups, making use of the Mann-Whitney U test for two independent samples. The Non-parametric Spearman correlation coefficient was used to study the relationship between age, vitamin $B_{12}$ and thcy blood levels.

\subsection{RESULTS}

Mean (and range) of vitamin $B_{12}$ levels were $553 \mathrm{pmol} / \mathrm{L}(303-907 \mathrm{pmol} / \mathrm{L}$ ), $637 \mathrm{pmol} / \mathrm{L}(283-1200 \mathrm{pmol} / \mathrm{L})$ and $333 \mathrm{pmol} / \mathrm{L}(179-566 \mathrm{pmol} / \mathrm{L})$ in CF patients receiving a PPI, CF patients without a PPI, and control participants, respectively. In the same patient groups mean and range of tHcy were $7.49 \mu \mathrm{mol} / \mathrm{L}(3.8-13.7$ $\mathrm{mol} / \mathrm{L}), 6.52 \mu \mathrm{mol} / \mathrm{L}(3.6-11.5 \mathrm{~mol} / \mathrm{L})$ and $7.76 \mu \mathrm{mol} / \mathrm{L}(4.0-10.5 \mathrm{~mol} / \mathrm{L}) .0 u r$ refe-

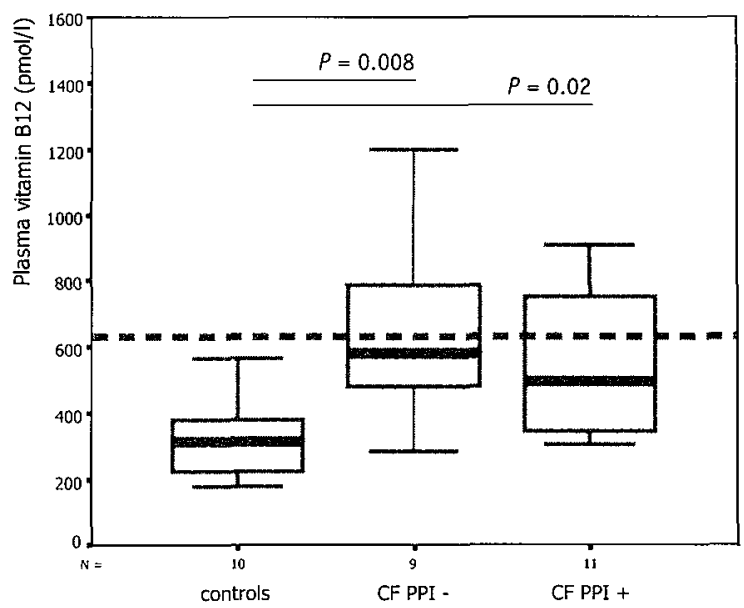

FIGURE 8.1. Box plots of vitamin $B_{12}$ concentrations ( $\mathrm{pmol} / \mathrm{L}$ ) in 10 healthy control participants, 9 CF patients not receiving a proton-pump inhibitor (PPI-) and 11 CF patients receiving a PPI (PPI+). The box plot shows the median (central horizontal line), the 25 th percentile (lower box border), the 75 th percentile (upper box border), and the range of values. The dashed line represents the vitamin $B_{12}$ upper limit of normal. 


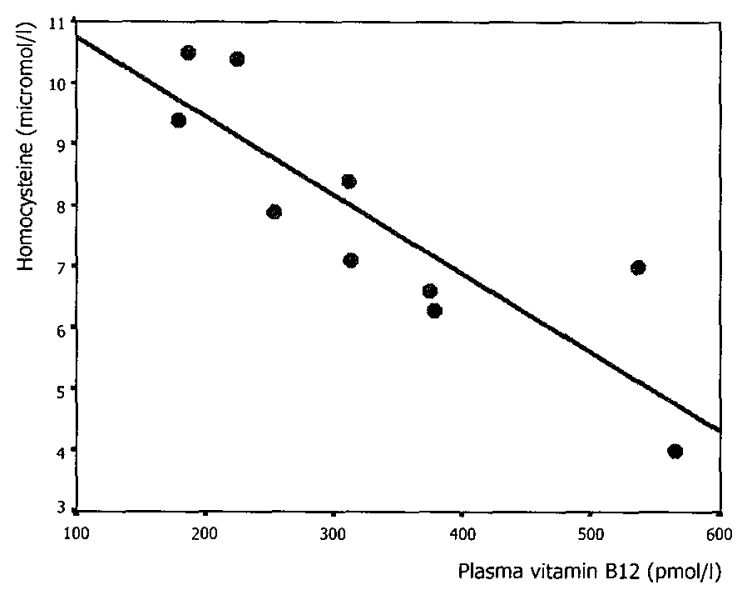

FIGURE 8.2. Correlation between homocysteine and vitamin $B_{12}$ blood levels in healthy control participants $(r=-0.915 ; P<0.001)$.

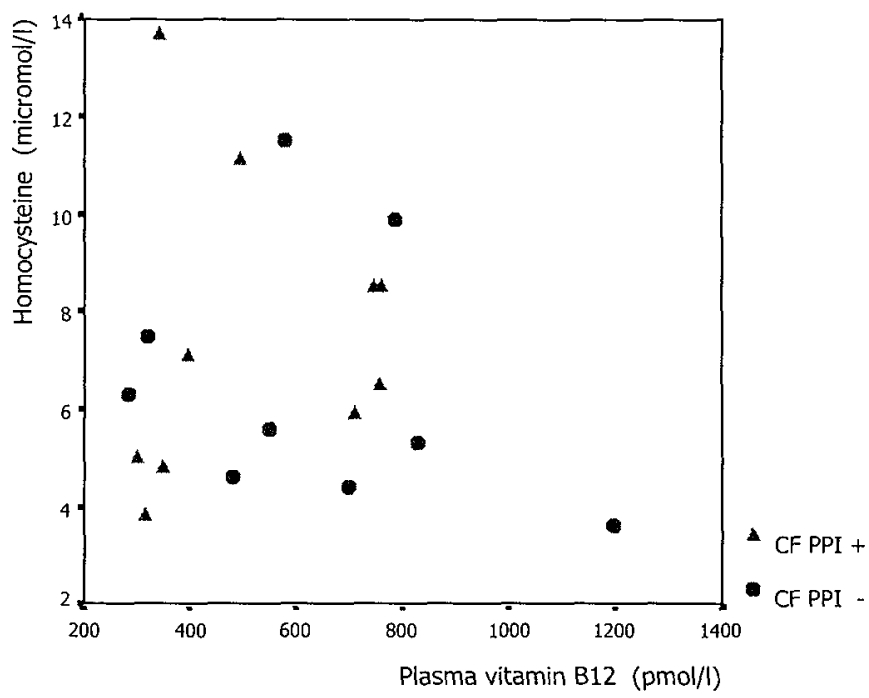

FIGURE 8.3. Relationship between homocysteine and vitamin $\mathrm{B}_{12}$ plasma levels in CF patients.

rence range of plasma tHcy in 61 children $(0-10$ years of age) was $2.9-10.2 \mu \mathrm{mol} / \mathrm{L}$ (mean \pm 2 standard deviations, $6,8 \pm 1,8 \mu \mathrm{mol} / \mathrm{L}$ ). Figure 8.1 shows a box plot of vitamin $B_{12}$ blood levels in our patient groups. Compared with values obtained in healthy control participants, vitamin $\mathrm{B}_{12}$ levels were significantly higher in CF patients treated with a PPI $(P=0.02)$ and in CF patients without a PPI $(P=0.008)$. There was no 
significant difference in vitamin $B_{12}$ between both CF patients groups $(P=0.621)$. Vitamin $B_{12}$ blood levels were more than the upper limit of normal $(>630 \mathrm{pmol} / \mathrm{L})$ in 9 of $20 \mathrm{CF}$ patients ( 5 with and 4 without a PPI). Homocysteine levels were normal and similar in all groups. We found no correlation between age and either vitamin $B_{12}$ or tHcy levels in our CF patient groups. However, in our control group, a significant positive correlation $(r=0.78 ; P=0.008)$ was found between age and thcy levels and a negative correlation $(r=-0.78 ; P=0.008)$ between age and vitamin $B_{12}$ levels. A strong negative correlation $(r=-0.915 ; P<0.001)$ was found between tHcy and vitamin $B_{12}$ levels in control participants (figure 8.2.), but not in $C F$ patients (figure 8.3.).

\subsection{DISCUSSION}

Proton-pump inhibitors, such as lansoprazole, suppress gastric acid secretion and impair the absorption of food cobalamin $[7,8]$. Several years of ongoing lansoprazole therapy could result in vitamin $B_{12}$ deficiency. The treatment of our CF patients with a PPI resulted in decreased fat malabsorption and increased body fat and bone mineral content [5]. However we were, concerned that vitamin $B_{12}$ deficiency could occur in these patients with pancreatic insufficiency receiving long-term treatment with a PPI.

Little is known about the malabsorption of vitamin $B_{12}$ in children with CF. The malabsorption of crystalline vitamin $B_{12}$ observed in $C F$ is the result of a mechanism independent of either intrinsic factor secretion or intrinsic factor biological activity [9]. The absorption of crystalline vitamin $B_{12}$ in $C F$ is corrected in most patients by administration of pancreatic supplements $[4,10,11]$.

We evaluated the effect of prolonged use of a PPI on vitamin $B_{12}$ and homocysteine blood levels. Our study shows normal homocysteine levels in all groups. Our results are within the reference intervals for children as described in two recent studies [12,13]. Because elevated homocysteine is a sensitive parameter for vitamin $B_{12}$ deficiency, these results probably rule out vitamin $B_{12}$ deficiency in our CF patients. As far as we know homocysteine blood levels in CF patients have not been reported previously. In contrast to homocysteine and compared with our normal control participants, vitamin $B_{12}$ was even found to be elevated in both our CF patient groups regardless of the use of a PPI. We must conclude that the use of a PPI for at least 2 years had no effect on vitamin $B_{12}$ blood levels in both $C F$ groups. A similar increase in serum vitamin $B_{12}$ has been reported previously. Lindemans et al. [14] found that in a large group of treated CF patients, serum vitamin $B_{12}$ levels in general were elevated, despite impaired vitamin $B_{12}$ absorption. The elevation of vitamin $B_{12}$ levels in these $C F$ patients occurred while they were not treated with a PPI and was associated with increased levels of transcobalamin II and haptocorrin. Increased levels of transcobalamins have been described in leucocytosis and myeloid leukemia, liver disease, polycythemia vera and autoimmune disorders [15-19]. In patients with alcoholic liver disease, highly elevated vitamin $B_{12}$ plasma levels were found as a result to leakage of vitamin $B_{12}$ from 
liver tissue into plasma. This resulted in lowered liver tissue vitamin $B_{12}$ content, increased plasma holo transcobalamin I and III concentration and decreased plasma transcobalamin II [16]. The biological active form of vitamin $B_{12}$ was significantly depressed because the percentage of vitamin $B_{12}$ bound to transcobalamin II was diminished [17]. We found a strong negative correlation between homocysteine and vitamin $B_{12}$ blood levels in our healthy control participants, but not in CF patients. A weaker, but significant, correlation was recently described in healthy Belgian schoolchildren [12]. Because methylcobalamin is a cofactor of homocysteine methyltransferase, such a negative correlation between vitamin $B_{12}$ and homocysteine blood levels is to be expected. The lack of such a correlation in our CF patients probably implies that because of disturbances in the various forms of circulating cobalamines, the measured 'total' cobalamin blood levels may not be representative of biologically 'active' vitamin $B_{12}$. Further studies of the different circulating forms of protein bound vitamin $B_{12}$ and their relationship with plasma homocysteine blood levels are necessary to answer this problem definitively.

\subsection{REFERENCES}

1. Lindgren A, Kilander A, Bagge E, Nexø E. Holotranscobalamin - a sensitive marker of cobalamin malabsorption. Eur J Clin Invest 1999;29:321-329.

2. Carmel R. Malabsorption of food cobalamin. Baillieres Clin Haematol 1995;8:639-55.

3. Scott JM. Bioavailability of vitamin $B_{12}$. Eur J Clin Nutr 1997;51:Suppl 1:S49-53.

4. Lindemans $\mathrm{J}$, Neijens $\mathrm{HJ}$, Kerrebijn KF, Abels J. Vitamin $\mathrm{B}_{12}$ absorption in cystic fibrosis. Acta Pædiatr Scand 1984;73:537-40.

5. Tran TMD, Van den Neucker A, Hendriks JJE, Forget P, Forget P-Ph. Effects of a proton-pump inhibitor in cystic fibrosis. Acta Pædiatr 1998;87:553-8.

6. Spaapen LJM, Waterval WAH, Bakker JA, Luijckx GJ, Vles JSH. Detectie van hyperhomocysteinemie bij vroegtijdige cerebrovasculaire ziekte. Mijds.NVKC1992; 17:194-9.

7. Marcuard SP, Albernaz L, Khazanie PG. Omeprazole therapy causes malabsorption of cyanocobalamin. Ann Intern Med1994;120:211-5.

8. Koop $H$, Bachem MG. Serum iron, ferritin, and vitamin $B_{12}$ during prolonged omeprazole therapy. J Clin Gastroenterol 1992;14:288-92.

9. Monin B, Gueant JL, Michalski JC, Vidaithet M, Grignon G, Nicolas JP. Physicochemical characterization and biological activity of intrinsic factor in cystic fibrosis. J Pediatr Gastroenterol Nutr 1990;10:87-94.

10. Deren JJ, Arora B, Toskes PP, Hansell J, Sibinga MS. Malabsorption of crystalline vitamin $B_{12}$ in cystic fibrosis. N Engl J Med 1973;288:949-50.

11. Harms HK, Kennel 0 , Bertele RM, Bidlingmeier F, Bohne A. Vitamin $B_{12}$ absorption and exocrine pancreatic insufficiency in childhood. Eur J Pediatr 1981;1:75-9. 
12. De Laet C, Wautrecht J-C, Brasseur D, Dramaix M, Boeynaems J-M, Decuyper J, Kahn A. Plasma homocysteine concentrations in a Belgian school-age population. Am J Clin Nutr 1999;69:968-72.

13. Vilaseca MA, Moyano D, Ferrer I, Artuch R. Total homocysteine in pediatric patients. Clin Chem 1997;43:690-2.

14. Lindemans J, Abels J, Neijens HJ, Kerrebijn KF. Elevated serum vitamin $B_{12}$ in cystic fibrosis. Acta Pædiatr Scand 1984;73:768-71.

15. Rachmilewitz B, Rachmilewitz M, Moshkowitz B, Gross J. Serum transcobalamin in myeloid leukemia. J Lab Clin Med 1971;78:275-88.

16. Retief FP, Vandenplas L, Visser $H$. Vitamin $B_{12}$ binding proteins in liver disease. Brit $J$ Haemat 1969;16:231-40.

17. Baker H, Leevy CB, DeAngelis B, Frank 0, Baker ER. Cobalamin (vitamin $B_{12}$ ) and holotranscobalamin changes in plasma and liver tissue in alcoholics with liver disease. J Am Coll Nutr 1998;17:235-8.

18. Rachmilewitz B, Manny N, Rachmilewitz M. The transcobalamins in polycythaemia vera. Scand J Haematol 1977;19:453-62.

19. Frater-Schroder $M$, Hitzig WH, Grob J, Kenny $A B$. Increased unsaturated transcobalamin II in autoimmune disease. Lancet 1987;29:2:238-9. 
CHAPTER NINE

\title{
General conclusions
}

\author{
Han Hendriks
}

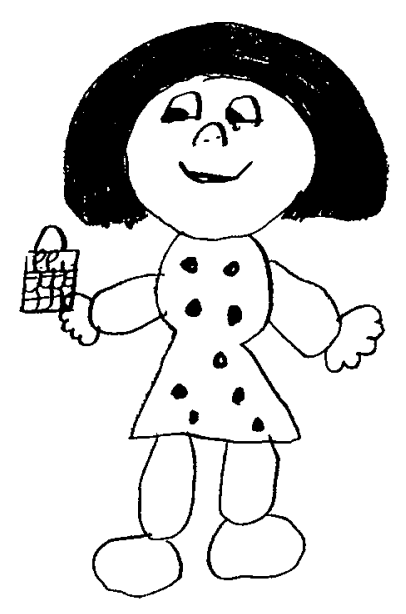




\subsection{CONCLUSIONS}

Cystic Fibrosis (CF) is relatively rare and the course of the disease is so severe that most patients die at an age of approximately 30 years. All over the world groups of researchers are trying to find out new evidence as to the cause, origin, patho-physiology, course, complications and/or treatment of this life threatening disease. Children with CF together with their parents look anxiously for new ways of increasing the duration and the quality of their lives. As we previously showed a short term beneficial effect of a proton-pump-inhibitor (PPI) in children with CF, we started a new set of studies.

Due to the character of the disease and the restricted number of subjects, the aims of our studies had to be rather limited and consisted of investigating whether or not the pharmacological intervention with a PPI, lansoprazole (Prezal ${ }^{(\otimes)}$ ), revealed predictable effects of this medication.

Based on our previous study a decrease of fecal fat excretion and an improvement of body composition could be expected. Possible additional effects of this adjuvant treatment are a decrease of intestinal permeability (IP), an improvement of lung function and of essential fatty acid (EFA) status. As the use of PPIs for a prolonged period might also induce side effects, such as vitamin $B_{12}$ deficiency, we also looked for evidence of vitamin $B_{12}$ deficiency in our treated patients. Besides direct evaluation of these effects our study was also intended to provide data, allowing us to perform a power analysis for the planning of further, placebo-controlled, studies. For these purposes an observational study, in 14 children diagnosed with CF and pancreatic insufficiency, was performed, with the approval of the parents, patients and the medical ethical committee.

To maximize the chance to demonstrate an effect, we compared the mean of the whole intervention period to the pre-trial (baseline) values. By this procedure we could demonstrate several effects. As in our previous study we found a decrease of fecal fat excretion immediately after starting the intervention. We also could show that total body fat increased, without a change in fat free mass. A new finding was that bone mineral status improved, probably because of the slow bone turn-over process this was only detected after treatment for 12 months. The effects on body composition, however, turned out to be temporary, as the results at 3 years dropped back to pre-study values. Further we could demonstrate an effect on IP, which in most CF patients decreased, during the first treatment year. We also confirmed the presence of hyperinflation in children with $C F$, which diminished during therapy. The coincidence between an improvement in fat excretion and body composition on the one hand and a decrease in hyperinflation on the other hand is remarkable, although a causal relationship remains unproven. The effects on EFA are less clear, as only docosa hexaenoic acid (DHA) levels improved significantly. Lastly we demonstrated that after use of a PPI for 3 years neither evidence of vitamin $B_{12}$ deficiency nor clinical complaints were found. When considering the effects of lansoprazole in CF patients, the following trends were observed. Some effects appeared at once and persisted at the same level during the whole first study year, like the decrease of fecal fat excretion and the hyperinflation 
parameters. Other possible effects of PPI such as those on mucosal inflammation $\left(\mathrm{NO}_{\mathrm{x}}\right)$ and bronchial lability (PEF variables) were more variable and uncertain.

One has to remember, that our main aim was to detect the presence of predictable effects of PPI in a small group of CF patients. We therefore abstain from making any hard recommendations for clinical use of PPIs in children with CF. However, the trends detected in the present study supplies sufficient data to perform a power analysis for future trials.

\subsection{POWER ANALYSIS FOR FURTHER STUDIES WITH PPI IN CF}

To elucidate definitively the role of PPI in improving fecal fat excretion, body composition, lung hyperinflation, IP, EFA deficiency and other abnormalities in CF, a larger double-blinded, placebo-controlled study would be necessary. This study should be performed in CF children, with comparable stages of the disease. In order to avoid differences in severity of the disease between groups, stratification would be necessary for CF disease score (Schwachman), degree of malnutrition, inflammation and/or lung function. Patients should be randomized in two arms, one PPI group and a placebo group, for one year.

While a cross-over design might be preferable, this would require for several research questions at least a study time of two years. As we do not know how long the carry-over effect is, the total study time would be even longer, up to three years. During such a long period various confounders could occur, interfering with the evaluation of the drug under investigation.

Moreover this study should also assess health economic issues, like cost-effectiveness of the addition of a PPI compared to the standard regime and differences in number of healthy days and number of exacerbations during the intervention. In relatively healthy young CF patients, this would require a large number of subjects. Taking account of our results and using the mean and SD, as computed from the differences between the start (st) and end (e) of study values of each patient variable, we performed a power analysis for future prospective studies. In order to test 2-sided, with $\alpha=0.05$ and $1-\beta=0.8$, the following numbers would be necessary per arm (table 9.1.):

In formula:

$n_{1}=n_{2} \geq 2 \times\left(Z_{\text {sig }}+Z_{\beta}\right)^{2} \times \frac{\sigma_{(\text {st }-\mathrm{e})^{2}}}{\mu_{(\text {st-e) }}{ }^{2}} \times \frac{Z_{\text {sig }}{ }^{2}}{4}\left(\right.$ where $z_{\text {sig }}=1.96$ and $\left.z_{\beta}=0.842\right)$

If we accept that the assessed mean and SD of the changes for each of the variables are sufficient, to prevent a type II error, over 100 patients would have to be included for most variables. In order to resolve all our questions over 100 patients would be needed in each arm. As it would be difficult to find enough children with comparable disease severity (as mentioned above), a multi-center study would certainly be necessary. In the Netherlands just over 400 children with CF are between 5 and 16 years of age. As we demonstrated persisting steatorrhea despite adequate pancreatic enzyme suppletion 
TABLE 9.1. Estimated numbers of subjects needed per arm for future studies.

(if $\alpha=0.05 ; 1-\beta=0.8$ and 2-sided testing; based upon values from the present study)

\begin{tabular}{lllll}
\hline Item & & $\mu_{\text {st-e }}$ & $\sigma_{\text {st-e }}$ & $\mathrm{N}$ \\
\hline Fecal fat excretion: acid steatocrit & $(\%)$ & 8 & 14 & 50 \\
Height & $($ SDS & 0.1 & 0.23 & 85 \\
Weight & $($ SDS $)$ & 0.2 & 0.40 & 65 \\
Body composition: TBF & $($ SDS & 0.3 & 0.42 & 32 \\
BMC & $($ SDS & 0.16 & 0.21 & 29 \\
BMD & $($ SDS) & 0.3 & 0.34 & 22 \\
Lung Function: TLC & $(\%$ predicted) & 8 & 15 & 57 \\
RV & $(\%$ predicted) & 35 & 76 & 76 \\
RV/TLC & $($ ratio) & 0.05 & 0.13 & 108 \\
EFA: DHA & (mg/L) & 8 & 8 & 17 \\
IP: lactulose recovery & $(\%)$ & 1.1 & 2.6 & 90 \\
L/M ratio & (ratio) & 0.1 & 0.21 & 71 \\
L/Rh ratio & (ratio) & 0.12 & 0.18 & 37 \\
\hline
\end{tabular}

For abbreviations see list of abbreviations (page 6).

in only $25 \%$ of our patients, this means that in the Netherlands a maximum of 100 patients could be recruited. As the usefulness of a PPI is not the only single question in CF studies and cooperation of so many patients is needed, the involvement of the national and perhaps even the European CF Foundations would be required. Therefore it would be worthwhile, similarly to the CF research consortia in the USA, to organize and establish European CF research consortia.

\subsection{PLANS FOR STUDIES IN CF IN MAASTRICHT}

Although many studies in the past two decades show some relationship between nutritional status, body composition, lung and gut functioning, the mechanisms involved are still poorly understood. Chronic inflammation in CF can possibly explain several of these disturbances and the effects of a PPI could be related to decreased inflammation. Furthermore, adjuvant therapy with a PPI does not normalize fat absorption completely in all patients; therefore other interventions will still be necessary.

In order to contribute to the study of fat malabsorption in CF patients we are planning the following studies, some in collaboration with the CF center in Rotterdam:

The effects of PPIs on intestinal absorption of fat-soluble vitamins $D, K$, and bone turnover markers, in order to assess the impact of CF on bone metabolism. We have collected data on this subject (to be submitted, see chapter 4). Based on these results we are 
planning to assess the effects of suppletion of vitamin $K$ on bone markers in children and adults with CF.

In order to study inflammation in CF, markers, particularly of pulmonary origin and obtained non-invasively, should become available. Measurements of inflammatory proteins and inflammation-related products in induced sputum and condensated exhaled air are two possibilities to assess pulmonary inflammation in a much less invasive way than Broncho-Alveolar-Lavage. These types of inflammation markers will be evaluated in relation to systemic inflammation, lung function parameters and the nutritional status.

Evaluation of the effects of fish-oil suppletion, a combination of several (n-3)-EFAs, DHA enriched diet, in combination with a PPI on the EFA status and inflammatory parameters in CF patients. 



\title{
CHAPTER TEN
}

\section{Summary in English and Dutch}

\author{
Han Hendriks
}

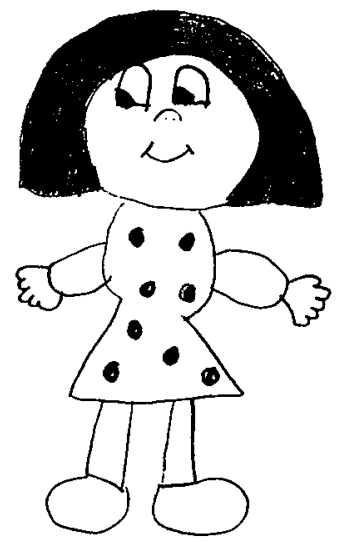




\section{SUMMARY OF THE DIFFERENT CHAPTERS}

In chapter one the rationale for the use of a proton pump inhibitor (PPI) in Cystic Fibrosis (CF) patients is described. Persisting malabsorption is still a problem in many CF patients, despite supplementation with pancreatic enzymes. Factors involved in malabsorption, as reported in the literature, are given and indicate the importance of duodenal acidity. Normal gastric acid production is buffered with pancreatic bicarbonate, which production is hampered early and severely in CF patients. By adding a proton pump inhibitor (PPI) to the standard regime of CF children with ongoing steatorrhea, despite supplementation with pancreatic enzymes, gastric acid production is reduced which will allow duodenal $\mathrm{pH}$ to rise, resulting in a more efficient utilization of pancreatic enzyme capsules and better fat absorption.

Chapter two describes the aims, the patients and methods of the complete study protocol. Our previous, short-term, study had demonstrated a possible effect of administration of PPI on fecal fat excretion and total body fat (TBF) of CF patients. A new observational study was planned, to estimate these as well as additional effects of lansoprazole treatment administered during one year, on several biological variables in children with CF. This study was primarily aimed at looking for possible predictable effects of PPI in children with CF. As it was possible to include only a limited number of patients no definitive conclusions or recommendations as to the clinical use of PPI in CF can be made.

In chapter three we report growth data of our young CF patients. In contrast to most published studies, reporting cross-sectional growth data in large CF populations, we used longitudinal growth data to assess growth patterns. We demonstrated that stunting contributed more to growth retardation than wasting, and therefore the use of weight-for-age growth charts instead of weight-for-height reference values to assess growth failure in a CF patient will be more appropriate. These data also support the use of for screening programs for $C F$, as growth was severely retarded in $80 \%$ of our patients at initial assessment and early intervention has been shown to prevent stunting in these patients.

Chapter four described the evaluation of both the short term (one year) and long term (3 years) effects of adjuvant therapy with a PPI on body composition in CF. Fecal fat excretion was monitored throughout the year by the acid steatocrit method. Body composition was assessed at the start of the study and at 6,12 and 36 months by dual energy $X$-ray absorptiometry (DEXA). Body composition data are expressed in standard deviation scores (SDS) instead of absolute values, in order to take into account the normal growth process in children. The addition of a PPI to the treatment of young CF patients resulted in an immediate and long lasting decrease of fat excretion. During the first year of the intervention an improvement not only of TBF, but also of bone mineral content (BMC) and bone mineral density (BMD) occurred. As body composition values at 3 years returned to pre-treatment values, our results demonstrated the beneficial 
effect of PPI on body composition in CF to be temporary. We propose to assess body composition by DEXA in CF patients regularly, allowing a better monitoring of the nutritional condition compared to anthropometric data alone.

The changes in lung function parameters in CF patients, during the use of PPIs, were described in chapter five. Our results confirmed the presence of hyperinflation in CF and showed a decrease of hyperinflation during the use of a PPI, which can only partly explain the improvement of inspiratory muscle performance. Whether the association between an improvement of body composition and a decrease of lung hyperinflation is causal or coincidental cannot be ascertained from our study. Furthermore daily recording of peak expiratory flow (PEF) confirmed that PEF variability is increased in CF, which might point to the presence of bronchial lability in these patients.

In chapter six we confirmed the well-known and severely increased intestinal permeability (IP) in CF patients. Our results showed that the increased IP, at least partly, can be corrected by the use of a PPI during one year. As the paracellular permeability pathway mainly improved, we suggested that acid luminal contents might damage the intestinal mucosa, particularly the tight junctions, contributing to the increase of IP in CF.

Biochemical results concerning signs of essential fatty acid (EFA) deficiency in our patients were presented in chapter seven and showed plasma phospholipid fatty acids to be mainly affected. Although the EFA status of patients receiving PPIs showed some trend towards normalization, the only difference between CF patients with PPI and those without, consisted in a higher plasma docosa hexaenoic acid (DHA) level in the PPI group. DHA has been reported to play a role in CF pathophysiology and CFTR-related disease. These results suggest that fat malabsorption contributes to the EFA deficiency of CF patients.

As explained in chapter one, most adverse effects of PPI are mild and probably do not outweigh the beneficial effects. However, prolonged use of a PPI may result in vitamin $B_{12}$ deficiency due to impaired release of vitamin $B_{12}$ from food in a non-acid environment.

In chapter eight we showed that vitamin $B_{12}$ is significantly higher in CF patients compared to healthy controls, independent of PPI administration. In PPI treated and non-PPI treated CF patients homocysteine blood levels, a sensitive indicator of vitamin $B_{12}$ deficiency, were in the normal range. As there was no significant difference in both vitamin $B_{12}$ and homocysteine blood levels between both CF groups, we assumed that PPI's, even when used for nearly three years, had no adverse effect on vitamin $B_{12}$ status. 


\section{GENERAL SUMMARY}

The effects of decreasing luminal acidity on several biological variables was studied, using a pharmaceutical intervention in CF patients. Our main aim was to look for possible beneficial effects of lansoprazole on fecal fat excretion, body composition, lung function, gut permeability and EFA status without causing important side effects, like a vitamin $B_{12}$ deficiency. As our aim was mainly to look for predictable effects of PPIs in CF, we chose for an open, observational study in a small patient group which makes it necessary to interpret our results cautiously. Similarly to our findings in a previous study, we confirmed that the use of lansoprazole resulted in a decrease of stool fat and a temporary increase of body fat and bone mineral status. Additional effects showed by the present thesis are a decrease in hyperinflation of the lung, bronchial lability, intestinal permeability and improvement of EFA status without evidence of vitamin $B_{12}$ deficiency.

Although possibly important changes of clinical variables in children with CF have been observed, their causal relationship with the use of a PPI remains unproven due to the observational design and the small number of patients involved. However our results do now allow us to perform a power analysis in order to estimate the number of patients needed for future double-blind, placebo-controlled studies. Results of that evaluation show that large multi-center (multi-national?) studies would be necessary, involving high costs. This, in addition to the fact that several other questions have to be solved urgently in CF, makes it unlikely that such studies will be performed in the near future.

Although the use of PPIs in the Netherlands is already general practice in adult CF patients with persisting steatorrhea despite adequate supplementation of pancreatic enzymes, hard evidence for the use of this treatment in children is lacking. Although the present thesis suggests possible beneficial effects of adjuvant therapy with a PPI in CF children with ongoing steatorrhea, it does not allow us to recommend the routine clinical use of PPI in these children. Based on our limited data we encourage the early detection of malabsorption and malnutrition in CF. To this end the yearly assessments of body composition by DEXA seems reasonable. If despite adequate pancreatic enzyme supplementation malabsorption and malnutrition persists, a trial with a PPI seems warranted. 


\section{SAMENVATTING VAN DE AFZONDERLIJKE HOOFDSTUKKEN.}

In hoofdstuk één is de rationale voor het gebruik van protonpomp remmers (PPI) in patiënten met Cystic Fibrosis (CF) beschreven. Ondanks de inname van pancreas enzymen blijft verlies van vet met de ontlasting een probleem voor menig CF patiënt. Middels literatuurstudie werd een overzicht gegeven van de verschillende factoren die betrokken zijn bij de zogenaamde malabsorptie, met daarbij speciale aandacht voor de zuurgraad in het duodenum. Normaal gesproken wordt maagzuur in het duodenum gebufferd door bicarbonaat uit de pancreas. Bij CF patiënten is de productie van bicarbonaat, al in een vroege fase van de ziekte, ernstig aangetast. Door een PPI toe te voegen aan de standaard behandeling van CF patiënten met malabsorptie, ondanks suppletie van pancreas enzymen, wordt minder maagzuur geproduceerd. Hierdoor zal de zuurgraad in het duodenum lager zijn, resulterend in een meer efficiënt gebruik van de pancreas enzymen, zich vooral uitend in een betere vetabsorptie.

Hoofdstuk twee beschreef de doelstellingen, de patiënten en de methoden van het complete studie protocol. In een eerdere, korte termijn, studie hadden wij al een mogelijk effect van toediening van PPI op de fecale vet excretie en totaal lichaamsvet (TBF) in kinderen met CF aannemelijk gemaakt. Een nieuwe, observationele studie, werd gepland om deze én additionele effecten van lansoprazol (een PPI) toediening gedurende een jaar, op verschillende biologische variabelen in kinderen met $\mathrm{CF}$ te meten. Deze studie was primair bedoeld om te onderzoeken of er voorspelbare effecten van PPI in kinderen met CF zijn en hoe groot deze effecten dan zijn. Omdat slechts een beperkt aantal patiënten in deze studie bestudeerd is, kunnen derhalve geen definitieve conclusies of aanbevelingen aangaande het klinisch gebruik van PPI in kinderen met CF gemaakt worden.

In hoofdstuk drie rapporteerden wij de groeigegevens van onze jonge CF patiënten. In tegenstelling tot de meeste gepubliceerde studies, met cross-sectionele groeidata in grote $\mathrm{CF}$ populaties, gebruikten wij longitudinale groeigegevens om groeipatronen vast te stellen. Wij toonden aan dat achterblijven in lengtegroei (stunting) meer bijdraagt aan de groeivertraging dan te weinig aankomen in gewicht naar lengte alleen (wasting). Hierbij werden de CF kinderen vergeleken met naar leeftijd gematchte, gezonde kinderen. $0 \mathrm{~m}$ een groeivertraging te meten is daarom het gebruik van gewicht naar leeftijd groeicurven adequater dan het gebruik van gewicht naar lengte groeicurven. Verder ondersteunen deze bevindingen de noodzaak voor neonatale screening naar CF. Enerzijds omdat reeds bij de eerste meting een groeivertraging in $80 \%$ van onze patiënten aanwezig was en anderzijds omdat van vroege interventie is aangetoond dat "stunting" bij deze patiënten wordt voorkomen.

Hoofdstuk vier beschreef zowel de korte termijn (één jaar) als de lange termijn ( 3 jaren) effecten van aanvullende therapie met een PPI op de lichaamssamenstelling bij CF patiënten. Het verlies van vet met de ontlasting werd gedurende één jaar gemeten met 
de "zure steatocrit" methode. De lichaamssamenstelling werd gemeten bij de start van de studie en na 6, 12 en 36 maanden met behulp van dual energy $X$-ray absorptiometrie (DEXA). De gegevens van de lichaamssamenstelling werden uitgedrukt in standaard deviatie scores (SDS) in plaats van absolute waarden, om rekening te kunnen houden met het normale groeiproces in kinderen. De toevoeging van een PPI aan de behandeling van jonge CF patiënten resulteerde in een onmiddellijke en lang aanhoudende afname van het verlies van vet met de ontlasting. Gedurende het eerste jaar van de interventie trad er niet alleen een verbetering van het TBF op, maar ook van het mineraal gehalte (BMC) en minerale densiteit van bot (BMD). Omdat de waarden van de lichaamssamenstelling na 3 jaren gelijk waren aan de waarden bij de start, toonden onze resultaten slechts een tijdelijk positief effect van PPI op de lichaamssamenstelling in kinderen met CF. Wij stellen voor om regelmatig de lichaamssamenstelling te meten van CF patiënten, met behulp van DEXA, waardoor een betere monitoring van de voedingstoestand mogelijk is, dan alleen met wegen en meten.

In hoofdstuk vijf werden de veranderingen in longfunctieparameters tijdens het gebruik van PPI's in onze CF patiënten beschreven. De resultaten bevestigden de aanwezigheid van een hyperinflatie van de longen in CF patiënten en toonden, tijdens het gebruik van een PPI, een afname van hyperinflatie aan. Dit kon slechts gedeeltelijk de verbetering van de kracht van de inademings-spieren verklaren. Naar aanleiding van deze studie kon niet bepaald worden of de associatie tussen een verbeterde lichaamssamenstelling en een afname van de longhyperinflatie causaal dan wel toeval was. Tevens bevestigden dagelijkse registratie van uitademings-piekstroom (PEF), dat de variabiliteit in PEF toegenomen is in CF patiënten, wat zou kunnen duiden op de aanwezigheid van bronchiale labiliteit.

In hoofdstuk zes bevestigden wij de bekende, fors verhoogde doorlaatbaarheid van de darmen in CF patiënten, ook wel intestinale permeabiliteit (IP) genoemd. Onze resultaten toonden aan dat de toegenomen IP tenminste deels gecorrigeerd werden door het gebruik van een PPI gedurende een jaar. Omdat voornamelijk de permeabiliteit tussen darmcellen (paracellulaire route) verbeterde, nemen wij aan dat de zure darminhoud in CF patiënten vooral de bindingen tussen darmcellen beïnvloeden met een toegenomen IP als gevolg.

De biochemische bevindingen, voor aanwijzingen van een tekort aan essentiële vetzuren (EFA), in onze CF patiënten werden gepresenteerd in hoofdstuk zeven. Het tekort bleek met name in de vetzuren van plasma fosfolipiden. Hoewel de meeste EFA van patiënten, die PPI's gebruikten, een geringe trend naar normalisatie toonden, bleek alleen het verschil in plasma docosa hexaenoic acid (DHA) in de PPI-groep significant hoger dan in de niet gebruikers groep. Van DHA is beschreven dat het een rol speelt in de pathofysiologie van CF en CFTR-gerelateerde aandoeningen. Onze resultaten suggereren dat vetmalabsorptie bijdraagt aan de EFA deficiëntie in CF patiënten. 
Zoals beschreven in hoofdstuk één, zijn de meeste bijwerkingen van PPI's mild en wegen waarschijnlijk niet op tegen de gunstige effecten. Echter, langdurig gebruik van een PPI zou kunnen leiden tot een vitamine $B_{12}$ tekort. Dit is te verwachten omdat aan voedsel gebonden vitamine $B_{12}$ in een niet-zure omgeving minder loslaat en daardoor niet opgenomen wordt.

In hoofdstuk acht tonen wij juist aan dat, in vergelijking met gezonde controle patiënten, plasma vitamine $B_{12}$ significant hoger is in CF patiënten, onafhankelijk van het gebruik van een PPI. Zowel in de PPI behandelde groep, als de niet-PPI behandelde groep zijn de homocysteïne serumwaarden, een sensitieve indicator van vitamine $B_{12}$ tekort, in de normale range. Omdat er geen significant verschil was in zowel vitamin $B_{12}$ als homocysteïne serumwaarden tussen beide CF groepen, concludeerden wij dat PPI's, zelfs indien gedurende bijna drie jaar gebruikt, geen invloed hadden op de vitamine $B_{12}$ status.

\section{ALGEMENE SAMENVATTING}

De effecten van een afgenomen zuurgraad van de darminhoud op diverse biologische variabelen is bestudeerd, middels een medicamenteuze interventie bij kinderen met CF. Het hoofddoel was om mogelijke gunstige effecten van lansoprazole, een PPI, aan te tonen op vetverlies met de ontlasting, lichaamssamenstelling, longfunctie, darm permeabiliteit en EFA status bij kindere met CF. Tevens werd gekeken naar mogelijke bijwerkingen van langdurig PPI gebruik, zoals een vitamine $B_{12}$ tekort. Omdat de doelstellingen vooral gericht waren op het aantonen van specifieke effecten van PPIs in CF, was het mogelijk om te kiezen voor een open, observationele studie in een patiënten groep met kleine aantallen. Dit maakt het echter nodig om onze resultaten voorzichtig te interpreteren en zijn de resultaten derhalve niet conclusief. De bevindingen uit onze eerdere studie, werden bevestigd, het gebruik van lansoprazole resulteerde in een afname van vet in de ontlasting met, een tijdelijke, toename van totaal lichaamsvet en botmineralisatie. Andere uitkomsten van onze studie zijn zowel een afname van de hyperinflatie van de long, bronchiale labiliteit en darm permeabiliteit, als een verbetering van de EFA status en dat zonder een vitamine $B_{12}$ tekort te veroorzaken.

Hoewel belangrijke veranderingen in klinische variabelen in kinderen met CF geobserveerd zijn, is een oorzakelijke relatie met het gebruik van een PPI niet bewezen als gevolg van het observationele design en het kleine aantal patiënten. Echter met de verkregen resultaten hebben we een power-analyse uitgevoerd, om het benodigde aantal patiënten voor een toekomstige dubbel-blinde, placebo-gecontroleerde studie te berekenen. Resultaten van deze evaluatie tonen dat grote multi-center (multinationale?) studies nodig zijn, leidend tot hoge kosten. Dit naast het feit dat andere, meer dringende, vraagstellingen opgelost dienen te worden in CF, maakt het 
onwaarschijnlijk dat dergelijke studies in de nabije toekomst zullen worden uitgevoerd.

Het gebruik van PPI in Nederland is algemeen gebruik bij volwassen CF patiënten, die vetverlies via de ontlasting houden ondanks gebruik van pancreasenzymen. Daarentegen bestaat er geen bewijs voor een dergelijke behandeling bij kinderen. Het onderzoek in dit proefschrift suggereert mogelijke gunstige effecten van toevoegen van een PPI in kinderen met CF met voortgaand vetverlies met de ontlasting, maar het staat ons niet toe om het routinematige gebruik van PPI in deze kinderen aan te bevelen. Gebaseerd op onze beperkte gegevens moedigen wij de vroege detectie van malabsorptie en ondervoeding bij patiënten met CF aan. Met dit als doel lijkt het jaarlijks meten van de lichaamssamenstelling met DEXA logisch. Als ondanks adequate hoeveelheden pancreasenzymen, malabsorptie en ondervoeding persisteren, lijkt toevoegen van een PPI verantwoord. 


\section{CHAPTER ELEVEN}

\section{Dankwoord en Curriculum Vitae}

Han Hendriks

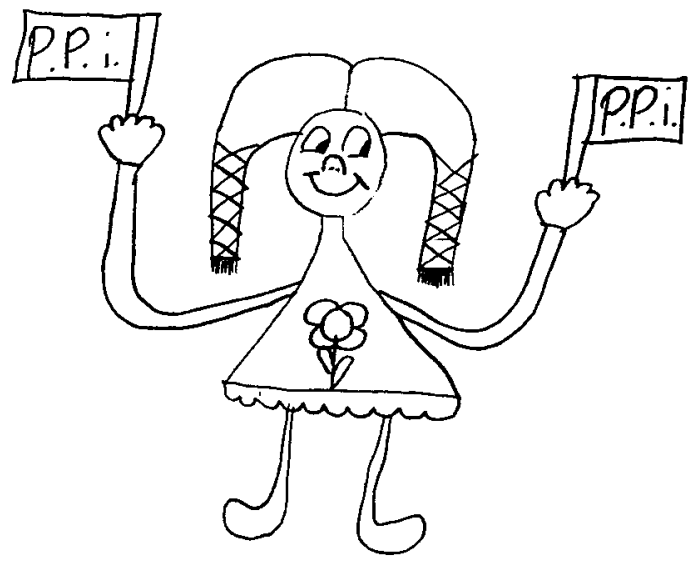




\section{DANKWOORD}

Als er één waarheid is over het schrijven van een proefschrift dan is het wel dat het niet het werk is van slechts éen persoon. Ik wil dan ook bij voorbaat iedereen zeer hartelijk danken voor hun bijdrage aan het tot stand komen van dit proefschrift, ook degenen die ik nu niet vernoem. Elke hulp, hoe klein ook, is van belang en wordt zeker ook door mij niet vergeten. Maar een aantal personen verdienen speciale dank en die wil ik nu verwoorden.

Allereerst natuurlijk de kinderen en hun ouders die zo van ganser harte en zonder enig wanklank mee gedaan hebben aan deze studie, naar leeftijd: Bart, Wouter, Rick, Kris, Denise, Pieter, Nick, Marco, Dennis, Nick, Sandra, Joyce, Chantal en Nadinja. Jullie zijn kanjers en ik zal jullie nooit vergeten. Zonder jullie medewerking was dit werk nooit tot stand gekomen en door jullie enthousiasme wist ik het vol te houden, ook toen de publicaties niet meteen wilden lukken.

Naast de kinderen is mijn co-promotor dr. P.Ph. Forget de grootste drijfveer en voorbeeld geweest, beste Philippe nadat jij zelf al twee keer gepromoveerd bent, heb je nog een derde proefschrift meegeschreven. Ik zal je geduld, je talenknobbels, je vertrouwen en vooral de snelheid van corrigeren, nooit vergeten noch evenaren. Nee, aan jou heeft het zeker niet gelegen dat ik net geen zes jaren over het bedenken, aanvragen, uitvoeren, verzamelen, verwerken, interpreteren, opschrijven, publiceren en drukken gedaan heb.

Naast mijn co-promotor, wil ik natuurlijk ook mijn twee promotoren Prof.dr. R.A.M.G. Donckerwolcke en Prof.dr. E.F.M. Wouters bedanken, zij voerden steeds van achter de coulisse de regie. Door dit werk is de samenwerking tussen de afdelingen Pediatrie en Pulmonologie bestendigd en lijkt een bloeiende toekomst in het verschiet te liggen.

Voor ingewijden moet het opgevallen zijn dat ik derhalve begeleid ben door drie hele slimme Belgen. Daarom, zonder flauwe grappen te maken, wij Nederlanders dienen alle eer te betonen aan deze mensen, zij gaan tenslotte deze zomer wél naar het wereldkampioenschap voetbal en wij niet!

Verder wil ik de leden van de beoordelingscommissie: Prof.dr. R.W. Stockbrügger, Prof.dr. J.C. de Jongste, Prof.dr.ir. C.P. van Schaijck, dr.ir. A.M.W.J. Schols en Prof.dr. D.J. Shale, evenzeer danken voor hun bereidwilligheid en kritische opmerkingen, die zeer opbouwend zijn gebleken.

Minstens evenveel dank gaat uit naar dr. A. Kester van de afdeling Methodologie en Statistiek. Arnold hoewel menigeen niet weet dat wij jou voor het blok gezet hebben al voor de start van deze studie, bleef jij in alle omstandigheden rustig onder de kritiek dat dit geen gecontroleerde studie is. Jij maakte ons duidelijk dat een goede, niet gecontroleerde studie óók bruikbare gegevens kan leveren. Hoewel terecht alle 
aandacht uitgaat naar grote, gerandomiseerde, dubbel blinde en placebo gecontroleerde studies, moeten wij niet vergeten dat studies, zoals in dit proefschrift beschreven, mede de basis vormen waarop dergelijke studies hun aantallen en design baseren. Verder dient bij een relatief zeldzame ziekte, zoals Cystic Fibrosis, er zoveel tegelijkertijd onderzocht te worden dat dergelijke grote en dure studies nooit uitgevoerd worden. Daarentegen is de noodzaak groot om met beide handen iedere verbetering van het beloop van deze gevreesde aandoening aan te pakken, opdat patiënten niet alleen langer leven maar ook hun kwaliteit van leven verbeterd.

Drie personen wil ik persoonlijk danken voor hun verschillende bijdragen aan de verschillende hoofdstukken: dr. A.M. Van den Neucker, drs. H. ter Heide en dr. T.M.D. Tran. Anita, Henriëtte en My-Dung, jullie hebben samen met mij de protonpomp remmer bij kinderen met CF onderzocht en wij zullen nog een hele tijd moeten "vechten" om een definitieve plaats te krijgen voor deze medicamenten bij deze kinderen.

Minstens even belangrijk was de bijdrage van de afdeling diëtetiek, waar vooral mevr. E.M.C. van der Ploeg, ondanks haar zwangerschap, veel werk verzette. Liesbeth ik zal nooit je gezelligheid vergeten tijdens de CF-team bijeenkomsten en het CF congres, je aanstekelijke lag doet iedereen weer opvrolijken.

Tijdens deze studie heb ik velen voor de voeten gelopen, en hopelijk niet op hun tenen gestaan! Hierbij wil ik het personeel van enkele afdelingen expliciet noemen. Van de longfunctie: Ingrid, Wim, Marie-José, Brigitte, Michael, Manon, Monique en alle anderen die sindsdien de kinderen alle lucht laten uitblazen. Van de kinderpoli: Marlies, Gaby, Carmen, Marianne, Yolanda, Peggy en Sandra, die alles keurig regelden en de kinderen, hun ouders en mij, waar mogelijk ondersteunden. De laboranten van het klinisch chemisch laboratorium, onder leiding van dr. B. van Kreel en dhr. Habets. De laboranten van het nucleair geneeskundig laboratorium, onder leiding van Prof.dr. G. Heidendal. Het metabole laboratorium, met name dr. J.M. Spaapen em J.A. Bakker.

Ook dank aan Inge van der Sluis, die via e-mail contact mijn DEXA gegevens omrekende in Nederlandse SDS en mij 2 maanden vlugger af is met promoveren.

Prof.dr. G. Hornstra en dr. R. van Houwelingen, Gerard en Rian door jullie ben ik ingeleid in de wereld van de essentiële vetzuren, waarvoor dank.

Niet vergeten wordt het werk van meerdere studenten die al of niet bij mij hun wetenschapsstage volbrachten en zo hun eerste schreden op het wetenschappelijk pad met mij deelden: Femke Schuurmans, Hiltje Heijmans, Arno Brouwers en Estelle Rekkers.

A special acknowledgement to mr. B. Wilkinson, who edited most chapters of this thesis. 
Dank ook aan het hele CF-team van het azM dat inmiddels ruim 10 jaar bestaat. Marlies, Liesbeth, Marja, Carlo, Helga, Jacques, Karin, Anita, Rijn, Edward en Geert-Jan allen bedankt voor de prettige samenwerking en jullie deskundige inzet en de enthousiaste steun, die ik steeds weer bemerkte.

Uiteraard bedank ik ook de hele afdeling Kindergeneeskunde, verpleegkundigen en artsen van B2, E2 en de KIC. Aan mijn collega's: wij zijn nog altijd één groep, misschien wel de enige in een academische setting, waar Kindergeneeskunde nog met grote " $K$ " geschreven wordt. Ik vind het een hele eer dat ik mee mag bouwen aan het groter worden van deze kleinste academische Kinderafdeling van Nederland.

Hierbij denk ik natuurlijk niet in de laatste plaats aan de subafdeling Kinderpulmonologie. Ik dank dan ook met name mijn directe collega's dr. Q. Jöbsis en dr. E. Dompeling, Rijn en Edward omdat jullie mij het laatste jaar de tijd gunden om dit boek te schrijven, waardoor het toch nog snel is afgekomen. Bovendien dank ik jullie voor een laatste kritische lezing van enkele hoofdstukken. Zoals onderling afgesproken, wij zijn als drie musketiers: "Eén voor allen en Allen voor één". In dit kader wil ik ook drs. J.W.C.M. Heijnens noemen, Jan jij bent waarschijnlijk de vierde musketier, d'Artagnan, die ons completeert. Ik wil ook vermelden dat jij twee kinderen met CF hebt aangedragen voor deze studie. Inmiddels komen alle kinderen met CF uit Sittard ook in Maastricht ter controle. Zo is ook een patient aangedragen door dr. G.J. Wesseling van de afdeling Pulmonologie, Geert-Jan, ik vind het nog steeds verfrissend, verhelderend en amusant om met jou te praten over allerlei onderwerpen. Ik heb heel veel van jouw geleerd, met name ook tijdens de diverse huisartsen symposia. Ik ben ervan overtuigd dat er een chronisch longcentrum in Maastricht zal komen, waar alle betrokken disciplines elkaar zullen versterken.

Een heel speciaal woord van dank aan mijn twee paranimfen, dr. R.J. Roorda en dr. Q. Jöbsis, al is het een erebaantje, ik vind het een grote eer om jullie uit te nodigen voor deze zware taak. Ruurd-Jan, dit is al vele jaren geleden afgesproken, ik heb je veel te lang laten wachten, bedankt voor het geduld, het begrip, maar vooral de echte vriendschap die jij mij al zovele malen hebt getoond. Rijn, eerst zou jij promoveren daarna $i k$, dat was de deal, laten wij nu samen anderen helpen met promoveren.

Rest mij nog mijn dierbaarste van allen te bedanken, Paula, Carl en Britt, het boekje is af. Paula, ik weet dat wij elkaar zoveel mogelijk gerespecteerd hebben tijdens deze fase van ons leven, deze houding van gelijkwaardigheid heeft ons weer verder gesterkt. Ik bewonder je rust, geduld en vele goede woorden die je me toe vertrouwde. Wij wisten beiden dat het zou lukken, ondanks wat tegenslagen. Carl en Britt het lezen van dit boek zal jullie niet plezieren, gezien al die moeilijke geneeskundige taal en nog wel in het Engels. Ik hoop dat ik nu weer meer tijd heb om andere boeken met jullie te lezen, en wie weet schrijven jullie ooit ook eens een of meerdere boeken! 0ok wil ik jullie nog van harte bedanken voor de mooie tekeningen die op het omslag en bij ieder hoofdstuk de kern van de onderzoeksmethode uitbeelden. Tot slot dank ik mijn ouders, want ik weet dat zij trots op mij zullen zijn, zoals ik ook trots op hun ben. 


\section{CURRICULUM VITAE}

BORN:

March $19^{\text {th }} 1958$, Maastricht, The Netherlands.

\section{EDUCATION:}

Highschool: 1970 - 1976 Vw0, Henric van Veldeke college, Maastricht, The Netherlands.

Medical education: September 1976 - 1983, Catholic University Nijmegen, The Netherlands. Medical Degree: October $14^{\text {th }} 1983$.

Military Service: November $1^{\text {st }} 1983 /$ January $31^{\text {st }} 1985$ : Medical Staff of $4^{\text {th }}$ Division. Residency for Pediatrics, February $1^{\text {st }} 1985$ / April $30^{\text {th }} 1988$ : Department of Pediatrics, St. Radboud Hospital, Catholic University Nijmegen, The Netherlands and May $1^{\text {st }} 1988$ / January $31^{\text {st }} 1989$ University Hospital Maastricht, University of Maastricht, The Netherlands. Certification: February $1^{\text {st }} 1989$ as Dutch Pediatrician.

\section{EDUCATION IN SUBSPECIALITY OF PEDIATRIC PULMONOLOGY:}

Lungfunction department: June $1^{\text {st }} 1989$ - December $31^{\text {st }} 1989$, University Hospital Maastricht, The Netherlands.

Pediatric Pulmonology: May $1^{\text {st }} 1990$ - December $31^{\text {st }} 1990$, department of Pediatrics, section of Pediatric Pulmonology (Head: prof.dr. Klaas Knol), University Hospital Groningen, The Netherlands.

Bronchoscopy in children: June $30^{\text {th }}-$ July $28^{\text {th }} 1991$, Bronchological Department, Pediatric Institute Szabadsaghegy Budapest, Hungary (Head: dr Edgar Szekely PhD) Registration as Pediatric Pulmonologist: (retrograde registry) by the Dutch Pediatric Society: january 1999.

\section{FACULTY POSITION:}

February $1^{\text {th }} 1989$ - today: Academic Medical Specialist at the department of Pediatrics, University Hospital, Maastricht University, The Netherlands (Head: Prof.dr. R.A.M.G. Donckerwolcke).

FUNCTIONS (WITHIN THE UNIVERSITY HOSPITAL MAASTRICHT): Chef de clinique of the Pediatric dept.: February 1989 - May 1990.

Coordinator of the CF-team: November $1^{\text {st }} 1991$ - today.

Lecture Committee of dept. of Pediatrics (member): 1993 - today.

Case history Committee of dept. of Pediatrics (chairman): 1994 - today.

Educational Committee of dept. of Pediatrics (member): 1995 - today.

Head out-patient clinic for children: May $1^{\text {st }} 1996$ - today.

Executive Committee of dept. of Pediatrics (member): May $1^{\text {st }} 1996$ - today.

Farmacology Committee (member): 2001 - today. 


\section{CURRICULUM VITAE}

De schrijver van dit boek werd op 19 maart 1958 geboren, in Maastricht aan de voet van de Sint Pietersberg. In 1976 behaalde hij het VW0-diploma, aan het toenmalige Henric van Veldeke College te Maastricht. Nog hetzelfde jaar startte hij met zijn studie Geneeskunde aan de Katholieke Universiteit van Nijmegen, alwaar hij op 14 october 1983 zijn artsexamen behaalde. Zijn militaire dienstplicht, als reserve kapitein arts bij de stafcie van de 4e divisie, mocht hij een maand eerder beëindigen, om zijn opleiding tot kinderarts te starten. Van februari 1985 tot mei 1988 werd hij opgeleid in het St.Radboud ziekenhuis te Nijmegen (opleider: prof.dr. GBA Stoelinga) om daarna tot februari 1989 zijn opleiding voort te zetten in het Academisch Ziekenhuis Maastricht (opleider: prof.dr. RH Kuyten).

Sinds 1 februari 1989 is hij werkzaam als kinderarts bij de vakgroep Kindergeneeskunde van het AZM. Na een periode gefunctioneerd te hebben als chef de clinique, ging hij zich verder specialiseren in de kinderlongziekten. Daartoe werkte hij van mei december 1990 in het Academisch Ziekenhuis Groningen (opleider: prof.dr. K.Knol), verdere stages werden gevolgd in het AZM bij prof.dr. EFM Wouters en in Boedapest, Hongarije, bij dr. E. Szekely.

Sinds januari 1991 werkt hij als kinderarts op het gebied van de kinderlongziekten, daarbij krijgt hij sinds januari 1998 versterking van Rijn Jöbsis en sinds april 2000 van Edward Dompeling. Na invoering van een registratie van subspecialismen binnen de Kindergeneeskunde, werd hij in januari 1999 retrograad geregistreerd als kinderarts-pulmonoloog. Momenteel bekleedt hij meerdere functies binnen het AZM, het coördinatorschap van het CF-team en de geneesmiddelen commissie. Ook binnen de vakgroep Kindergeneeskunde worden diverse functies bekleed binnen de refereer, de opleidings en de status commissie. Tevens is hij sinds 1996 hoofd van de polikliniek Kindergeneeskunde en lid van het dagelijks bestuur van de vakgroep Kindergeneeskunde. 